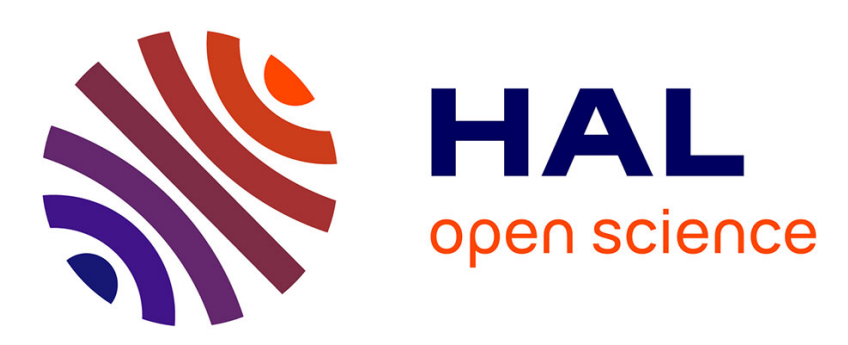

\title{
A dynamic mathematical model of bile acid clearance in HepaRG cells
}

\author{
D. Kaschek, A. Sharanek, A. Guillouzo, J. Timmer, R.J. Weaver
}

\section{To cite this version:}

D. Kaschek, A. Sharanek, A. Guillouzo, J. Timmer, R.J. Weaver. A dynamic mathematical model of bile acid clearance in HepaRG cells. Toxicological Sciences, 2018, 161 (1), pp.48-57. 10.1093/toxsci/kfx199 . hal-01696669

\section{HAL Id: hal-01696669}

\section{https://hal-univ-rennes1.archives-ouvertes.fr/hal-01696669}

Submitted on 31 Jan 2018

HAL is a multi-disciplinary open access archive for the deposit and dissemination of scientific research documents, whether they are published or not. The documents may come from teaching and research institutions in France or abroad, or from public or private research centers.
L'archive ouverte pluridisciplinaire HAL, est destinée au dépôt et à la diffusion de documents scientifiques de niveau recherche, publiés ou non, émanant des établissements d'enseignement et de recherche français ou étrangers, des laboratoires publics ou privés. 


\section{A dynamic mathematical model of bile acid clearance in HepaRG cells}

Daniel Kaschek, Ahmad Sharanek, André Guillouzo, Jens Timmer, Richard J. Weaver

Institute of Physics, Freiburg University, Germany (D.K., J.T.); BIOSS Centre for Biological Signalling Studies, Freiburg (J.T); Freiburg Center for Systems Biology (J.T.); Inserm UMR 991 Foie, métabolismes et Cancer, Rennes, France (A.S., A.G.); Université Rennes 1, Rennes, France (A.S., A.G.); Institute de Recherches Internationales Servier, Suresnes, France (R.J.W.)

Running Title: A model of bile acid clearance in HepaRG cells

This is an accepted article/manuscript 


\section{Abstract}

A dynamic model based on ordinary differential equations that describes uptake, basolateral and canalicular export of taurocholic acid in human HepaRG cells is presented. The highly reproducible inter-assay experimental data were used to reliably estimate model parameters. Primary human hepatocytes were similarly evaluated to establish a mathematical model, but with notably higher inter-assay differences in taurocholic acid clearance and bile canaliculi dynamics. By use of the HepaRG cell line, the simultaneous taurocholic acid clearance associated to basolateral uptake, canalicular and sinusoidal efflux, was predicted. The mathematical model accurately reproduced the dose-dependent inhibition of taurocholic acid clearance in the presence and absence of the prototypical cholestatic drugs cyclosporine $\mathrm{A}$ and chlorpromazine. Rapid inhibition of taurocholic acid clearance and recovery were found to be major characteristics of cyclosporine A. Conversely, the action of chlorpromazine was described by slow onset of inhibition relative to inhibition of taurocholic acid clearance by cyclosporine A. The established mathematical model, validated by the use of these two prototypical cholestatic drugs and the integration of bile canalicular dynamics, provides an important development for the further study of human hepatobiliary function, through simultaneous temporal and vectorial membrane transport of bile acids in drug-induced cholestasis.

Key Words: human hepatocytes, HepaRG cells, mathematical model, taurocholic acid, chlorpromazine, cyclosporine A

Non-standard abbreviations: BSEP, bile salt transport pump; MRP, multidrug resistanceassociated protein; NTCP, sodium-taurocholate co-transporting polypeptide; OATP, organicanion transport protein; CPZ, chlorpromazine; CsA, cyclosporine A; TCA, taurocholic acid; $\mathrm{PHH}$, primary human hepatocytes; $\mathrm{BC}$, bile canaliculi; $\mathrm{SCHH}$, sandwich cultured human hepatocytes; $\mathrm{CCHH}$, conventional cultured human hepatocytes; ODEs, ordinary differential equations; AUC, area under the curve; PBPK, Physiologically-Based Pharmacokinetics. 


\section{INTRODUCTION}

The underlying pathophysiological mechanisms for most hepatocellular forms of druginduced hepatic injury remain poorly understood. However, there is reasonable evidence that intrahepatic cholestatic forms of drug-induced liver damage frequently result from a drug- or metabolite-mediated inhibition of hepatobiliary transporter systems (Goldring et al., 2017; Hillgren et al., 2013). In addition to the function of these key transporters in determining hepatic drug exposure and clearance, the coordinated action of these transport systems is essential for bile formation and the biliary secretion of cholephilic compounds and drugs (Chiang, 2009). A drug-mediated functional disturbance of these processes, directly or indirectly, can lead to the arrest of bile formation and flow with the development of cholestatic liver cell damage (Pauli-Magnus and Meier, 2006). In addition to drug-mediated inhibition of hepatocellular transport function, the inter-individual variability of transporter expression and function are altered by pre-existing hepatic diseases and genetic factors, which are believed to contribute to the development of drug-induced risk of cholestasis in susceptible individuals (Trauner et al., 1998). Recently, some of us reported that cholestatic drugs caused alteration of bile canaliculi dynamics associated with impairment of the Rhokinase/ myosin light chain kinase signaling pathway using human HepaRG cells (Burbank et al., 2016; Sharanek et al., 2016).

Although the use of primary human hepatocytes $(\mathrm{PHH})$ for the study of drug effects on bile formation and secretion by hepatocytes is well documented (Guo et al., 2016; Swift et al., 2010), the donor-donor variability and inherent dedifferentiation of the hepatocellular phenotype in culture can often greatly influence their practical routine use in early screening in drug discovery. Moreover, these biological donor-donor variabilities associated with $\mathrm{PHH}$ may confound opportunities to sequentially build an integrated time-resolved mathematical model using a singularly phenotypically stable, reproducible and robust in vitro model by which to describe bile acid clearance and flow, and study the impact of drug effects with time 
in culture. By contrast, the HepaRG cell line exhibits a well-characterized and stable hepatocyte-like phenotype (Guguen-Guillouzo and Guillouzo, 2010) by which to reproducibly measure bile formation and bile canalicular $(\mathrm{BC})$ clearance (Sharanek et al., 2015), to establish a dynamic mathematical model describing bile acid clearance.

Modeling the flow of drugs or substrates by ordinary differential equations (ODEs) is a common approach in pharmacokinetic modeling. Indeed, mathematical models of drug disposition (Jones et al., 2012; Li et al., 2014) and bile flow (Guo, et al. 2016; Yang et al., 2015) into and out of hepatocytes have been previously presented. All these models have a common model structure, including cellular, canalicular/biliary and medium compartments. Bile acids are transported between these compartments. This model structure is also used in this work. However, drug-mediated transporter inhibition is frequently modeled as a static process as the transport rates are reduced in a dose-dependent manner; . time-dependence of the inhibitory process and the recovery is neglected, and the effects are assumed to occur immediately. In contrast, our model incorporates transporter inhibition as a dynamic timeresolved process into the ODE model. Also, the compartment size, such as the volume of $\mathrm{BC}$ that changes dynamically with the concentration of cholestatic drugs and are importantly implemented into our ODEs. These features are important events identified in the acute phase of cholestasis associated with vectorial transport of bile acids and initiation of bile flow.

In this study, we describe the use of experimental data derived from human HepaRG cells to establish a quantitative and predictive dynamic model of bile acid clearance, using a prototypical bile acid, taurocholic acid (TCA), for the study of hepatobiliary transport. A validation of the model was further achieved by use of two prototypical cholestatic drugs, cyclosporine $A(C s A)$ and chlorpromazine (CPZ), previously shown to exhibit differences in the mechanisms of apical and basolateral transporter inhibition (Antherieu et al., 2013; Sharanek et al., 2014) and their effect on BC dynamics (Burbank, et al 2016). 


\section{Materials and Methods}

\section{Data sources and statistical analysis}

Chemical reagents, details of biological experiments and techniques used to prepare and characterize HepaRG cells and PHH are provided in the supplement (Section 1). In brief, wet-bench assay data from experiments with CPZ (Bachour-El Azzi et al., 2014) and CsA (Sharanek, et al. 2014) were used to develop a mathematical model. In addition, new experiments with the use of $\mathrm{CPZ}$ and CsA were performed during the course of the present study with model-informed study design. At least 4 independent experiments with HepaRG cells and PHH were performed and analyzed.

\section{Pre-processing of time-resolved data}

For each protocol, experiments were repeated at least 4 times. Since TCA is radiolabeled, the count data follows a Poisson distribution. In our case the number of counts is in the order of $10^{2}$ to $10^{3}$. "For statistical analysis, it is beneficial to have normally distributed data with equal expected variance of all data points. The transformation $n=2 \sqrt{\mathrm{N}}$ translates the Poisson-distributed number of counts $\mathrm{N}$ into (almost) normally distributed numbers $\mathrm{n}$ with unit variance." . Differences between independent experiments, $j$, that exceed the expected variance are due to heterogeneity between the preparations of cultures of HepaRG cells. These differences can be attributed to a different number of cells between experiments, represented by a scaling factor $S$, which translates into a factors $=2 \sqrt{S}$ of the numbers n. . In total, the mathematical model to describe all replicate readouts is described;

$$
n_{j, k, r}(t)=s_{j} \cdot n_{k}(t)+\epsilon_{j, k, r}(t)+\eta_{j, k, r}(t)
$$

where $n_{j, k, r}(t)$ is the transformed number of counts of experiment $j$, set-up/treatment $k$ and replicate $r$ at time point $t$. The numbers $\epsilon_{j, k, r}(t) \sim N(0,1)$ and $\eta_{j, k, r}(t) \sim N\left(0, \sigma_{\text {celltype }}^{2}\right)$ describe random contributions due to the stochasticity of radioactive decays and 
heterogeneity between HepaRG cell and treatment preparations. The parameters of interest, $n_{k}(t)$, represent the true transformed number of counts for each set-up/treatment $k$ as being used for dynamic modeling. They are determined jointly with the scaling parameters $s_{j}$ and the cell-type heterogeneity $\sigma_{\text {celltype }}$ by least-squares estimation. Parameter uncertainties $\sigma_{n_{k}(t)}$ are obtained from the least-squares fit. They account for the number of replicates, the uncertainty of the estimated scaling parameters and the heterogeneity between experiments. The heterogeneity parameters $\sigma_{\text {celltype }}$ are employed to quantify the reproducibility of experiments for the cell types HepaRG, human hepatocytes in sandwich culture and human hepatocytes in conventional culture. See supplement Figure S2 [Data pre-processing] for a comparison of the different cell types.

\section{A dynamic model of TCA transport}

TCA transport is modeled by ordinary differential equations (ODEs). The equations are based on mass-action or Michaelis-Menten kinetics and account for the transport between three compartments, i.e. incubation medium, cells (cyto) and canaliculi with volumes $V_{\text {buffer, }}$ $V_{\text {cyto }}$ and $V_{\text {cana. }}$ A schematic overview of the model is shown in Figure 1 . The basic transport processes are

$$
\mathrm{TCA}_{\text {buffer }} \underset{k_{2}}{\stackrel{k_{1}}{\rightleftharpoons}} \mathrm{TCA}_{\text {cyto }} \stackrel{k_{3}}{\longrightarrow} \mathrm{TCA}_{\text {cana }} \stackrel{k_{4}}{\longrightarrow} \mathrm{TCA}_{\text {buffer }}
$$

where $k_{1}, \ldots, k_{4}$ denote transport rates. These rates are susceptible to temperature, calcium/magnesium and sodium changes and depend on the activity of the corresponding basolateral and canalicular membranes to TCA transport. In this study, each transport process can be associated to one membrane transporter known to be associated with the basolateral, sinusoidal and canalicular cell membranes, i.e. uptake $\left(T_{1}\right)$, sinusoidal efflux $\left(T_{2}\right)$ and canalicular efflux $\left(T_{3}\right)$. In summary, the rate constants are expressed by the equations 


$$
\begin{aligned}
k_{1} & =\frac{k_{1}^{\prime} \cdot\left[T_{1}\right] \cdot\left(1+a_{1} \cdot\left[\mathrm{Na}^{+}\right]\right)}{\left(1+d_{1}\left(1-\frac{\Delta \vartheta}{33^{\circ} \mathrm{C}}\right)\right)} \\
k_{2} & =\frac{k_{2}^{\prime} \cdot\left[T_{2}\right]}{\left(1+d_{2}\left(1-\frac{\Delta \vartheta}{33^{\circ} \mathrm{C}}\right)\right)} \\
k_{3} & =\frac{k_{3}^{\prime} \cdot\left[T_{3}\right]}{\left(1+d_{3}\left(1-\frac{\Delta \vartheta}{33^{\circ} \mathrm{C}}\right)\right)} \\
k_{4} & =\frac{k_{4}^{\prime}}{\left(1+d_{4}\left(1-\frac{\Delta \vartheta}{33^{\circ} \mathrm{C}}\right)\right) \cdot\left(K_{4}+\left[\mathrm{Ca}^{2+}\right]\right)}
\end{aligned}
$$

where $k_{1}^{\prime}, \ldots, k_{4}^{\prime}$ are the transport parameters, $\Delta \vartheta$ is the temperature change with respect to $4{ }^{\circ} \mathrm{C}, d_{1}, \ldots, d_{4}$ denotes deceleration parameters associated to a temperature drop, $a_{1}$ is the acceleration parameter associated to sodium in the buffer and $K_{4}$ represents the effect of calcium on canalicular efflux.

The kinetic principles used to model uptake, sinusoidal efflux and canalicular efflux is Michaelis-Menten Kinetics whereas the transport from the canalicular compartment to the buffer compartment is modeled by mass-action kinetics.

$$
\begin{aligned}
\frac{\mathrm{d}}{\mathrm{d} t} \mathrm{TCA}_{\text {buffer }} & =-\frac{k_{1} \cdot \mathrm{TCA}_{\text {buffer }}}{1+\frac{\mathrm{TCA}_{\text {buffer }}}{K_{\text {import }}}}+\frac{k_{2} \cdot \mathrm{TCA}_{\text {cyto }}}{1+\frac{\mathrm{TCA}_{\text {cyto }}}{K_{\text {baso }}}}+k_{4} \cdot \mathrm{TCA}_{\text {cana }} \\
\frac{\mathrm{d}}{\mathrm{d} t} \mathrm{TCA}_{\text {cyto }} & =\frac{k_{1} \cdot \mathrm{TCA} A_{\text {buffer }}}{1+\frac{\mathrm{TCA}_{\text {buffer }}}{K_{\text {import }}}}-\frac{k_{2} \cdot \mathrm{TCA}_{\text {cyto }}}{1+\frac{\mathrm{TCA}_{\text {cyto }}}{K_{\text {baso }}}}-\frac{k_{3} \cdot \mathrm{TCA}_{\text {cyto }}}{1+\frac{\mathrm{TCA}_{\text {cyto }}}{K_{\text {cana }}}} \\
\frac{\mathrm{d}}{\mathrm{d} t} \mathrm{TCA}_{\text {cana }} & =\frac{k_{3} \cdot \mathrm{TCA} A_{\text {cyto }}}{1+\frac{\mathrm{TCA}_{\text {cyto }}}{K_{\text {cana }}}}-k_{4} \cdot \mathrm{TCA}_{\text {cana }}
\end{aligned}
$$

The transporter activity $T_{i}, i=1, \ldots, 3$, is dynamically regulated being modeled by the reactions $\emptyset \stackrel{\alpha_{i}}{\underset{\alpha_{i}}{\rightleftharpoons}} T_{i}$. Where, “ $\rightarrow \emptyset$ and " $\emptyset \rightarrow$ "denote deregulation and production. The parameterization by $\alpha_{i}$ implies that the equilibrium of the reaction is $T_{i}=1$ for all transporters and the time-scale how quickly the disturbed system returns to the initial measures of TCA clearance is determined by the value of $\alpha_{i}$. TCA clearance in control incubations can in the 
meantime be reduced by cholestatic drugs. Within the mass-action formalism, inhibition by a drug is implemented as

$$
D+T_{i} \underset{k_{-}^{(i)}}{\stackrel{k_{+}^{(i)}}{\rightleftharpoons}} D T_{i}
$$

where $D$ is the drug and $D T_{1}, \ldots, D T_{3}$ are the inhibited transporters, see Figure $1 \mathrm{~B}$. The rate parameters $k_{+}^{(i)}$ represent the effective inhibition of the drug on transporter $T_{i}$ while $k_{-}^{(i)}$ represents the transporters' ability to recover when the compound-containing buffer is removed.

In the absence of the drug, membrane associated transport activity is equal to unity and assigned the value of 1 across the membranes. By the addition of the drug, a new equilibrium between active and inactive membrane transport activity is approached which is determined by the equilibrium constants $K_{c}^{(i)}=\frac{k_{+}^{(i)}}{k_{-}^{(i)}}$. Conversely, when the free drug is removed, the system transitions to another equilibrium retaining some of the drug's inhibitory effect for reversible inhibition of transporter activity. The drug-induced dynamics is overlain by the transporter regulating mechanism steering all transporter activities associated to membranes to unity of 1 . The possibility of irreversible changes of the transporter activity is equally incorporated into the model by choosing drug-specific values for the membrane transporter activity, $\alpha_{i}$.

When cells are exposed to TCA for more than 30 minutes, the uptake can be seen to effectively accelerate. This is possibly accounted for by changes in membrane transport with time of TCA exposure in culture. In our model, TCA uptake is controlled by the $T_{1}$ state variable. To account for the accelerated uptake, we include a gain term for the $T_{1}$ state, proportional to the integrated TCA buffer concentration, $A \mathrm{UC}_{\mathrm{TCA}(\text { buffer), }}$, see Figure $1 \mathrm{C}$. In summary, the transporter dynamics is described by the differential equations. 


$$
\begin{aligned}
& \frac{\mathrm{d}}{\mathrm{dt}} T_{1}=\alpha_{1} \cdot\left(1-T_{1}\right)-k_{+}^{(1)} \cdot D \cdot T_{1}+k_{-}^{(1)} \cdot D T_{1}+b \cdot \mathrm{AUC}_{\mathrm{TCA}(\text { buffer })} \\
& \frac{\mathrm{d}}{\mathrm{dt}} T_{2}=\alpha_{2} \cdot\left(1-T_{2}\right)-k_{+}^{(2)} \cdot D \cdot T_{2}+k_{-}^{(2)} \cdot D T_{2} \\
& \frac{\mathrm{d}}{\mathrm{dt}} T_{3}=\alpha_{3} \cdot\left(1-T_{3}\right)-k_{+}^{(3)} \cdot D \cdot T_{3}+k_{-}^{(3)} \cdot D T_{3} \\
& \frac{\mathrm{d}}{\mathrm{dt}} \mathrm{AUC}_{\mathrm{TCA}(\text { buffer })}=\mathrm{TCA}_{\text {buffer }}
\end{aligned}
$$

Besides their effects on membrane transporter activity, cholestatic drugs can have both constriction and dilatation effects on BC, such that the volume of the canalicular compartment is either reduced or increased. For low CsA concentration treatments, the dilatation effect prevails whereas for higher doses constriction of $B C$ are observed. This behavior can be implemented by a linear and a saturating rate for dilatation and constriction:

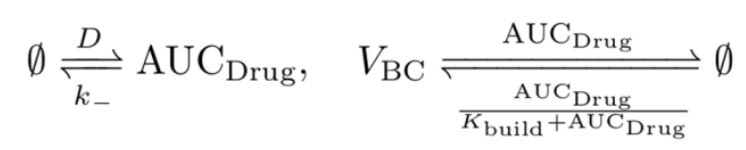

The dilatation/constriction rates are linked to the integrated drug concentration over time, see Figure $1 \mathrm{~A}$. The integrated drug concentration is restricted by a reduction of the rate, $k$. Because we expect a certain delay between drug treatment and reduction of the volume, canalicular volume constriction is linked to the integrated drug concentration $A U C_{\text {drug }}$ instead of simply drug concentration.

A list of all reactions and the corresponding differential equations are available in the supplement Section 3 [Model specification].

\section{Parameter estimation and uncertainty analysis}

Parameter estimation is based on the maximum-likelihood method. As discussed in the section on pre-processing of time resolved data, the observational noise is composed of a random contribution due to the stochasticity of radioactive decays and a random contribution 
due to the heterogeneity between repeated preparations. Although results for the HepaRG cell line are highly reproducible, heterogeneity $\sigma_{\text {celltype }}$ still presents the major contribution to the observation noise of around $15 \%$.

Maximization of the likelihood is equivalent to minimization of the objective function

$$
\chi^{2}(p)=\sum_{i, j} \frac{\left(x_{j}\left(t_{i}, p\right)-x_{j, i}^{D}\right)^{2}}{\sigma_{i, j}^{2}}
$$

where $x_{j}\left(t_{i}, p\right)$ denotes the model prediction for state $j$ at time-point $t_{i}$ given the parameter values $p$. The squared residuals between model prediction and data points $x_{j, i}^{D}=\frac{n_{j}^{2}\left(t_{i}\right)}{4}$ are weighted by the variances $\sigma_{i, j}^{2}=\frac{n_{j}^{2}\left(t_{i}\right)}{4} \sigma_{\text {celltype }}^{2}$. Optimization of the objective function is performed by a trust-region algorithm (Nocedal and Wright, 2006) that relies on derivative information. Therefore, the ODEs of the dynamic system are combined with their forward sensitivity equations (Leis and Kramer, 1988) and solved numerically by the LSODES integrator (Soetaert et al., 2010). Nonlinear optimization is usually compromised by the existence of several local optima. To search the parameter space for the best optimum, we follow a multi-start strategy to initialize the trust-region optimizer. Identification of the parameter determinants has been checked based on the symmetries that are admitted by the system (Merkt et al., 2015). Practical non-identifiability and parameter confidence bounds were analyzed using the profile likelihood method (Kreutz et al., 2013; Raue et al., 2009).

All analyses have been performed in $\mathrm{R}$ with the packages cOde/dMod (Kascheck et al., 2016) for dynamic modeling and parameter estimation in $R$, available on Comprehensive $R$ Archive Network (CRAN). More details about the parameter estimation process are available in the supplement Section 4 [Model fitting and model reduction]. 


\section{Results}

The results described in this work are based on dynamic modeling in combination with parameter estimation to match the experimental TCA data with our mathematical model. Thus, the nature of our model turns from being descriptive to being predictive. The model of TCA transport in HepaRG cells is based on ordinary differential equations describing the TCA flux between three compartments; incubation medium, cells and canaliculi. The impact of the cholestatic drugs CsA and CPZ on uptake and efflux activities has been implemented as a dynamic process with changing transporter activity and canalicular volume over time.

The experimental conditions are characterized by different treatments times, incubations times or changing $\mathrm{Ca} 2+/ \mathrm{Mg} 2+$ levels in the buffer. These conditions are fully accounted for by the model which ultimately depends on a single set of parameters. From these parameter values, the simulated model outcome is uniquely determined for all experimental conditions. The building of the model was achieved by use of four different experimental protocols, two efflux and two uptake protocols. For the sake of clarity, these protocols with the corresponding model predictions are discussed separately, keeping in mind that they are connected by a single model structure and parameter set.

\section{Temperature and $\mathrm{Ca}^{2+} / \mathrm{Mg}^{2+}$ conditions}

The first protocol sheds light on the temperature dependency of transport rates and shows how strongly the presence of $\mathrm{Ca}^{2+} / \mathrm{Mg}^{2+}$ in the buffer contributes to the formation of canalicular junctions to retain TCA in the canaliculi. Figure 2 shows the efflux dynamics of $\left[{ }^{3} \mathrm{H}\right]-\mathrm{TCA}$ in the cells and in the buffer at two temperature conditions, $37^{\circ} \mathrm{C}$ and $4{ }^{\circ} \mathrm{C}$, and two buffer conditions, with and without $\mathrm{Ca}^{2+} / \mathrm{Mg}^{2+}$. Cellular levels of $\left[{ }^{3} \mathrm{H}\right]-\mathrm{TCA}$ (Figure 2A), remain almost constant for low temperature (blue) while showing a quick reduction at $37^{\circ} \mathrm{C}$ (red).

In building the dynamic model of TCA transport, we introduced deceleration parameters $d_{1}$, $\ldots, d_{4}$ to express the change of transport rates from $37^{\circ} \mathrm{C}$ to $4^{\circ} \mathrm{C}$. Exploring the parameter 
space, we found several locally optimal solutions that explained the temperature and $\mathrm{Ca}^{2+} / \mathrm{Mg}^{2+}$ dependency as shown in Figure $2 \mathrm{~A}$. Locally optimal solutions involved either dominant deceleration of sinusoidal/canalicular efflux mediated TCA transport or dominant deceleration of canalicular efflux. However, only the latter solution is able to reproduce the pronounced effect between $\mathrm{Ca}^{2+} / \mathrm{Mg}^{2+}$ and $\mathrm{Ca}^{2+} / \mathrm{Mg}^{2+}$-free conditions at $37{ }^{\circ} \mathrm{C}$ while, at the same time, showing no difference at $4{ }^{\circ} \mathrm{C}$.

The dynamic model allows separation of the intracellular and canalicular contributions which summarized, represents the observation of cellular TCA content. Together with a priori knowledge about the total TCA amounts, a prediction of the $\left[{ }^{3} \mathrm{H}\right]-$ TCA distribution throughout the compartments is feasible, shown in Figure $2 \mathrm{~B}$. After 30 min uptake, $75 \%$ of all TCA is located in the cytoplasm of cells and $25 \%$ in the canaliculi. Under calcium-free conditions at $37^{\circ} \mathrm{C}$, it takes around 10 to $20 \mathrm{~min}$ for the canalicular junctions to disrupt, as can been seen from the model prediction for canalicular TCA.

\section{Efflux of TCA in the presence of cholestatic drugs}

The second protocol focuses on the inhibitory effect of the cholestatic drugs CsA and CPZ on TCA efflux. HepaRG cells were incubated with $\left[{ }^{3} \mathrm{H}\right]-T C A$ for $30 \mathrm{~min}$ and then treated for $2 \mathrm{~h}$ in the presence or absence of drug in standard buffer containing $\mathrm{Ca}^{2+} / \mathrm{Mg}^{2+}$. The experimental results and corresponding model fits are shown in Figure 3. Cellular levels of TCA over a time period of $120 \mathrm{~min}$ are shown in Figure 3A. With increasing concentrations, CsA-treated cells (squares and solid lines) show the expected inhibition of TCA efflux. To obtain a measurement that reflects the cytoplasmic TCA level as close as possible, the efflux buffer was exchanged by a $\mathrm{Ca}^{2+} / \mathrm{Mg}^{2+}$-free medium is added after incubation with $\left[{ }^{3} \mathrm{H}\right]-$ TCA and drug to measure total TCA efflux. The buffer exchange has been included as

a discontinuity into the mathematical model. Therefore, for each data point there is one corresponding model trajectory to fit this data points. The typical trajectory shows a slow exponential decay followed by a fast transition caused by the disruption of canalicular junctions before returning to a slow decay. The range in which the cytoplasmic TCA 
contents changes due to the buffer exchange is shown as shaded area. The bottom part of the shaded area, a dotted line, reflects the TCA concentration after buffer exchange which is to be compared with the data points. Relative to CPZ, CsA shows a much stronger inhibitory effect on TCA clearance by comparison with CPZ at a dose of $50 \mu \mathrm{M}$.

Figure 3B shows the predicted absolute amounts of TCA in the different compartments for an efflux buffer with $\mathrm{Ca}^{2+} / \mathrm{Mg}^{2+}$. All active transport processes are inhibited by $\mathrm{CsA}$, as shown by Figure $3 \mathrm{C}$ and remain low over 120 min except for MRP3 as confirmed by immunostaining (Sharanek, et al., 2015) which begins to recover cellular efflux of TCA over the period following addition of CsA. CPZ has no apparent inhibitory effect on sinusoidal efflux, albeit in the model is shown to inhibit uptake and canalicular efflux. The most evident difference between CsA and CPZ is the slower time scale by which CPZ inhibits uptake and canalicular efflux. Therefore, cells treated with $50 \mu \mathrm{M}$ of $\mathrm{CPZ}$ are able to clear almost all of the contained TCA although canalicular efflux transporters activity drops to almost $0 \%$ as similarly observed for CsA.

The inhibitory constant $(\mathrm{Ki})$ reflects binding affinity and functional strength for the inhibition of activity and becomes important for helping to predict clinically relevant drug interactions. These are normally reported as static measures. Figure $3 C$ indicates that transporter recovery and different time scales of CsA and CPZ action are major characteristics of the system. These properties being identified by our semi-mechanistic drug-transporter response cannot be captured by a classical inhibition model i.e., based on $\mathrm{K}_{\mathrm{i}}$ values, as shown in the Supplement. Exposure to high concentrations $(50 \mu \mathrm{M})$ of either cholestatic drug resulted in constriction of $B C$ as early as $2 \mathrm{~h}$ (Figure $3 \mathrm{C}$, canalicular volume). At lower concentrations (5-10 $\mu \mathrm{M})$, only CsA exhibited 
an effect characterized by bile canaliculi dilatation as shown by phase-contrast microscopy in Figure 4.

\section{Uptake of TCA in the presence of cholestatic drugs}

The third protocol was performed to investigate the effect of treatment time on the concentration-dependent inhibitory effect of CsA. The results are shown in Figure 5. The effects of the CsA on BA uptake was estimated through measurement of intracellular accumulation of $\left[{ }^{3} \mathrm{H}\right]-\mathrm{TCA}$. Briefly HepaRG cells were treated for 15,30 or 60 min with different concentrations of $\operatorname{CsA}(0,1,5,10,25$ and $50 \mu \mathrm{M})$ and measurements were taken 10 min after incubation with TCA. CsA induced a dose-dependent inhibition of TCA uptake as early as 10 minutes after treatment. On the other hand, TCA levels of equivalent doses for different treatment times roughly achieve the same response, see Figure $5 \mathrm{~A}$. This is also reflected in the predicted absolute amounts in the three compartments, Figure 5B. In accordance with the observation, the estimated time-scale parameters for transporter inhibition are fast enough to realize the full inhibitory effect within few minutes, Figure $5 \mathrm{C}$. During incubation with $\left[{ }^{3} \mathrm{H}\right]-\mathrm{TCA}$, no drug is contained in the incubation buffer. The membrane transporter activity can recover and regain their activity to some extent during this phase. The curves for canalicular export and uptake transporter activity are almost exactly superimposable, producing the same efflux dynamics whether the treatment with CsA was for 15,30 or 60 min. By parameter estimation we find that TCA transport to the canaliculi is four times higher than sinusoidal export, limiting the possible impact of sinusoidal export on the shape of the curves. This relative preferential clearance of TCA is confirmed by the observed activities of BSEP and MRP3 activities in heterologous expressed vesicle membranes (unpublished observations). Similarly since we observe cellular uptake of TCA, the reduction of canalicular volume has no direct feedback on the observed cellular levels.

Finally, by the fourth experimental protocol, the effects of the two cholestatic drugs, CPZ and CsA, on bile acids uptake was estimated through measurement of intracellular accumulation 
of $\left[{ }^{3} \mathrm{H}\right]-\mathrm{TCA}$. HepaRG cells were treated for $30 \mathrm{~min}$ with either drug and then loaded with $\left[{ }^{3} \mathrm{H}\right]-$ TCA for different time points over 120 min. As shown in Figure 6 our model predicts that the TCA dynamics upon CPZ treatment is more linear than upon CsA treatment and turns earlier into the phase of accelerated uptake (Figure $6 \mathrm{~A}$ ). This is also visible in the predicted intracellular TCA levels, (Figure 6B) which show a different shape for CsA and CPZ. Although the exposure to high TCA concentrations for more than two hours might be nonphysiological, the insight that continuous TCA exposure could lead to increased TCA uptake is valuable for future mathematical model development.

Evaluating the ratio between intracellular and canalicular TCA amounts by the mathematical model, we find 2-4 times more TCA intracellular content than in the canaliculi. The ratio is even higher for higher drug concentrations. All these observations are in line with the estimated effects of CsA and CPZ on the transporter activity shown in Figure 6C. CPZ inhibition is slower, but more sustained and its effect on canalicular export and cellular uptake is similar. Also, CsA inhibition of basolateral uptake is similar to efflux inhibition. The effect is more immediate for CsA than for CPZ but transporters can partially recover after the removal of CsA. The strongly inhibited accumulation of TCA in the cells upon CsA treatment is supported by the quick recovery and over compensation of sinusoidal response, which can be attributed to sinusoidal transporter activity.

\section{Primary human hepatocytes}

We relate our findings on HepaRG cells to the TCA efflux dynamics observed in human hepatocytes. Hepatocytes were kept in either conventional $(\mathrm{CCHH})$ or sandwich $(\mathrm{SCHH})$ culture. The direct comparison of cellular TCA levels is shown in Figure 7.

The measurements in HepaRG cells, $\mathrm{CCHH}$ and $\mathrm{SCHH}$ are normalized by the respective mean values at $t=30 \mathrm{~min}$, just before the uptake buffer is replaced to measure efflux. Since the efflux is approximately described by an exponential curve, differences between the cell 
types are visualized on the log-scale where a steeper slope corresponds to a higher export rate. On average, the human hepatocytes show a faster export of TCA. The efflux from human hepatocytes is not stopped at $4{ }^{\circ} \mathrm{C}$ but is in the same range as at $37{ }^{\circ} \mathrm{C}$ with $\mathrm{Ca}^{2+} / \mathrm{Mg}^{2+}$ in the buffer; conventional cultured hepatocytes are partly affected. There is the tendency that human hepatocytes are more susceptible to $\mathrm{Ca}^{2+} / \mathrm{Mg}^{2+}$ removal which might indicate that $\mathrm{BC}$ tight junctions are perhaps more disposed to $\mathrm{Ca} 2+\operatorname{depletion}$, which in $\mathrm{CsA}$ treated $\mathrm{PHH}$ is supported by the observation of fewer fully closed $\mathrm{BC}$ in culture.

The comparative analysis of all data reveals that the variability in $\mathrm{CCHH}$ and $\mathrm{SCHH}$ is much larger than in HepaRG cells, see Section 2 [data-preprocessing] in the supplement. This was to be expected due to the known donor-donor differences in transport activity and intracellular amounts of bile acids. This is attributable at least in part due to source of resection tissue from patients, the hepatocytes of which may carry pathologies not consummate with normal liver tissue,thus corroborating our approach to start with a mathematical model of HepaRG cells by which to study the simultaneous effect of TCA transport, BC volume and drug effect. Despite the observed donor-donor differences with $\mathrm{PHH}$, it is nevertheless feasible future work using the model established with HepaRG cells can potentially form the basis of further studies using PHHs. This opens the perspective of pointing towards extending our work with the use of primary human hepatocytes for the development of models to eventually incorporate donor-donor differences, using the dynamic mathematical model described herein.

\section{Discussion}

In the current study, we describe a dynamic mathematical model of TCA uptake and clearance on the basis of experimental data obtained with untreated and CsA- and CPZtreated human HepaRG cells. Data from both previously performed and new experiments on untreated and drug-treated cells were analyzed. All our results were obtained by dynamic modeling of time-resolved experimental data and parameter estimation. Our basic model of 
bile acid transport was established on ordinary differential equations and was extended by a dynamic drug-effect model introducing transporter activity and canalicular volume as dynamic states. These features are important components of bile acid secretion and flow, the deregulation of which are implicated in drug-induced cholestasis (Watanabe, et al., 2007) (Watanabe, et al, 1991).

We analyzed TCA clearance by measuring uptake and both canalicular and sinusoidal efflux that are predominantly performed by NTCP, BSEP and MRP3 membrane transporters respectively. Although passive diffusion is reported for some bile acids the predominant clearance of the prototypical bile acid, TCA, for hepatobiliary studies is through active transport by the involvement of these membrane transporters. In untreated cells, TCA was found in the three compartments, i.e. cells (intracellularly), BC lumen and medium after a short incubation. Time-dependent increased accumulation in the medium during the $30 \mathrm{~min}$ incubation likely reflected an increased sinusoidal efflux associated with the activation of the MRP3 membrane transporter in the presence of drugs, which has been described as a compensatory mechanism in the event of BSEP inhibition (Yang et al., 2013). In support of this, immuno-localization of MRP3 showed a more intense labeling of the sinusoidal membrane after 30min of CsA treatment (Sharanek, et al., 2015). However, it cannot be excluded that a fraction of TCA was effluxed to the supernatant via BC. Indeed, we recently showed that BC exhibit asynchronism contraction and relaxation cycles of around $60 \mathrm{~min}$ each to evacuate BC content into the supernatant (Sharanek, et al; , 2016).

In our model, membrane transporter activity returns close to its basal level following CsA treatment. By parameter estimation we found that this regulatory mechanism could play a major role for sinusoidal export but not for cellular uptake and canalicular export. The model favors a scenario where sinusoidal transporters quickly recover after CsA treatment and restores full sinusoidal membrane transporter activity, whereas for uptake and canalicular export transporters the recovery of activity remains partially inhibited. Consequently, TCA export is shifted from canalicular to sinusoidal export which, under normal conditions, contributes only $20 \%$ to the total export. Thereby, the sinusoidal membrane transporter 
activityconfirms its role as an alternative route of TCA export when the canalicular membrane transporter (i.e. BSEP) is inhibited. These observations hold promising insights for the study on the simultaneous inhibition and recovery of membrane transporter activities in acute drug-induced cholestasis. Further work to extend these observations to other cholestatic drugs will provide important developments to establish if the effects of CsA and CPZ on membrane transporters are drug specific, or equally applies to cholestatic drugs and rarely cholestatic drugs.

Inhibition of transporter activity by the two prototypical inhibitors, CsA and CPZ, was modeled phenomenologically by reversible and irreversible binding reactions. Parameter estimation revealed that all transporters have a well-defined forward- and backward reaction to CsA due to competitive inhibition characteristics of CsA. This means that the time-scales of inhibition and recovery as well as the extent of inhibition during and after CsA treatment can be uniquely determined from the time-course experiments for the three membrane containing transporters. CPZ which is an inhibitor of cellular uptake and canalicular export but not sinusoidal export (Antherieu, et al., 2013) was found to act on TCA clearance rates more slowly when compared to CsA. In agreement, by parameter estimation we could show that inhibition by $\mathrm{CPZ}$ is irreversible, the two reaction parameters corresponding to reversibility being compatible with zero. Indeed, experimental studies showed that the cholestatic mechanism of CPZ is indirect and slower, depending on generation of reactive oxygen species that lead to irreversible bile flow inhibition (Antherieu, et al., 2013). This indicates that the mathematical model is capable of distinguishing between the two cholestatic drugs which act by different mechanisms. In addition, the effect on clearance by both CsA and CPZ causes reduction of canalicular size which was confirmed by direct light microscopic observation. Therefore, the canalicular volume was included as a dynamic state into the mathematical model. We found that the volume reduction is well described when linked to compound exposure and effect on TCA clearance. These features are important when considering testing unknown drug safety profiles for cholestasis in drug discovery. 
Moreover, the model predicts $\mathrm{Ki}$ and can be extended to the study of drug-drug interactions, bile acid perturbation and bile canalicular deregulation in drug safety testing. The assessment of Ki was performed by two approaches in our work with generally comparable results (supplement 5). The observed differences by two the approaches can be attributed to the temporal effect of inhibition and transport recovery. The ability to model both inhibition and recovery can provide important insight when defining drug safety by use of the dynamic model.

Finally, to validate that data from experiments on HepaRG cells are adequate to build a physiologically relevant mathematical model, we analyzed sets of data on TCA uptake and efflux from $\mathrm{PHH}$. As expected, the mathematical analysis of all data reveals expected variability in $\mathrm{PHH}$ clearance of TCA that was considerably larger than in HepaRG cells attributed to the statistical fluctuations of inter-donor variability. By contrast, statistical analysis of HepaRG cells data showed high inter-assay reproducibility, further supporting the stable phenotype of this cell line and its suitability to construct a mathematical model to explore for the first time the hepatobiliary function and apparent inter-relationship of membrane transport, bile canalicular dynamics by drug-induced impairment of TCA clearance. Use of HepaRG cells, which confers stable biological phenotype consummate with primary human hepatocytes, would permit use in the screening and modeling of novel drug candidates in pharmaceutical drug discovery. The approach herein would equally contribute to known works on Systems Pharmacology Modeling that describe delayed bile acid mediated drug induced hepatotoxicity by use of Physiologically-based Pharmacokinetics (PBPK) and virtual population approaches previously described (Yang et al., 2014).

Our model further identifies a number of similarities and dissimilarities between TCA clearance in HepaRG cells, $\mathrm{CCHH}$ and $\mathrm{SCHH}$. In standard experimental conditions of temperature $\left(37^{\circ} \mathrm{C}\right)$ and $\mathrm{Ca}_{2} / \mathrm{Mg}_{2}$-containing buffer, similar TCA efflux rates were observed 
and a temperature-dependent effect was also observed with the linear regression model. Indeed, the mathematical curves showed a decrease of TCA active transport in the three cell models at $4^{\circ} \mathrm{C}$ as indicated by the smaller slope of the regression lines. However, even though the efflux rates were close, human hepatocytes showed a tendency for a faster export of TCA than HepaRG cells that can be attributed to the known higher constitutive expression of BSEP protein at the canalicular membrane (Bachour-El Azzi et al., 2015) and a higher number of hepatocytes per surface unit in $\mathrm{PHH}$ cultures. The higher level of BSEP expression in $\mathrm{PHH}$ thus confers the capacity (Vmax), but not the ability $(\mathrm{Km})$ to transport TCA across the bile canalicular membrane. The primitive biliary cell population present in HepaRG cell cultures do not exhibit any of the bile acid transporters and do not contribute to uptake and accumulate bile acids (Sharanek, et al., 2014). CCHH were less susceptible to low temperature and reduction of TCA efflux at $4^{\circ} \mathrm{C}$ and was less pronounced compared to either HepaRG cells or SCHH. Importantly, while HepaRG cells are maintained for 30 days in culture to reach differentiation, human hepatocytes are only maintained for 4-5 days before use. In this short culture period, isolated human hepatocytes in sandwich configuration recover to form tight-junctions and well-sealed $\mathrm{BC}$ by comparison with conventional collagen culture conditions of cells (LeCluyse et al., 1994; Liu et al., 1998). Similarly, as observed with HepaRG cells, the regression model revealed a dependency of $\mathrm{BC}$ tight junctions on $\mathrm{Ca}_{2+} / \mathrm{Mg}_{2+}$ in human hepatocytes. It also showed that $\mathrm{PHH}$ are more vulnerable to cation depletion than HepaRG cells. Due to the long culture period, HepaRG cells developed tight junctions of larger size than in human hepatocytes and thus are less sensitive to a $\mathrm{Ca}_{2+} / \mathrm{Mg}_{2+}$ depletion. It may also be possible that $\mathrm{CCHH}$ have more poorly formed junctions and consequently accumulate less bile acids in canalicular lumens than their SCHH counterparts and thus potentially diffusion of bile acids to possibly explain the apparent and reduced susceptibility to $4^{\circ} \mathrm{C}$ and higher vulnerability to cation depletion observed in this study. Nevertheless, if some differences were observed between HepaRG cells and PHH, the largely similar clearance of TCA between these two cell models open the perspective of future developments of refining the mathematical model described herein for 
use in extending this work to explore mechanisms of hepatobiliary regulation e.g. FXR gene regulation of transporters in HepaRG cells and inter-individual variabilities in the transport of bile acids and bile canalicular kinetics using phenotypically characterized primary human hepatocytes.

\section{Supplementary data}

Listing further details of biological experiments and techniques used to prepare and characterize HepaRG cells and primary human hepatocytes; data pre-processing details on the comparison of the different cell types; corresponding differential equations on model specification; details on parameter estimation process, model fitting and model reduction. Implementation and fitting of a simplified Ki model (Provided as Separate PDF file) 


\section{Funding Information}

This work was supported by the European Community [Contract MIP-DILI-115336]. The MIP-DILI project has received support from the Innovative Medicines Initiative Joint Undertaking, resources of which are composed of financial contribution from the European Union's Seventh Framework Programme [FP7/20072013] and EFPIA companies' in kind contribution. http://www.imi.europa.eu/.

Daniel Kaschek and Ahmad Sharanek were financially supported by the MIP-DILI project

\section{Conflict of interest}

There is no conflict of interest

\section{Acknowledgements \& Author contributions}

Research design: Richard Weaver;

Mathematical model concept and design, Daniel Kaschek;

Conducted experiments: Biological experiments, Ahmad Sharanek;

Performed data analysis: Interpretation of data, Daniel Kaschek, Ahmad Sharanek, Andre Guillouzo, Richard Weaver.

Wrote or contributed to the writing of the manuscript: Writing and review of manuscript Daniel Kaschek, Ahmad Sharanek, Andre Guillouzo, Richard Weaver;

Review of manuscript Jens Timmer 


\section{References}

Antherieu, S., Bachour-El Azzi, P., Dumont, J., Abdel-Razzak, Z., Guguen-Guillouzo, C., Fromenty, B., Robin, M. A., and Guillouzo, A. (2013). Oxidative stress plays a major role in chlorpromazine-induced cholestasis in human HepaRG cells. Hepatology 57, 1518-29.

Bachour-El Azzi, P., Sharanek, A., Abdel-Razzak, Z., Antherieu, S., Al-Attrache, H., Savary, C. C., Lepage, S., Morel, I., Labbe, G., Guguen-Guillouzo, C., et al. (2014). Impact of inflammation on chlorpromazine-induced cytotoxicity and cholestatic features in HepaRG cells. Drug Metab Dispos 42, 1556-66.

Bachour-El Azzi, P., Sharanek, A., Burban, A., Li, R., Guevel, R. L., Abdel-Razzak, Z., Stieger, B., Guguen-Guillouzo, C., and Guillouzo, A. (2015). Comparative Localization and Functional Activity of the Main Hepatobiliary Transporters in HepaRG Cells and Primary Human Hepatocytes. Toxicol Sci 145, 157-68.

Burbank, M. G., Burban, A., Sharanek, A., Weaver, R. J., Guguen-Guillouzo, C., and Guillouzo, A. (2016). Early Alterations of Bile Canaliculi Dynamics and the Rho

Kinase/Myosin Light Chain Kinase Pathway Are Characteristics of Drug-Induced Intrahepatic Cholestasis. Drug Metab Dispos 44, 1780-1793.

Chiang, J. Y. (2009). Bile acids: regulation of synthesis. J Lipid Res 50, 1955-66.

Goldring, C., Weaver, R., Kramer, B., Klingmueller, O. A., Van der Water, C. J., Guillouzo, A., et al., (2017). Drug-Induced Liver Injury: Mechanism-Informed Prediction in Drug. In Comprehensive Medicinal Chemistry, 3rd Ed (pp. 1-18). Oxford: Elsevier.

Guguen-Guillouzo, C., and Guillouzo, A. (2010). General review on in vitro hepatocyte models and their applications. Methods Mol Biol 640, 1-40.

Guo, C., Yang, K., Brouwer, K. R., St Claire, R. L., 3rd, and Brouwer, K. L. (2016). Prediction of Altered Bile Acid Disposition Due to Inhibition of Multiple Transporters: An Integrated Approach Using Sandwich-Cultured Hepatocytes, Mechanistic Modeling, and Simulation. J Pharmacol Exp Ther 358, 324-33.

Hillgren, K. M., Keppler, D., Zur, A. A., Giacomini, K. M., Stieger, B., Cass, C. E., Zhang, L., and International Transporter, C. (2013). Emerging transporters of clinical importance: an update from the International Transporter Consortium. Clin Pharmacol Ther 94, 52-63.

Jones, H. M., Barton, H. A., Lai, Y., Bi, Y. A., Kimoto, E., Kempshall, S., Tate, S. C., ElKattan, A., Houston, J. B., Galetin, A., et al. (2012). Mechanistic pharmacokinetic modeling for the prediction of transporter-mediated disposition in humans from sandwich culture human hepatocyte data. Drug Metab Dispos 40, 1007-17.

Kaschek, D., Mader, W., Fehling-Kaschek, M., Rosenblatt, M., and Timmer, J. (2016). Dynamic modeling, parameter estimation and uncertainty analysis in R. bioRxiv. Jan $1: 085001$.

Kreutz, C., Raue, A., Kaschek, D., and Timmer, J. (2013). Profile likelihood in systems biology. FEBS J 280, 2564-71.

LeCluyse, E. L., Audus, K. L., and Hochman, J. H. (1994). Formation of extensive canalicular networks by rat hepatocytes cultured in collagen-sandwich configuration. Am J Physiol 266, C1764-74.

Leis, J. R., and Kramer, M. (1988). The simultaneous solution and sensitivity analysis of systems described by ordinary differential equations. ACM Trans Math Software, 14, 45-60. ACM Trans Math Software 14, 45-60.

Li, R., Ghosh, A., Maurer, T. S., Kimoto, E., and Barton, H. A. (2014). Physiologically based pharmacokinetic prediction of telmisartan in human. Drug Metab Dispos 42, 1646-55. 
Liu, X., Brouwer, K. L., Gan, L. S., Brouwer, K. R., Stieger, B., Meier, P. J., Audus, K. L., and LeCluyse, E. L. (1998). Partial maintenance of taurocholate uptake by adult rat hepatocytes cultured in a collagen sandwich configuration. Pharm Res 15, 1533-9.

Merkt, B., Timmer, J., and Kaschek, D. (2015). Higher-order Lie symmetries in identifiability and predictability analysis of dynamic models. Phys Rev E Stat Nonlin Soft Matter Phys $\mathbf{9 2}$, 012920.

Nocedal, J., and Wright, S. (2006). Numerical Optimization (second ed.). Springer Science \& Business Media.

Pauli-Magnus, C., and Meier, P. J. (2006). Hepatobiliary transporters and drug-induced cholestasis. Hepatology 44, 778-87.

Raue, A., Kreutz, C., Maiwald, T., Bachmann, J., Schilling, M., Klingmuller, U., and Timmer, J. (2009). Structural and practical identifiability analysis of partially observed dynamical models by exploiting the profile likelihood. Bioinformatics 25, 1923-9.

Sharanek, A., Azzi, P. B., Al-Attrache, H., Savary, C. C., Humbert, L., Rainteau, D., GuguenGuillouzo, C., and Guillouzo, A. (2014). Different dose-dependent mechanisms are involved in early cyclosporine a-induced cholestatic effects in hepaRG cells. Toxicol Sci 141, 244-53.

Sharanek, A., Burban, A., Burbank, M., Le Guevel, R., Li, R., Guillouzo, A., and GuguenGuillouzo, C. (2016). Rho-kinase/myosin light chain kinase pathway plays a key role in the impairment of bile canaliculi dynamics induced by cholestatic drugs. Sci Rep 6, 24709.

Sharanek, A., Burban, A., Humbert, L., Bachour-El Azzi, P., Felix-Gomes, N., Rainteau, D., and Guillouzo, A. (2015). Cellular Accumulation and Toxic Effects of Bile Acids in Cyclosporine A-Treated HepaRG Hepatocytes. Toxicol Sci 147, 573-87.

Soetaert, K., Thomas, P., and Woodrow-Setzer, R. (2010). Solving Differential Equations in $\mathrm{R}$ : Package deSolve. Retrieved from J Stat Softw: http://dx.doi.org/10.18637/jss.v033.i09.

Swift, B., Pfeifer, N. D., and Brouwer, K. L. (2010). Sandwich-cultured hepatocytes: an in vitro model to evaluate hepatobiliary transporter-based drug interactions and hepatotoxicity. Drug Metab Rev 42, 446-71.

Trauner, M., Meier, P. J., and Boyer, J. L. (1998). Molecular pathogenesis of cholestasis. N Engl J Med 339, 1217-27.

Watanabe, N., Takashimizu, S., Kojima, S., Kagawa, T., Nishizaki, Y., Mine, T., \& Matsuzaki, S. (2007). Clinical and pathological features of a prolonged type of acute intrahepatic cholestasis. Hepatology Research, 37, 598-607.

Watanabe, N., Tsukada, N., Smith, C., \& Phillips, M. (1991). Motility of bile canaliculi in theliving animal: implications for bile flow. J Cell biol, 113, 1069-1680.

Yang, K., Kock, K., Sedykh, A., Tropsha, A., and Brouwer, K. L. (2013). An updated review on drug-induced cholestasis: mechanisms and investigation of physicochemical properties and pharmacokinetic parameters. J Pharm Sci 102, 3037-57.

Yang, K., Pfeifer, N. D., Kock, K., and Brouwer, K. L. (2015). Species differences in hepatobiliary disposition of taurocholic acid in human and rat sandwich-cultured hepatocytes: implications for drug-induced liver injury. J Pharmacol Exp Ther 353, 415-23.

Yang, K., Woodhead, J. L., Watkins, P. B., Howell, B. A., and Brouwer, K. L. (2014).

Systems pharmacology modeling predicts delayed presentation and species differences in bile acid-mediated troglitazone hepatotoxicity. Clin Pharmacol Ther 96, 589-98. 


\section{FIGURE LEGENDS}

Figure 1: Schematic representation of the dynamic model. (A) The flow of TCA between the three compartments is indicated by arrows. Transporters associated to each transport route are marked by red (uptake) and green (efflux) circular symbols. Canalicular content ejection back into buffer is marked by a blue circular symbol. The amount of TCA in each compartment and the canalicular volume are dynamic states. Canalicular volume changes are induced by drug exposure. (B) Drug-induced transporter inhibition is expressed by a phenomenological model which can be represented by a reaction network. During the absence of the drug, levels of the active transporter (green open circle) are in equilibrium. Upon drug stimulation, a new equilibrium between active and inactive transporters (grey circle) is approached. (C) TCA import is inhibited by the cholestatic drug. This is illustrated by the equilibrium reaction between active (red open circle) and inactive (grey circle) transporter. Additionally, continuous exposure to TCA in the buffer eventually leads to increased uptake. The regulation of active transporter is linked to the integrated buffer TCA concentration in the model. See methods \& materials for full description. Colour versions of illustrations are available in the online version.

Figure 2 TCA efflux in HepaRG cells. (A-B) Cells incubated at either $37^{\circ} \mathrm{C}$ or $4^{\circ} \mathrm{C}$ during efflux and the efflux buffer did or did not contain calcium (colors). (A) Data points and model fit are shown as dots and lines respectively. (B) The model prediction for the distribution of TCA amounts between the three compartments shows canalicular levels after uptake to be around $25 \%$. Colour versions of illustrations are available in the online version.

Figure 3 TCA efflux in HepaRG cells in the presence of cholestatic drugs. (A-C) Transporters have been inhibited by different concentrations (colors) of the cholestatic drugs CsA $(0,5,10$ and $50 \mu \mathrm{M})$ and CPZ $(50 \mu \mathrm{M})$ marked as linestyles and symbols. The buffer was exchanged by a calcium-free buffer 5 min before taking the measurement. (A) Measured 
cellular TCA (counts are dpm x103?). Data points and model prediction are shown as dots and lines. At low doses, canalicular efflux due to calcium removal reduces the observed cellular TCA levels significantly. (B) The model predicts $1 \%$ uptake of all TCA in the buffer. Amounts are in pmol Avogadro. (C) Transporter inhibition and volume constriction as predicted by the mathematical model shows a slower dynamics of CPZ-induced inhibition compared to CsA and significant volume constriction of BC only at higher concentrations. Colour versions of illustrations are available in the online version.

Figure 4: Alteration of BC morphology by CsA and CPZ in HepaRG cells. Untreated cells and cells treated with CsA (10 and $50 \mu \mathrm{M})$ or with CPZ (20 and $50 \mu \mathrm{M})$. Phase-contrast images were captured after $2 \mathrm{~h}($ bar $=30 \mu)$; White arrows indicate $B C$ constriction $(C)$ and dilatation (D).

Figure 5 TCA uptake in HepaRG cells at different CsA treatment times. (A-C) HepaRG treated with $0-50 \mu \mathrm{M}$ CsA for 15,30 or $60 \mathrm{~min}$, then change of buffer containing $\mathrm{H}^{3}$-TCA for 10 min prior to measurements of CA. Cells have been treated with different doses (colors) of CsA for 15,30 or $60 \mathrm{~min}$ and then incubated by TCA for $10 \mathrm{~min}$. (B) The model predicts similar TCA uptake dynamics in absolute amounts, independent of the treatment time. (C) The efflux across sinusoidal, canalicular membrane and uptake are similarly predicted irrespective of time of treatment at $0-50 \mu \mathrm{M}$ CsA are described. Replacing the treatmentbuffer with the TCA-incubation buffer, results in partial recovery of transporter inhibition (the transporter inhibition is partially reduced). Colour versions of illustrations are available in the online version.

Figure 6 TCA uptake in HepaRG cells for different TCA incubation times. (A-C) After a fixed treatment time of $30 \mathrm{~min}$, either with CsA or CPZ (line-type and symbols), the cells have been incubated with TCA for different times up to $120 \mathrm{~min}$. (A) The data shows an accelerated uptake of TCA at later time points. (B) Canalicular TCA amounts, expressed as 
percentages, are predicted to be smaller than cytoplasmic amounts by a factor $2-4$, which is even reinforced by the cholestatic drugs. (C) Uptake and canalicular export transporters show almost irreversible predicted inhibition, especially for CPZ. Uptake is increased due to the continuous exposure to TCA in the buffer. Colour versions of illustrations are available in the online version.

Figure 7: Comparison of TCA efflux in HepaRG cells and human hepatocytes for different temperature and $\mathrm{Ca}^{2+} / \mathrm{Mg}^{2+}$ conditions. Radioactive counts were normalized by time point 30 min. The normalized counts reflect cellular TCA concentrations, shown by squares, on a logarithmic scale. Colors indicate the cell type. Differences between the cell types are highlighted by dashed lines which are computed by linear regression from the data points. Although on average human hepatocytes show greater efflux activity than HepaRG cells, the efflux rate under standard conditions $\left(37^{\circ} \mathrm{C}\right.$ and $\left.\mathrm{Ca}^{2+} / \mathrm{Mg}^{2+}\right)$ remains broadly unaffected, as indicated by the similar slope of all three regression lines. Colour versions of illustrations are available in the online version. 


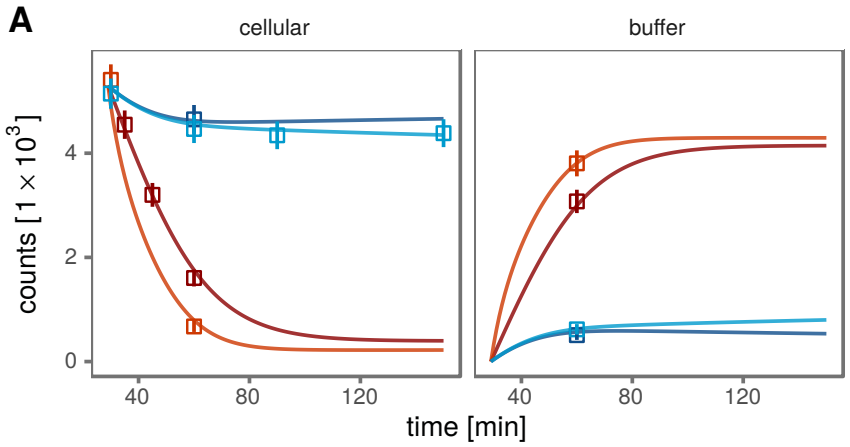

B

TCA buffer
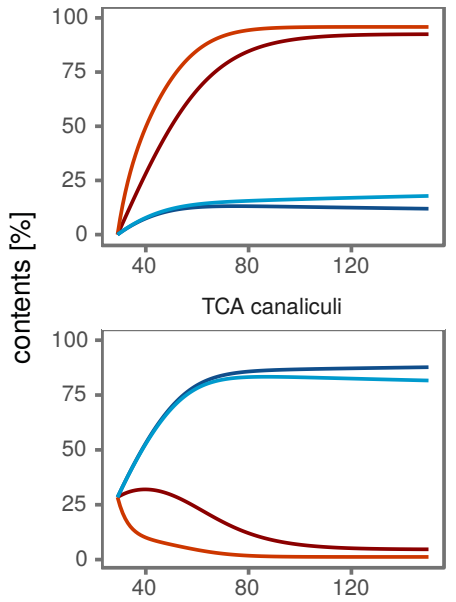

TCA cytoplasm

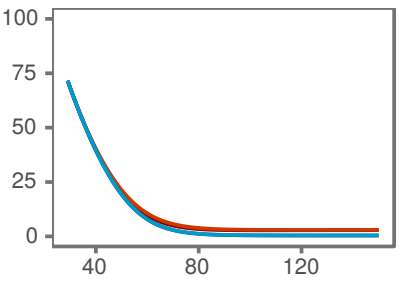

time [min]

$-37^{\circ} \mathrm{C}, \mathrm{Ca}^{2+}$

$-37^{\circ} \mathrm{C}$, no $\mathrm{Ca}^{2+}$

$-4^{\circ} \mathrm{C}, \mathrm{Ca}^{2+}$

$4^{\circ} \mathrm{C}$, no $\mathrm{Ca}^{2+}$ 
A cellular
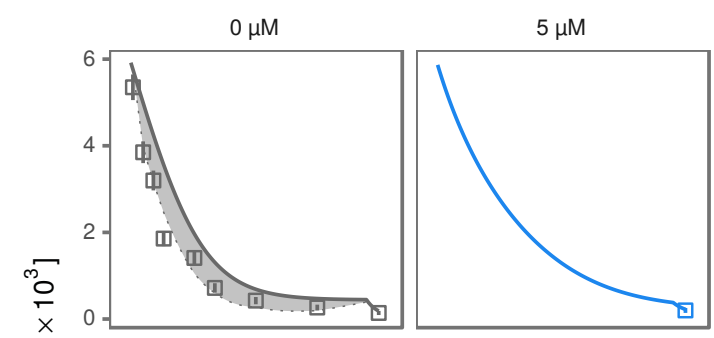

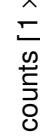

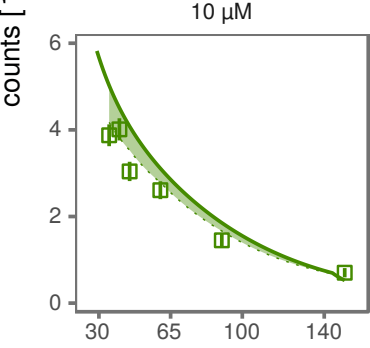

time [min]

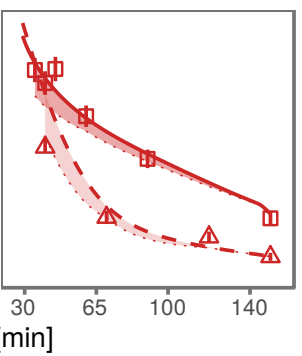

B

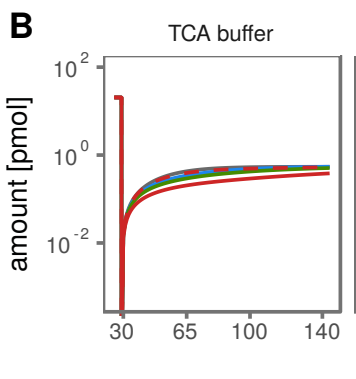

TCA cytoplasm
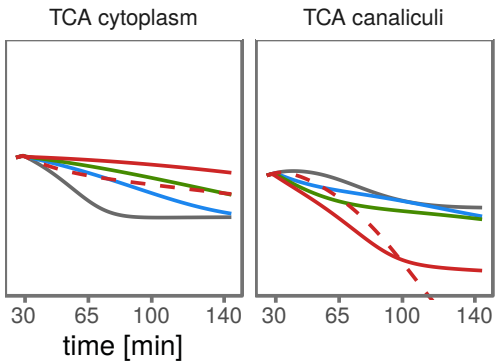

dose

$\rightarrow 0 \mu \mathrm{M}$

$-5 \mu \mathrm{M}$

- $10 \mu \mathrm{M}$

- $50 \mu \mathrm{M}$

compound

$\frac{\square}{-\triangle}$ CsA

C efflux (sinusoidal)

efflux (canalicular)

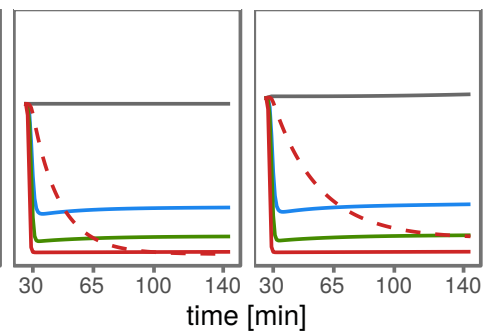

volume (canalicular)
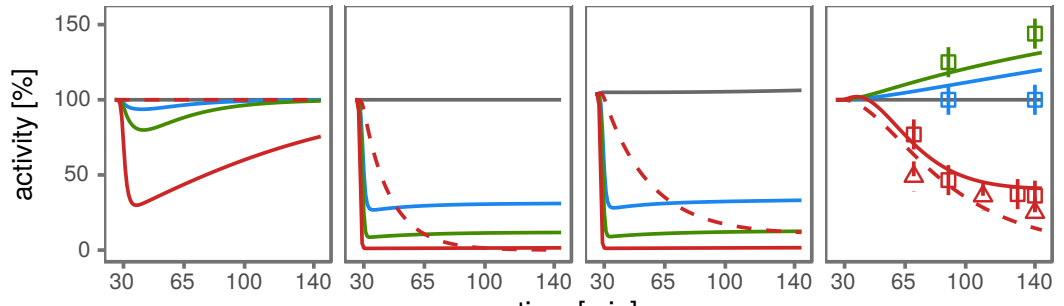
Figure 4

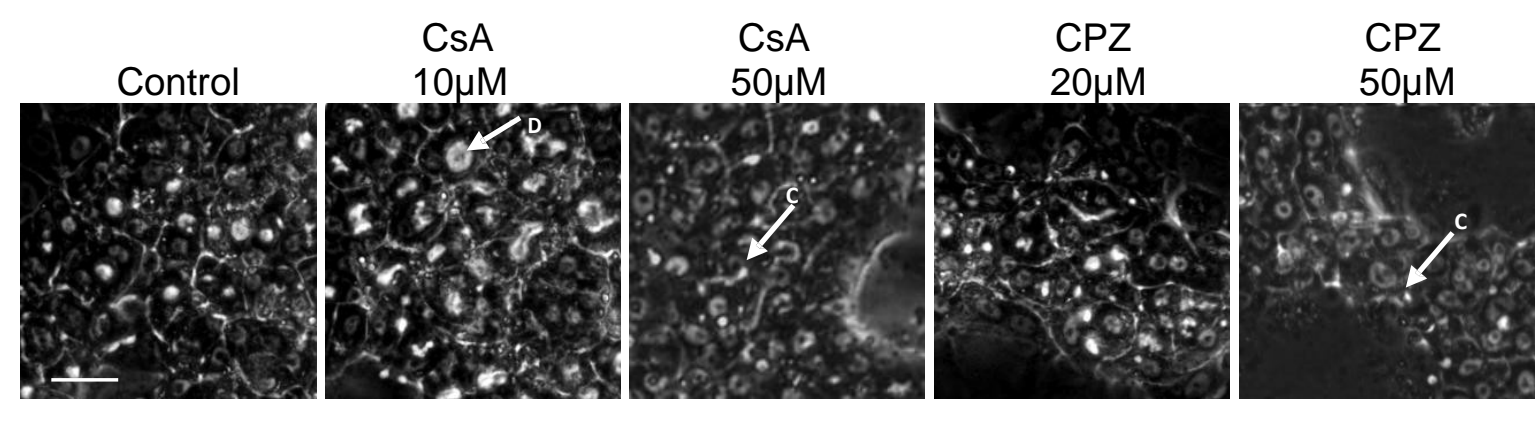


A cellular $\quad$ B $\quad$ CsA dose $-0 \mu \mathrm{M}-1 \mu \mathrm{M}-5 \mu \mathrm{M}-10 \mu \mathrm{M}-25 \mu \mathrm{M}-50 \mu \mathrm{M}$
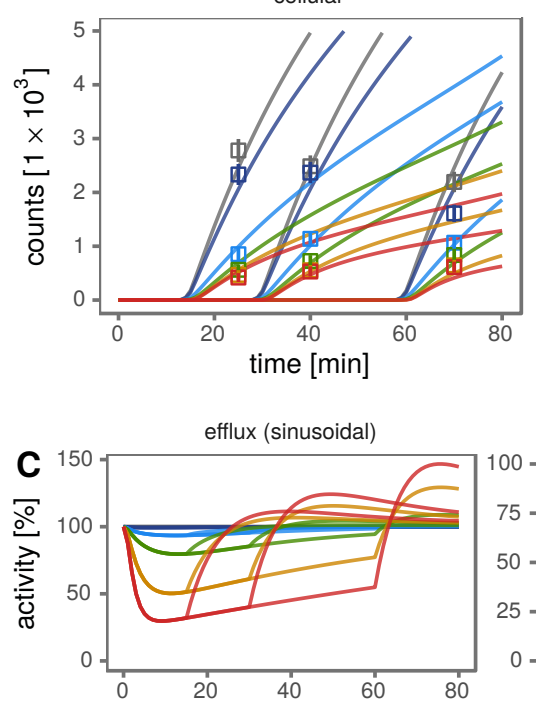

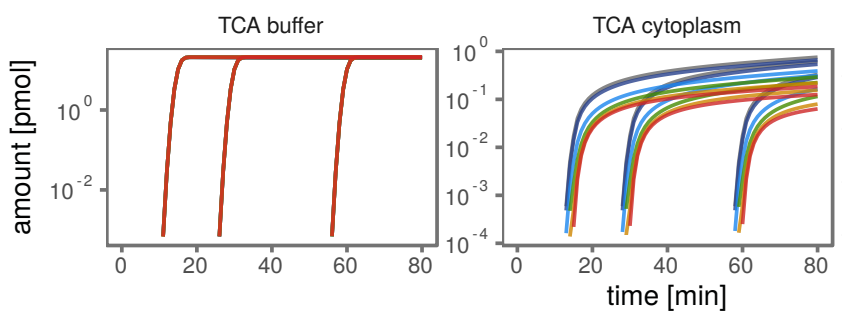

TCA canaliculi

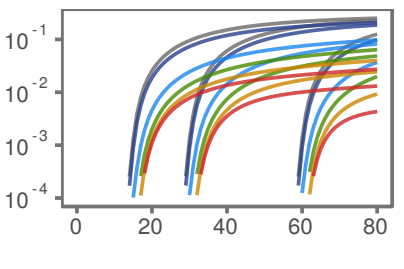

efflux (canalicular)

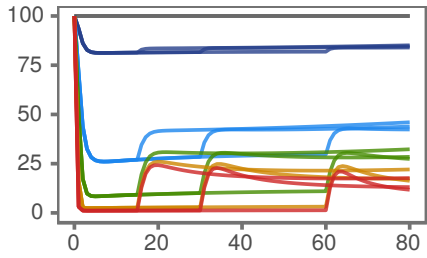

uptake

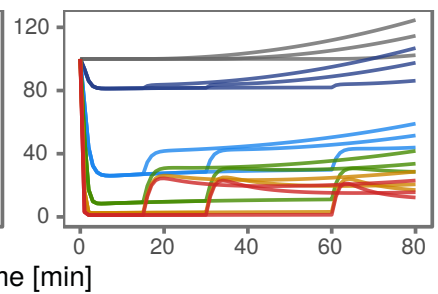

volume (canalicular)

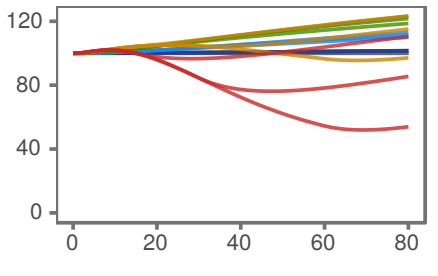




\section{$\begin{array}{lll}\text { A } & \text { cellular } & \text { B }\end{array}$}

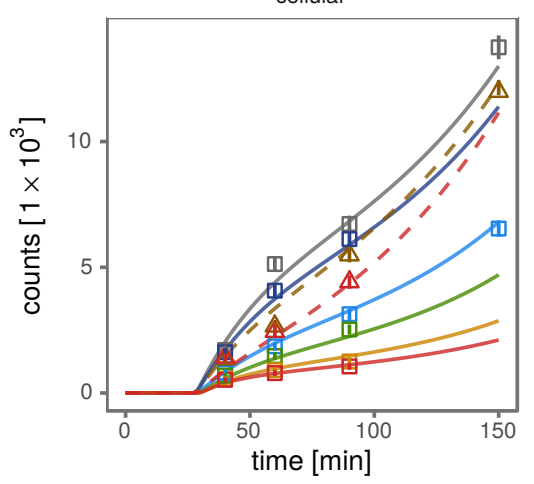

dose

$0 \mu \mathrm{M}$

$1 \mu \mathrm{M} \multimap 5 \mu \mathrm{M} \multimap-10 \mu \mathrm{M}$

$20 \mu \mathrm{M}-25 \mu \mathrm{M}$

compound $\square \mathrm{CsA} / \mathrm{no}-\triangleq{ }_{-} \mathrm{CPZ}$
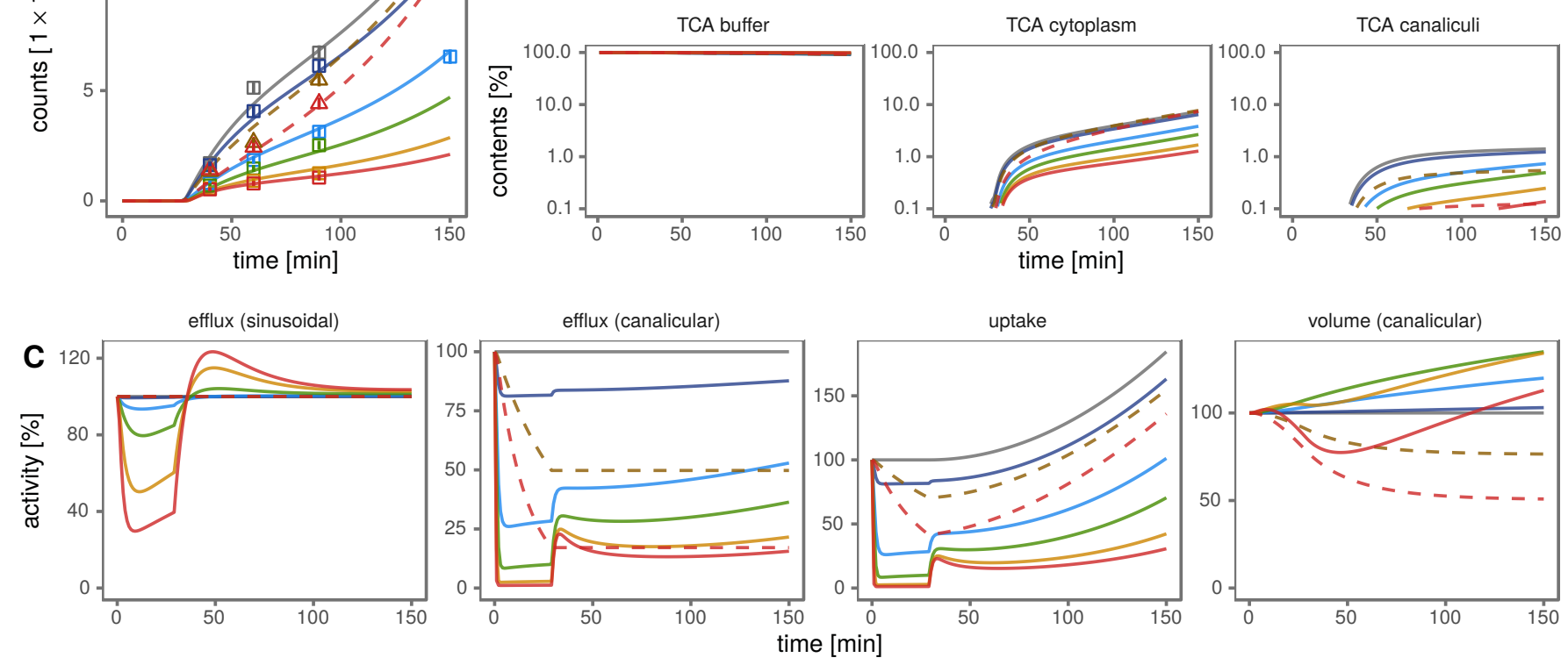

time [min] 


\section{Supplement: A dynamic mathematical model of bile acid clearance in HepaRG cells}

Daniel Kaschek, Ahmad Sharanek, André Guillouzo, Jens Timmer and Richard J. Weaver

\section{Contents}

1 Materials and Methods $\quad 1$

1.1 Reagents . . . . . . . . . . . . . . . . . . . . . . . . . . . . . 1

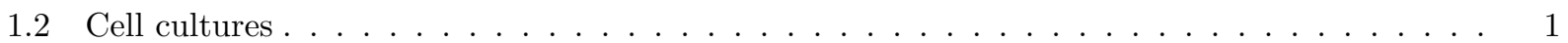

$1.3\left[{ }^{3} \mathrm{H}\right]$-TCA efflux in control (untreated) HepaRG cells and primary human hepatocytes $\ldots . .2$

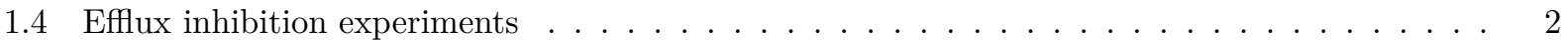

1.5 Uptake inhibition experiments . . . . . . . . . . . . . . . . . . . . 2

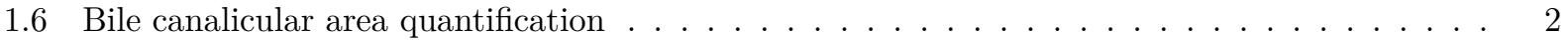

2 Data pre-processing $\quad 3$

3 Model specification $\quad 4$

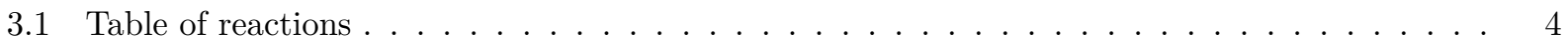

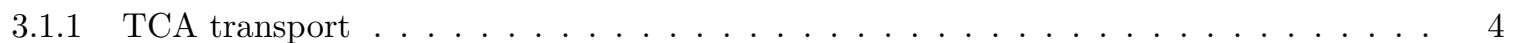

3.2 Specification of reaction rates $\ldots \ldots \ldots \ldots \ldots \ldots \ldots$

3.3 List of differential equations $\ldots \ldots \ldots \ldots \ldots \ldots \ldots \ldots \ldots$

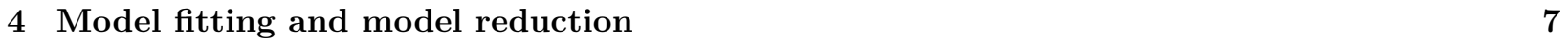

4.1 Table of parameters $\ldots \ldots \ldots \ldots \ldots \ldots \ldots$

\section{Materials and Methods}

\section{$1.1 \quad$ Reagents}

Cyclosporine A (CsA) and chlorpromazine (CPZ) were purchased from Sigma (St. Quentin Fallavier, France). $\left[{ }^{3} \mathrm{H}\right]$-Taurocholic acid $\left(\left[{ }^{3} \mathrm{H}\right]-\mathrm{TA}\right)$ was from Perkin Elmer (Boston, MA).

\section{$1.2 \quad$ Cell cultures}

HepaRG cells were seeded at a density of $2.6 \times 10^{4}$ cells $/ \mathrm{cm}^{2}$ in Williams' E medium supplemented with $2 \mathrm{mM}$ glutaMAX, $100 \mathrm{U} / \mathrm{mL}$ penicillin, $100 \mu \mathrm{g} / \mathrm{mL}$ streptomycin, $10 \%$ HyClone fetal calf serum, $5 \mu \mathrm{g} / \mathrm{mL}$ insulin, and $50 \mu \mathrm{M}$ hydrocortisone hemisuccinate. At confluence (after 2 weeks), HepaRG cells were further incubated in the same medium, but supplemented with $1.7 \%$ dimethyl sulfoxide for 2 additional weeks to obtain confluent 
differentiated cultures containing equal proportions of hepatocyte-like and progenitor/primitive biliary-like cells (16).

The differentiated hepatic cell cultures were used for the analytical assays. Human hepatocytes were obtained from Biopredic International (St Gregoire, France) in compliance with French bioethics legislation. Hepatocytes were isolated by collagenase perfusion of histologically normal liver fragments from 4 adult donors undergoing resection for primary and secondary tumors. Primary cultures were obtained by hepatocyte seeding at a density of $1.5 \times 10^{5}$ cells $/ \mathrm{cm}^{2}$ onto collagen-pre-coated plates in Williams' E medium supplemented as detailed above except for the addition of $10 \%$ fetal calf serum and $1 \mu \mathrm{g} / \mathrm{ml}$ bovine serum albumin. The medium was discarded $12 \mathrm{~h}$ after cell seeding, and the cultures were then maintained in the same medium as for the HepaRG cells and designated as conventional collagen cultured $\mathrm{HH}(\mathrm{CCHH})$, or maintained for 24 to $48 \mathrm{~h}$ and then washed with cold medium and overlaid with matrigel at a concentration of $0.25 \mathrm{mg} / \mathrm{mL}$ in ice-cold Williams' E medium for the preparation of sandwich cultured $\mathrm{HH}$ (SCHH). The medium of both the $\mathrm{CCHH}$ and $\mathrm{SCHH}$ preparations was renewed daily. $\mathrm{CCHH}$ and $\mathrm{SCHH}$ were prepared from the same donors and analyzed in parallel. SCHH cultures were used after at least a 3 day-matrigel overlay.

\section{$1.3\left[{ }^{3} \mathrm{H}\right]$-TCA efflux in control (untreated) HepaRG cells and primary human hepatocytes}

HepaRG cells and 4-5 days CCHHs and SCHHs were exposed to $\left[{ }^{3} \mathrm{H}\right]$-TCA for $30 \mathrm{~min}$. After washing, efflux of radiolabeled TCA was assessed for different time points $(0,5,15$ and $30 \mathrm{~min})$ in either standard with $\mathrm{Ca}^{2+}$ and $\mathrm{Mg}^{2+}$ or $\mathrm{Ca}^{2+}$ - and $\mathrm{Mg}^{2+}$-free buffer. Cells were then scraped in $0.1 \mathrm{~N} \mathrm{NaOH}$ and accumulation of radiolabeled substrate into cells + bile canaliculi (in the presence of $\mathrm{Ca}^{2+}$ - and $\mathrm{Mg}^{2+}{ }_{\text {-ions }}$ ) and into cells only (in the absence of $\mathrm{Ca}^{2+}$ - and $\mathrm{Mg}^{2+}$-ions) was measured through scintillation counting to evaluate TCA efflux. Absence of divalent cations promotes disruption of tight junctions and induces bile canaliculi opening (Swift, 2010).

\subsection{Efflux inhibition experiments}

HepaRG cells were first exposed to $43.3 \mathrm{nM}\left[{ }^{3} \mathrm{H}\right]$-TCA for $30 \mathrm{~min}$ to induce intracellular accumulation of $\left[{ }^{3} \mathrm{H}\right]$-TCA, then washed with standard buffer and incubated with CsA $(0,1,5,10,25$ and $50 \mu \mathrm{M})$ or CPZ $(0$, 20 and $50 \mu \mathrm{M})$ for different time points in a standard buffer with $\mathrm{Ca}^{2+}$ and $\mathrm{Mg}^{2+}$. After incubation, cells were washed and incubated for 5 min with $\mathrm{Ca}^{2+}$ - and $\mathrm{Mg}^{2+}$-free buffer in order to disrupt canalicular tight junctions. Cells were then scraped in $0.1 \mathrm{~N} \mathrm{NaOH}$ and the remaining radiolabeled substrate were measured through scintillation counting to determinate TCA efflux (Sharanek, 2014).

\subsection{Uptake inhibition experiments}

HepaRG cells were treated with different concentrations of CsA $(0,1,5,10,25$ and $50 \mu \mathrm{M})$ or CPZ $(0,20$ and $50 \mu \mathrm{M})$ for $30 \mathrm{~min}$. After washing, cells were loaded with $\left[{ }^{3} \mathrm{H}\right]$-TCA-containing buffer at different time points $(10,30,60$ and $150 \mathrm{~min})$. After the incubation period, $\left[{ }^{3} \mathrm{H}\right]-\mathrm{TCA}$-containing buffer was removed and cells were scraped in $0.1 \mathrm{~N} \mathrm{NaOH}$. The radiolabeled substrate was measured by scintillation counting to determinate TCA uptake. At the time they were used, HepaRG hepatocytes exhibited typical BC structures. As previously reported, HepaRG cells form bile acids (BA) and express BA metabolizing enzymes and BA transport activities and can be used to study drug-induced cholestatic effects. Primitive biliary cells do not express BA metabolizing enzymes or BA transporters (Sharanek, 2014).

\subsection{Bile canalicular area quantification}

Effects of CsA and CPZ on BC area were evaluated by time-lapse cell imaging and quantified by a software video analysis and a modelling tool (Tracker 4.87). Briefly, circular frames delimiting BC were manually 
identified using the free hand selection tool of Tracker 4.87 to track and record brightness variations. These records reflected the area of $\mathrm{BC}$.

\section{Data pre-processing}

All radioactive count data has been transformed by the transformation $n=2 \sqrt{N}$, where $N$ denotes the number of counts. Due to the Poissonian nature of count experiments, repeated measurements of the same sample would yield values for $n$ with unit variance. Repeated measurements for different samples, i.e. biological replicates, yield values for $n$ that necessarily have a higher variance. Therefore, the variance of $2 \sqrt{N}$ for these samples is a measure for the heterogeneity between biological replicates.

TCA has been measured in buffer or in cells for four experimental protocols, exp1, ., exp4. Data for each of these combinations have been pooled on a common scale and the variance has been estimated per celltype, i.e. HepaRG, HHclassic (human hepatocytes, classic culture) and HHsandwich (human hepatocytes, sandwich culture). The results are shown in Figure S1.

For the buffer measurements, human hepatocytes in sandwich culture (blue) show the highest variance, followed by the human hepatocytes in classic culture (red) and HepaRG cells (black). The shaded areas denote \pm 1 standard deviation and \pm 3 standard deviations of the pooled observations. The result is similar for cellular measurements where again human hepatocytes show a larger variance than HepaRG. Notably, the standard deviation of HepaRG does not exceed the value of 5.8 (cellular, exp1), for most experimental protocols it is even lower. 


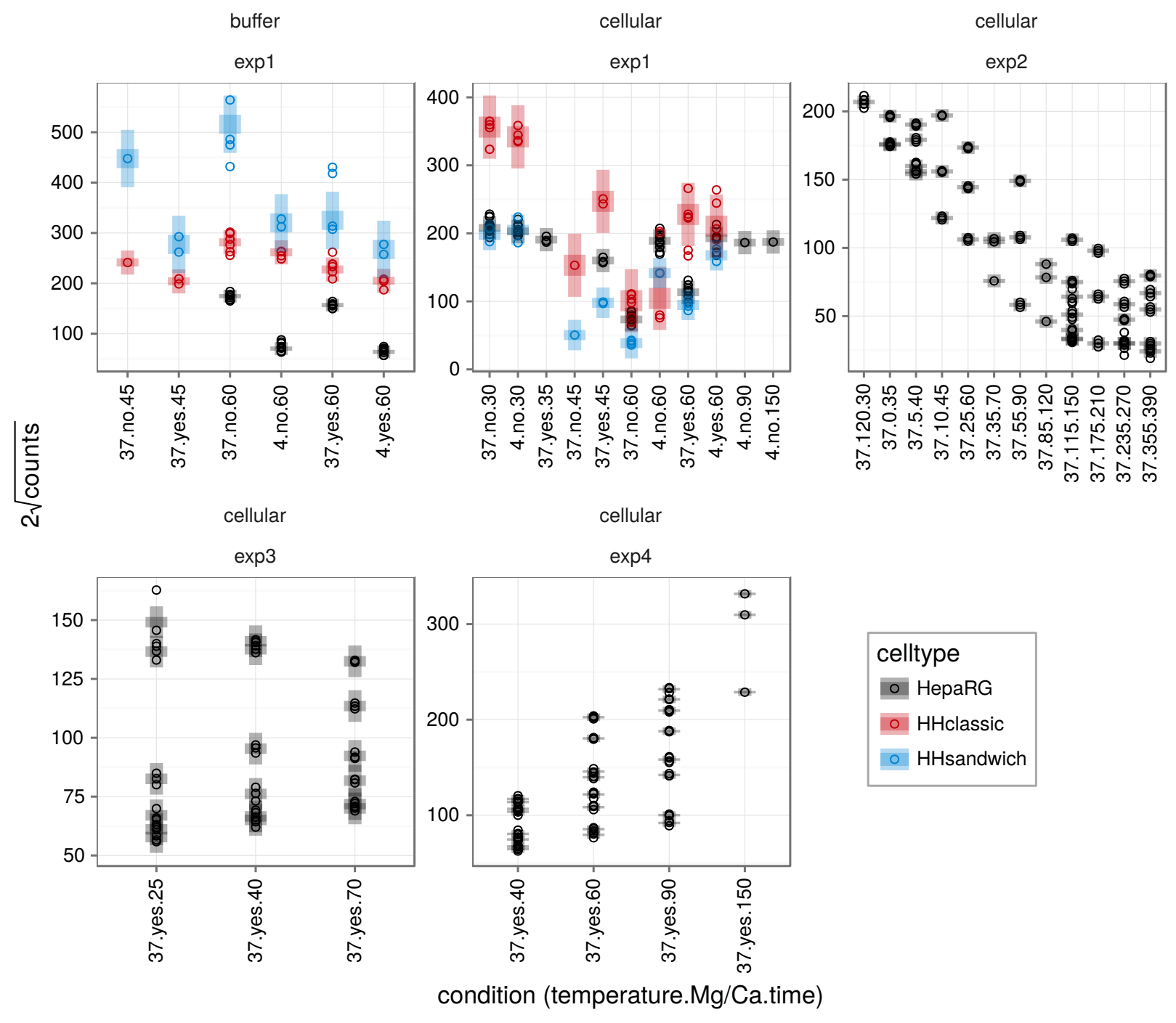

Figure S1: Data pre-processing. Twice the square root of the number of counts are plotted versus the different conditions. The data has been divided into buffer/cellular measurements and experimental protocols exp1, exp2, exp3 and exp4. Data from different celltypes are distinguished by color. Each dot represents one measurement. Confidence intervals with a $1 \sigma$ and $3 \sigma$ confidence level are visualized as shaded areas.

\section{Model specification}

The dynamic model of TCA transport in HepaRG cells is specified by a table of reactions and a list of expressions, specifying the rate constants and compartment volumes.

\subsection{Table of reactions}

The following table lists the elementary processes in the language of chemical reactions.

\subsubsection{TCA transport}




\begin{tabular}{lllll}
\hline Educt & $->$ & Product & Rate & Description \\
\hline Tca_buffer & $->$ & Tca_cyto & import_Tca * Tca_buffer & Basolateral uptake \\
Tca_cyto & $->$ & Tca_buffer & export_Tca_baso * Tca_cyto & Basolateral efflux \\
Tca_cyto & $->$ & Tca_canalicular & export_Tca_cana * Tca_cyto & Canalicular efflux \\
Tca_canalicular & $->$ & Tca_buffer & transport_Tca * Tca_canalicular & Transport bile \\
\hline
\end{tabular}

The table lists the four transport processes. The rates and how they are affected by temperature and calcium levels are listed below.

\begin{tabular}{|c|c|c|c|c|}
\hline Educt & $->$ & Product & Rate & Description \\
\hline & $->$ & Bsep & alpha_Bsep & Transporter levels \\
\hline \multirow[t]{2}{*}{ Bsep } & $->$ & & alpha_Bsep * Bsep & Transporter levels \\
\hline & $->$ & Ntcp & alpha_Ntcp & Transporter levels \\
\hline \multirow[t]{2}{*}{ Ntcp } & $->$ & & alpha_Ntcp $*$ Ntcp & Transporter levels \\
\hline & $->$ & Mrp3 & alpha_Mrp3 & Transporter levels \\
\hline \multirow[t]{3}{*}{ Mrp3 } & $->$ & & alpha_Mrp3 $*$ Mrp3 & Transporter levels \\
\hline & $->$ & AUC_Tca_buffer & Tca_buffer & Transporter levels \\
\hline & $->$ & Ntcp & build_Ntcp $*$ AUC_Tca_buffer & Transporter levels \\
\hline \multirow[t]{2}{*}{ rho_canalicular } & $->$ & & $\begin{array}{l}\text { beta_V_canalicular * } \\
\text { rho_canalicular }\end{array}$ & Volume level \\
\hline & $->$ & rho_canalicular & beta_V_canalicular & Volume level \\
\hline
\end{tabular}

The table shows the build-up and reduction of transporter levels. Both processes have equal rates to constrain the equilibrium to be 1. Large values for alpha parameters force the system to quickly go back into the equilibrium. To incorporate into the model that long exposure to TCA leads to increased uptake, the Tca_buffer concentrations are integrated over time, yielding AUC_Tca_buffer. Larger values of AUC_Tca_buffer cause higher import, attributed to the Ntca model state. Canalicular volumes are kept in an equilibrium, too. In analogy to transporter build-up and redution, the volume fraction $\rho_{\text {canalicular }}(t)=$ $\frac{V_{\text {canalicular }}(t)}{V_{\text {canalicular, equilibrium }}}$ is controlled by a rate beta_V_canalicular.

\begin{tabular}{|c|c|c|c|c|}
\hline Educt & $->$ & Product & Rate & Description \\
\hline Bsep + Drug & $->$ & DrugBsep & build_DrugBsep * Drug * Bsep & $\begin{array}{l}\text { DRUG } \\
\text { effect }\end{array}$ \\
\hline DrugBsep & $->$ & Bsep + Drug & decay_DrugBsep * DrugBsep & $\begin{array}{l}\text { DRUG } \\
\text { effect }\end{array}$ \\
\hline Ntcp + Drug & $->$ & DrugNtcp & build_DrugNtcp $*$ Drug $*$ Ntcp & $\begin{array}{l}\text { DRUG } \\
\text { effect }\end{array}$ \\
\hline DrugNtcp & $->$ & Ntcp + Drug & decay_DrugNtcp * DrugNtcp & $\begin{array}{l}\text { DRUG } \\
\text { effect }\end{array}$ \\
\hline $\begin{array}{l}\text { Mrp3 }+ \\
\text { Drug }\end{array}$ & $->$ & DrugMrp3 & build_DrugMrp3 ${ }^{*}$ Drug $*$ Mrp3 & $\begin{array}{l}\text { DRUG } \\
\text { effect }\end{array}$ \\
\hline \multirow[t]{2}{*}{ DrugMrp3 } & $->$ & $\begin{array}{l}\text { Mrp3 }+ \\
\text { Drug }\end{array}$ & decay_DrugMrp3 $*$ DrugMrp3 & $\begin{array}{l}\text { DRUG } \\
\text { effect }\end{array}$ \\
\hline & $->$ & AUC_Drug & Drug & $\begin{array}{l}\text { DRUG } \\
\text { effect }\end{array}$ \\
\hline AUC_Drug & $->$ & & deg_AUC_Drug $*$ AUC_Drug & $\begin{array}{l}\text { DRUG } \\
\text { effect }\end{array}$ \\
\hline rho_canalicula & & & red_V_cana_drug * rho_canalicular * AUC_Drug & $\begin{array}{l}\text { DRUG } \\
\text { effect }\end{array}$ \\
\hline
\end{tabular}




\begin{tabular}{lllll}
\hline Educt & $->$ & Product & Rate & Description \\
\hline & $->$ & rho_canalicularbuild_V_cana_drug * AUC_Drug / & DRUG \\
& & (K_build_V_cana_drug + AUC_Drug) & effect \\
\hline
\end{tabular}

Inhibition of transporters by the drug are modeled by drug binding and drug release. Only the "free" transporter is active. The different build and decay parameters determine equilibrium levels and time scales. The canalicular volume factor rho_canalicular is controlled by the integrated drug presence, AUC_Drug. Regeneration from the drug insult is captured in the rate deg_AUC_Drug. The integrated drug presence has both, stimulating and attenuating effects on the volume factor. The different functional dependency of the build and reduction rates on AUC_Drug leads to a separation of regimes where either of the processes dominates.

\begin{tabular}{lllll}
\hline Educt & $->$ & Product & Rate & Description \\
\hline & $->$ & Tca_buffer & injection_Tca & TCA input \\
& $->$ & Drug & injection_Drug & DRUG input \\
\hline
\end{tabular}

TCA injection and drug injection are modeled by bolus functions, see the rate specification below.

\subsection{Specification of reaction rates}

Some of the rates as well as the buffer volume are further specified by the following expressions:

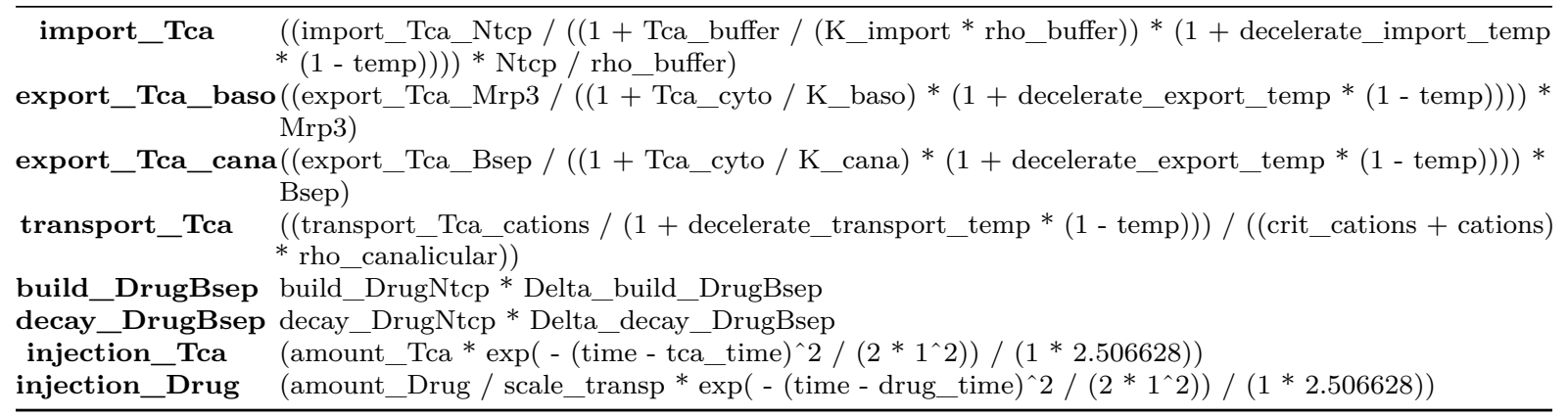

The rates import_TCA, export_Tca_baso, and export_Tca_cana associated to transporter activity are modeled by Michaelis-Menten kinetics. All transport processes, including the export from the canaliculi, are decelerated for the low-temperature measurement $\left(4{ }^{\circ} \mathrm{C}\right)$, i.e., temp $=0$. When temp $=1\left(37{ }^{\circ} \mathrm{C}\right)$, the deceleration parameter is switched off by the factor (1 - temp). Additionally, the transport rate is lowered by the presence of $\mathrm{Ca}^{2+}$ in the buffer, i.e., cations $=1$. Hence, the transport rate switches between transport_Tca_cations/crit_cations and transport_Tca_cations/(crit_cations +1 ) without and with calcium. Both, the compound and TCA get into the system by a bolus input function. The bolus function is the normalized Gauß peak

$$
G(t)=\frac{1}{\sqrt{2 \pi \Delta t^{2}}} \mathrm{e}^{-\frac{\left(t-t_{0}\right)^{2}}{2 \Delta t^{2}}},
$$

symmetric around $t_{0}$ with width $\Delta t$. In our case $\Delta t=1$ is fixed, hence, the factor $\sqrt{2 \pi \Delta t^{2}}$ becomes 2.506628 . 


\subsection{List of differential equations}

The reactions together with the rate specifications are translated in ordinary differential equations for each of the dynamic states. They read as follows:

\begin{tabular}{|c|c|}
\hline Tca_buffer & $\begin{array}{l}-1 *(((\text { import_Tca_Ntcp } /((1+\text { Tca_buffer } /(\mathrm{K} \text { _import } * \text { rho_buffer })) *(1+ \\
\left.\left.\text { decelerate_import_temp } *(1-\text { temp }))))^{*} \text { Ntcp } / \text { rho_buffer }\right) * \text { Tca_buffer }\right)+1 * \\
(((\text { export_Tca_Mrp3 / }((1+\text { Tca_cyto / K_baso }) *(1+\text { decelerate_export_temp } *(1-\text { temp })))) * \\
\text { Mrp3)* Tca_cyto })+1 *(((\text { transport_Tca_cations } /(1+\text { decelerate_transport_temp } *(1-\text { temp }))) \\
/((\text { crit_cations }+ \text { cations }) * \text { rho_canalicular })) * \text { Tca_canalicular })+1 *((\text { amount_Tca } * \text { exp }(-(\text { time } \\
\left.\left.\left.\text { - tca_time }) \wedge /\left(2 * 1{ }^{*} 2\right)\right) /(1 * 2.506628)\right)\right)\end{array}$ \\
\hline Tca_cyto & 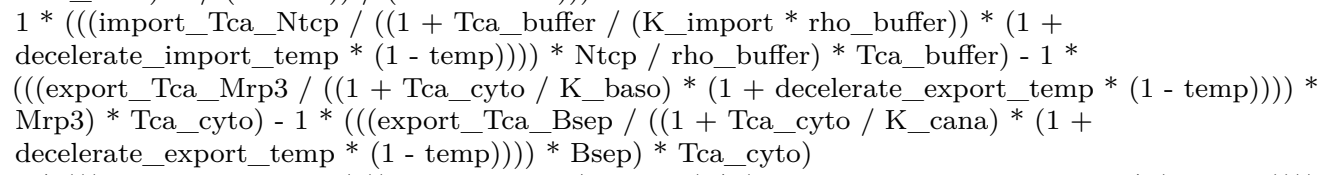 \\
\hline Tca_canalicular & $\begin{array}{l}1 *(((\text { export_Tca_Bsep } /((1+\text { Tca_cyto / K_cana }) *(1+\text { decelerate_export_temp } *(1-\text { temp })))) \\
* \text { Bsep }) * \text { Tca_cyto })-1 *(((\text { transport_Tca_cations } /(1+\text { decelerate_transport_temp } *(1-\text { temp }))) \\
/((\text { crit_cations }+ \text { cations }) * \text { rho_canalicular })) * \text { Tca_canalicular })\end{array}$ \\
\hline temp & $1 *(0)$ \\
\hline ca & $1 *(0)$ \\
\hline rho_buffer & $1 *(0)$ \\
\hline Bsep & $\begin{array}{l}1 * \text { (alpha_Bsep) }-1 *(\text { alpha_Bsep } * \text { Bsep })-1 * \text { (build_DrugNtcp } * \text { Delta_build_DrugBsep } * \text { Drug } \\
* \text { Bsep })+1 *(\text { decay_DrugNtcp } * \text { Delta_decay_DrugBsep } * \text { DrugBsep })\end{array}$ \\
\hline Ntcp & $\begin{array}{l}1 * \text { (alpha_Ntcp) }-1 *(\text { alpha_Ntcp } * \text { Ntcp })+1 *(\text { build_Ntcp } * \text { AUC_Tca_buffer })-1 * \\
\text { (build_DrugNtcp } * \text { Drug } * \text { Ntcp })+1 *(\text { decay_DrugNtcp } * \text { DrugNtcp })\end{array}$ \\
\hline Mrp3 & $\begin{array}{l}1 *(\text { alpha_Mrp3) }-1 *(\text { alpha_Mrp3 } * \text { Mrp3) }-1 *(\text { build_DrugMrp3 } * \text { Drug } * \text { Mrp3) }+1 * \\
\text { (decay_DrugMrp3 } * \text { DrugMrp3) }\end{array}$ \\
\hline AUC_Tca_buffer & $1 *($ Tca_buffer $)$ \\
\hline Drug & $\begin{array}{l}-1 * \text { (build_DrugNtcp } * \text { Delta_build_DrugBsep } * \text { Drug } * \text { Bsep })+1 *(\text { decay_DrugNtcp } * \\
\text { Delta_decay_DrugBsep } * \text { DrugBsep) }-1 *(\text { build_DrugNtcp } * \text { Drug } * \text { Ntcp })+1 *(\text { decay_DrugNtcp } \\
* \text { DrugNtcp })-1 *(\text { build_DrugMrp3 } * \text { Drug } * \text { Mrp3 })+1 *(\text { decay_DrugMrp3 } * \text { DrugMrp3 })+1 * \\
((\text { amount_Drug } / \text { scale_transp } * \exp (-(\text { time }- \text { drug_time }) \wedge /(2 * 1 \wedge 2)) /(1 * 2.506628)))\end{array}$ \\
\hline DrugBsep & $\begin{array}{l}1 * \text { (build_DrugNtcp } * \text { Delta_build_DrugBsep * Drug * Bsep) }-1 *(\text { decay_DrugNtcp } * \\
\text { Delta_decay_DrugBsep } * \text { DrugBsep) }\end{array}$ \\
\hline DrugNtcp & $1 *($ build_DrugNtcp $*$ Drug $*$ Ntcp $)-1 *($ decay_DrugNtcp $*$ DrugNtcp $)$ \\
\hline DrugMrp3 & $1 *($ build_DrugMrp3 $*$ Drug $*$ Mrp3) $-1 *($ decay_DrugMrp3 $*$ DrugMrp3) \\
\hline AUC_Drug & $1 *($ Drug $)-1 *($ deg_AUC_Drug * AUC_Drug $)$ \\
\hline rho_canalicular & $\begin{array}{l}-1 * \text { (beta_V_canalicular } * \text { rho_canalicular })+1 * \text { (beta_V_canalicular) }-1 * \text { (red_V_cana_drug } * \\
\text { rho_canalicular } * \text { AUC_Drug })+1 * \text { (build_V_cana_drug } * \text { AUC_Drug } /(\text { K_build_V_cana_drug } \\
+ \text { AUC_Drug) })\end{array}$ \\
\hline
\end{tabular}

\section{Model fitting and model reduction}

As described in the main text, the parameter space is explored by starting deterministic, derivative-based optimization runs from random points in parameter space. This way, the model has the chance to converge to different local optima. Figure S2 shows the 100 best fits out of 1000. Several local optima are found out of which the six best have been selected for further analysis (red squares).

Besides the contribution from the data points, the objective function contains a general quadratic prior on all parameters. For the analysis, the six selected fits have repeatedly been refitted while lowering the general prior. This yields six final fits, labled by 1 to 6 .

For the best fit, the profile likelihood has been computed, see Figure S3.

The profile likelihood indicates that some parameters which are open to the left, i.e., the profiles towards negative log-parameter values are flat and, consequently, parameter values are compatible with 0 . This is the case for decelerate_import_temp, decelerate_export_temp, beta_V_canalicular, s_T0_buffer_exp2, alpha_Bsep_Csa, alpha_Bsep_Cpz, alpha_Mrp3_Cpz, alpha_Ntcp_Csa, decay_DrugNtcp_Cpz, and the scal-

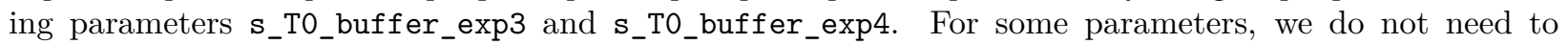




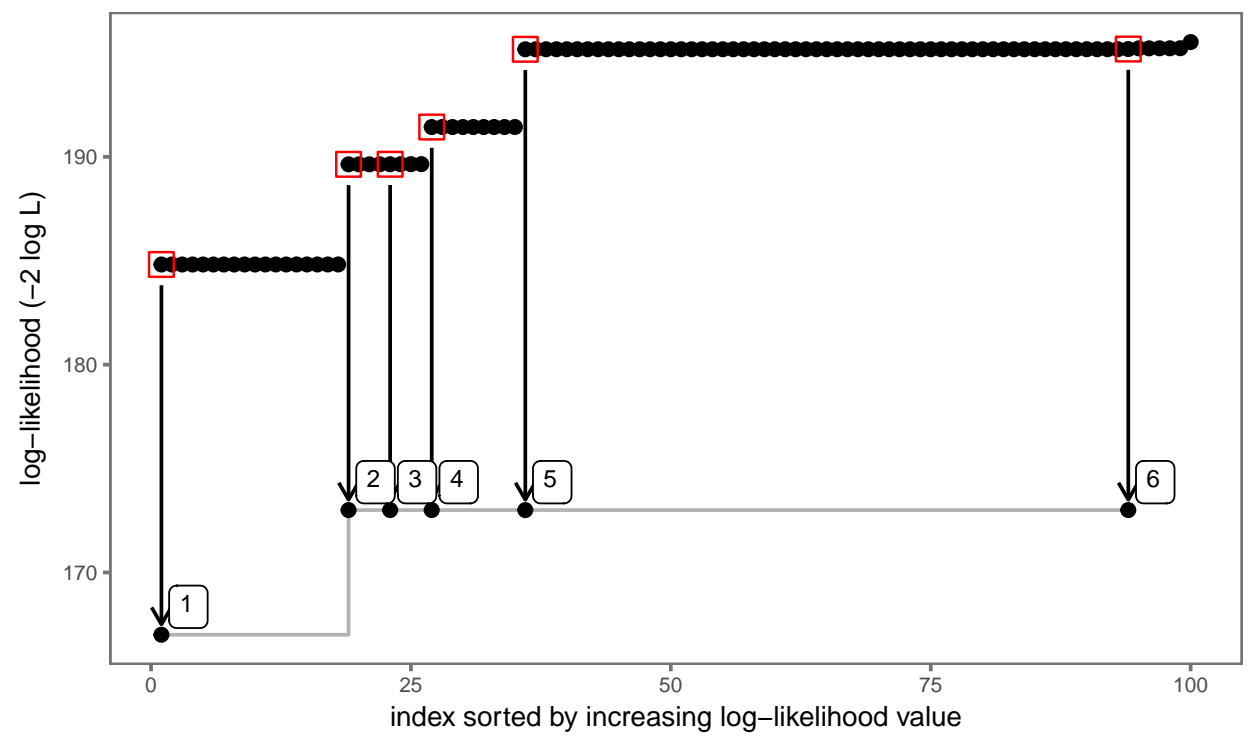

Figure S2: Fit objective values sorted by value. Each point corresponds to one fit and gives the final objective value for the corresponding optimization run. Six fits, marked by red squares, were selected for prior relaxation, resulting in fits labeled by 1 to 6 .

distinguish between the two drugs, e.g., deg_AUC_Drug_Csa = deg_AUC_Drug_Cpz. Also, some of the distinctions having made between the drug effect on Bsep compared to Ntcp turn out to be unnecessary, e.g., Delta_decay_DrugBsep_Cpz, Delta_decay_DrugBsep_Csa and Delta_build_DrugBsep_Csa which are compatible with 0 .

With these parameter reductions, the model has been fitted again 1000 times from different positions in parameter space. Again, we find local optima, however much less as being confirmed by the best 200 fit results, Figure S4.

Again, the profile likelihood has been computed, for the best optimum. See Figure S5.

\subsection{Table of parameters}

The following table shows the estimated parameter values. Since all parameters have been estimated on the log-scale, their values have been transformed back to normal scale. Confidence intervales are computed for a 95\% confidence level from the profile likelihood.

\begin{tabular}{lllll}
\hline parameter & value & lower [95\% CL] & upper [95\% CL] & unit \\
\hline alpha_Mrp3_Csa & 0.09987 & 0.02846 & 0.298 & $1 / \mathrm{min}$ \\
alpha_Ntcp_Cpz & 0.003349 & 0.001836 & 0.01188 & $1 / \mathrm{min}$ \\
alpha_Ntcp_Csa & $7.923 \mathrm{e}-05$ & 0.0002076 & 0.003253 & $1 / \mathrm{min}$ \\
build_DrugMrp3_Csa & 0.02014 & 0.01014 & 0.0431 & $1 / \mathrm{min}$ \\
build_DrugNtcp_Cpz & 0.001595 & 0.0009416 & 0.002696 & $1 / \mathrm{min}$ \\
build_DrugNtcp_Csa & 0.6275 & 0.2118 & $\infty$ & $1 / \mathrm{min}$ \\
build_Ntcp & $5.686 \mathrm{e}-06$ & $3.755 \mathrm{e}-06$ & $7.684 \mathrm{e}-06$ & $1 /\left(\mathrm{pmol} \cdot \mathrm{min}^{2}\right)$ \\
build_V_cana_drug_Csa & 0.02236 & 0.006742 & 0.09908 & $1 / \mathrm{min}$ \\
crit_cations & 0.3393 & 0.2072 & 0.5702 & 1 \\
decay_DrugMrp3_Csa & 0.0351 & 0.01297 & 0.1025 & $1 / \mathrm{min}$ \\
decay_DrugNtcp_Csa & 0.1348 & 0.06727 & $\infty$ & $1 / \mathrm{min}$ \\
decelerate_transport_temp & 237 & 79.26 & $\infty$ & 1 \\
deg_AUC_Drug & 0.03362 & 0.004143 & 0.349 & $1 / \mathrm{min}$
\end{tabular}




\begin{tabular}{lllll}
\hline parameter & value & lower [95\% CL] & upper [95\% CL] & unit \\
\hline Delta_build_DrugBsep_Cpz & 1.881 & 1.11 & 2.869 & 1 \\
export_Tca_Bsep & 0.1097 & 0.06808 & 0.2938 & $1 / \mathrm{min}$ \\
export_Tca_Mrp3 & 0.0146 & 0.01189 & 0.01851 & $1 / \mathrm{min}$ \\
import_Tca_Ntcp & 0.007098 & 0.003942 & 0.01338 & $1 / \mathrm{min}$ \\
K_baso & 1.905 & 0.2084 & $\infty$ & pmol \\
K_build_V_cana_drug_Csa & 70.74 & 5.724 & 337.6 & $\mathrm{~min}$ \\
K_cana & 0.1951 & 0.02757 & 0.5802 & $\mathrm{pmol}$ \\
K_import & 4.898 & 0.6874 & 18.17 & $\mathrm{pmol}$ \\
red_V_cana_drug_Cpz & $3.906 \mathrm{e}-05$ & $1.714 \mathrm{e}-05$ & 0.0002574 & $1 / \mathrm{min}^{2}$ \\
red_V_cana_drug_Csa & 0.0001086 & $4.858 \mathrm{e}-05$ & 0.0002448 & $1 / \mathrm{min}^{2}$ \\
s_T0_buffer_exp1 & 7.657 & 2.853 & 45.91 & $1 / \mathrm{pmol}$ \\
s_T0_cellular_exp1 & 9.042 & 3.369 & 53.65 & $1 / \mathrm{pmol}$ \\
s_T0_cellular_exp2 & 10.11 & 3.733 & 60.42 & $1 / \mathrm{pmol}$ \\
s_T0_cellular_exp3 & 9.284 & 3.648 & 52.35 & $1 / \mathrm{pmol}$ \\
s_T0_cellular_exp4 & 7.091 & 2.77 & 41.32 & $1 / \mathrm{pmol}$ \\
scale_transp & 2.299 & 1.595 & 2.862 & $\mathrm{mmol} / \mathrm{l}$ \\
Tca_buffer & 20.96 & 19.94 & 22.07 & $\mathrm{pmol}$ \\
transport_Tca_cations & 0.0839 & 0.06295 & 0.1185 & $1 / \mathrm{min}$ \\
\hline
\end{tabular}



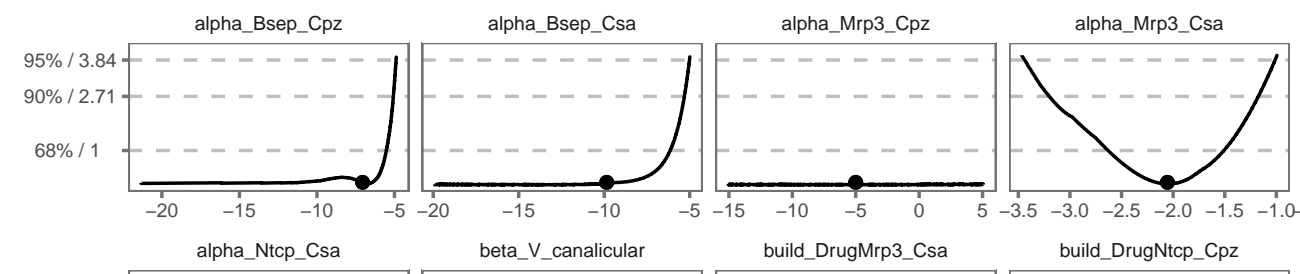

alpha_Ntcp_Cpz
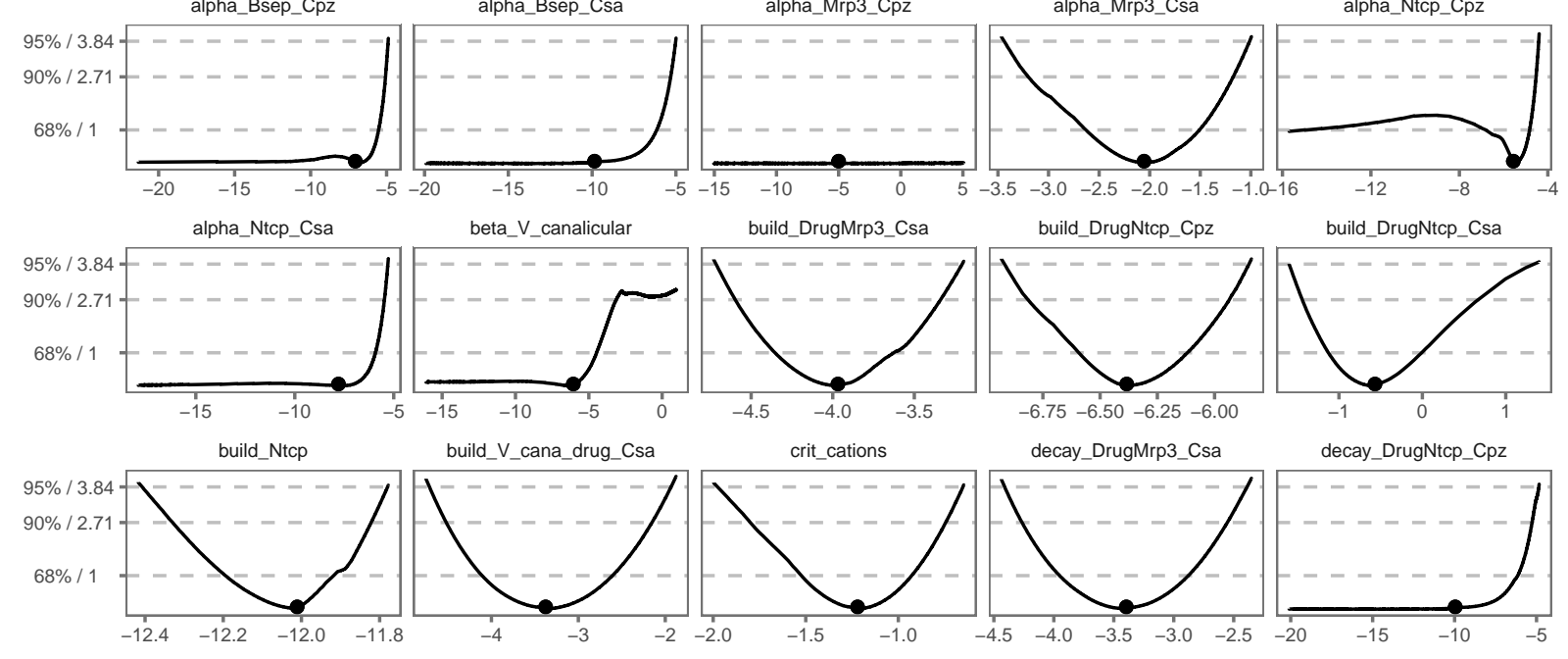

build_V_cana_drug_Csa

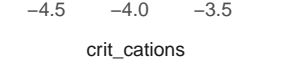

$-6.75-6.50-6.25-6.00$
decay_DrugMrp3_Csa
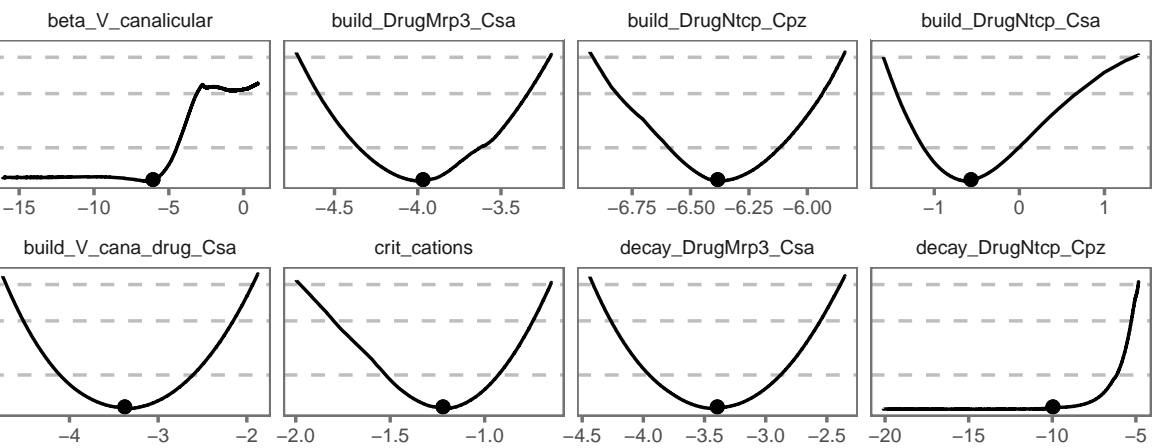

decay_DrugNtcp_Cpz
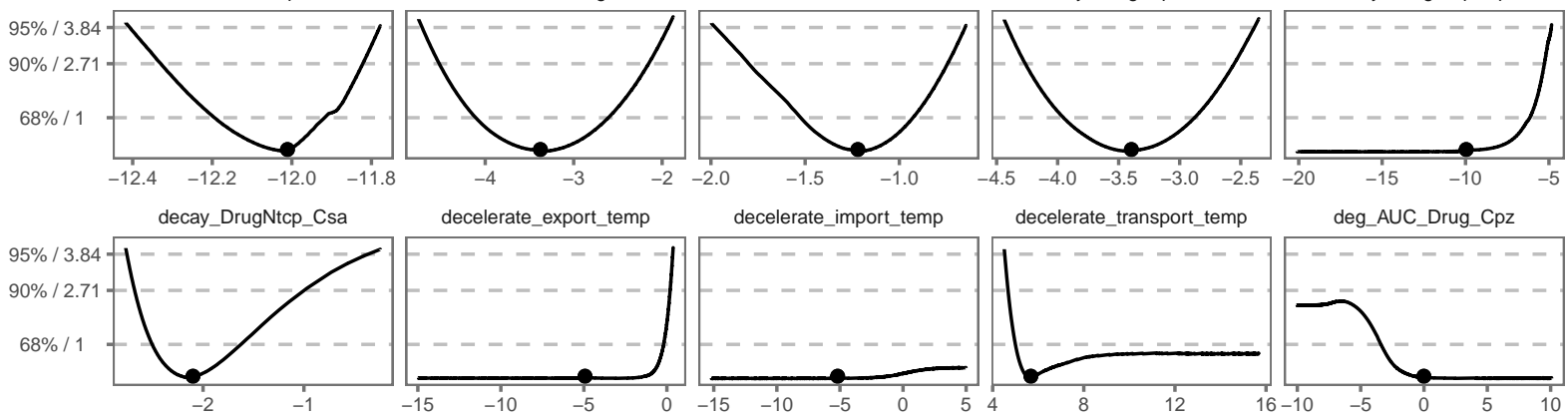

Delta_build_DrugBsep_Cpz

Delta build DrugBsep Csa
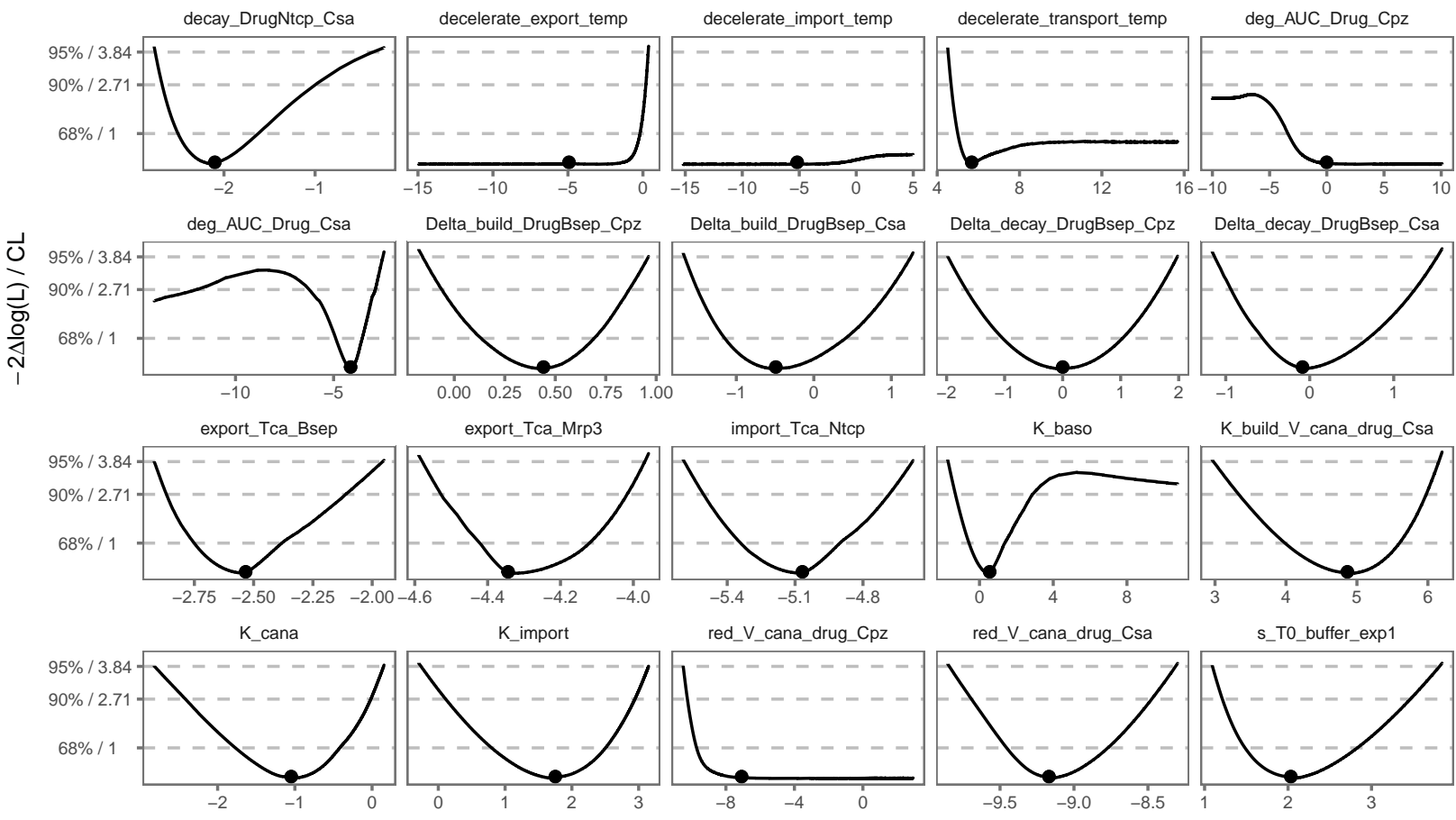

red_V_cana_drug_Cpz
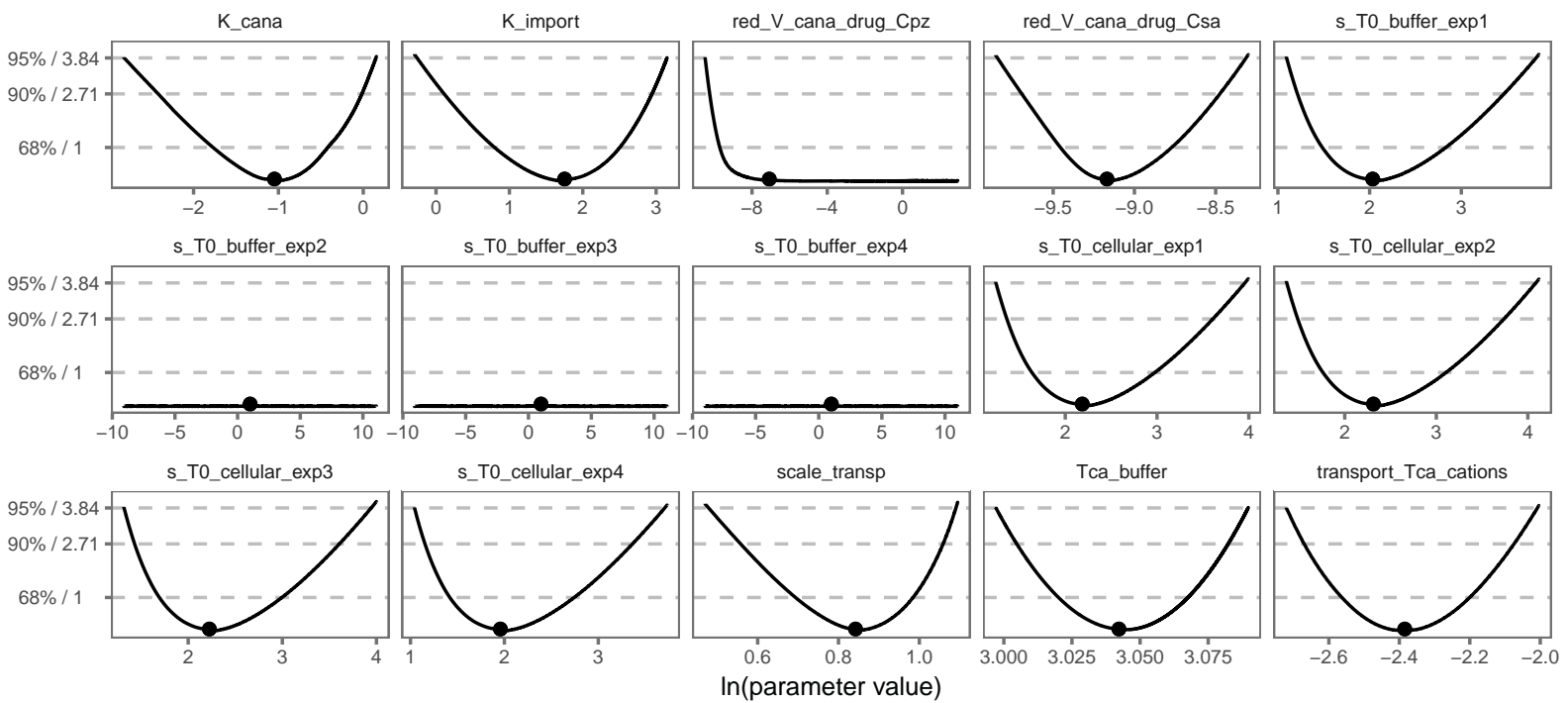

Figure S3: Profiles likelihood of the best optimum. The parameters of the best fit are indicated by dots. 


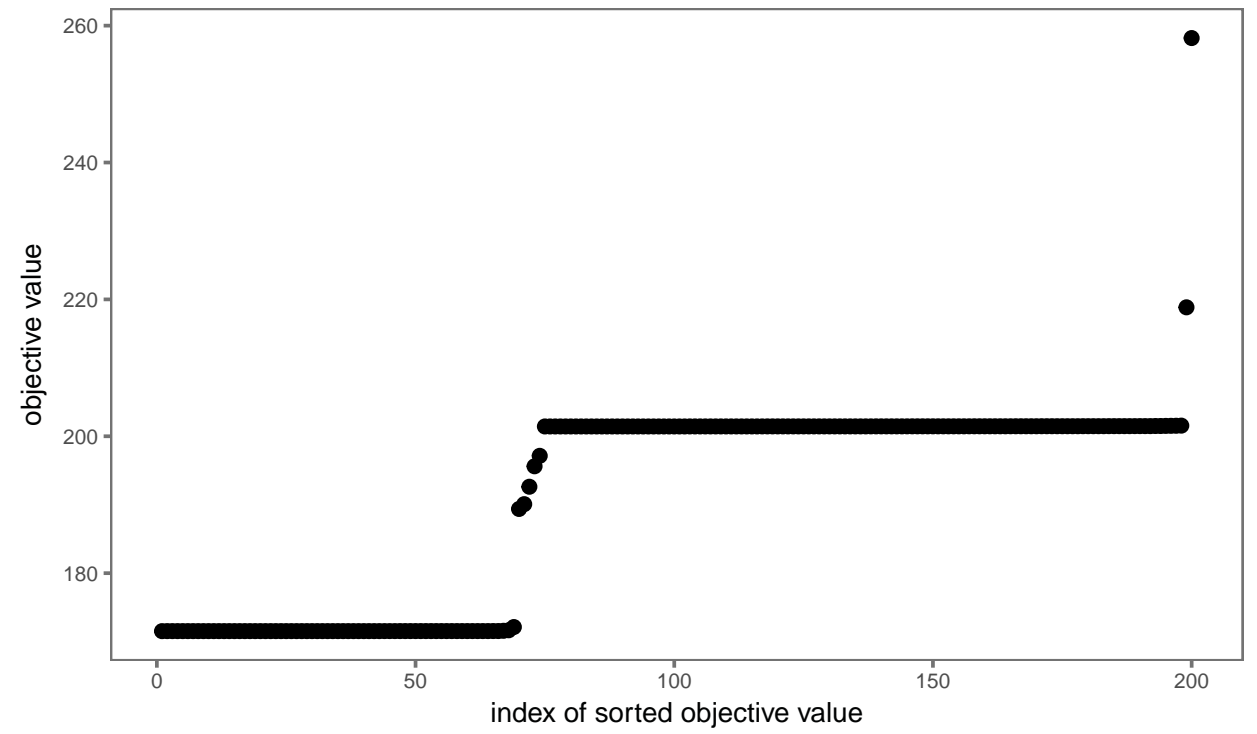

Figure S4: Fit objective values for the reduced model, sorted by value. Each point corresponds to one fit and gives the final objective value for the corresponding optimization run. 

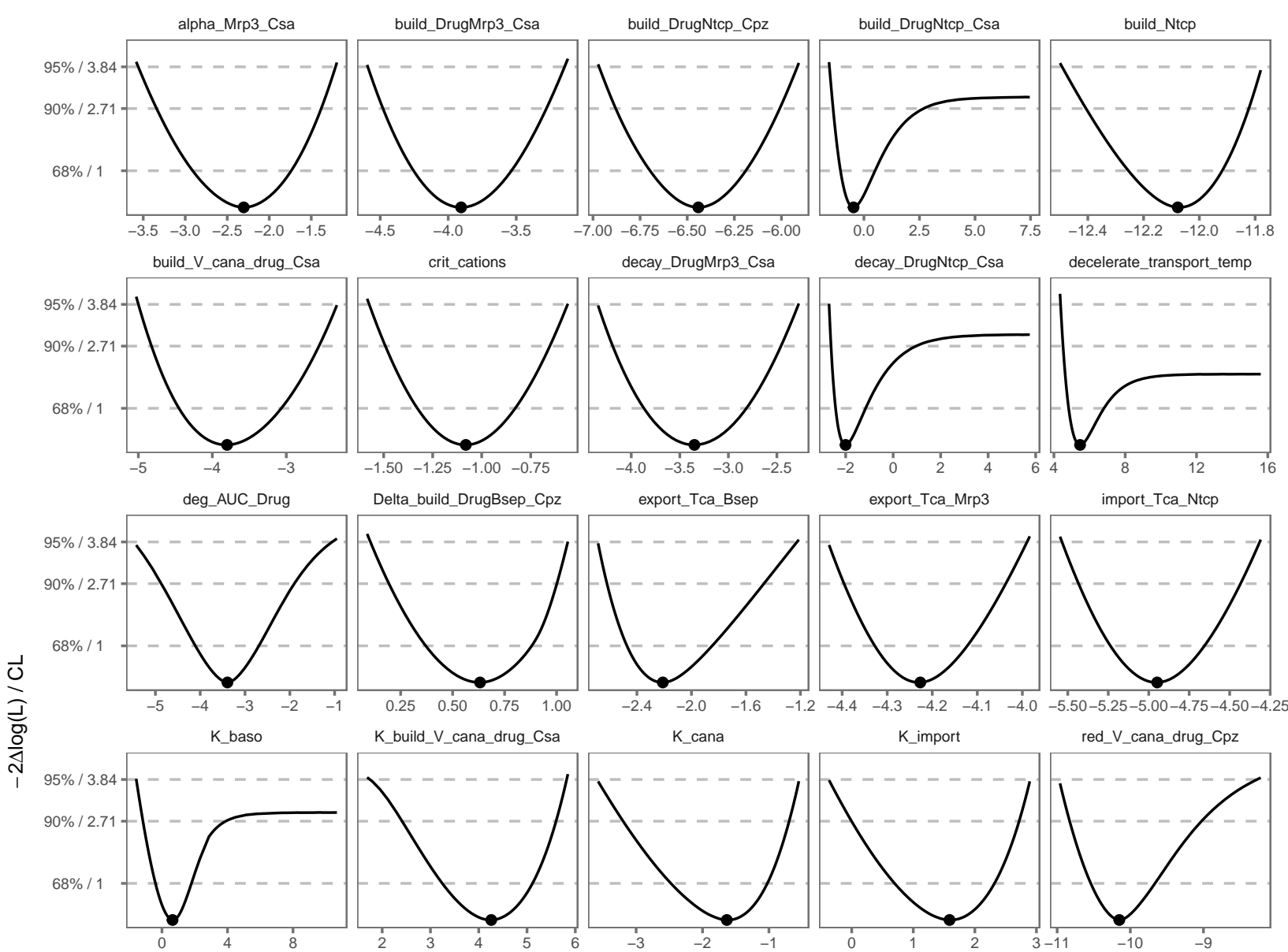

import_Tca_Ntcp
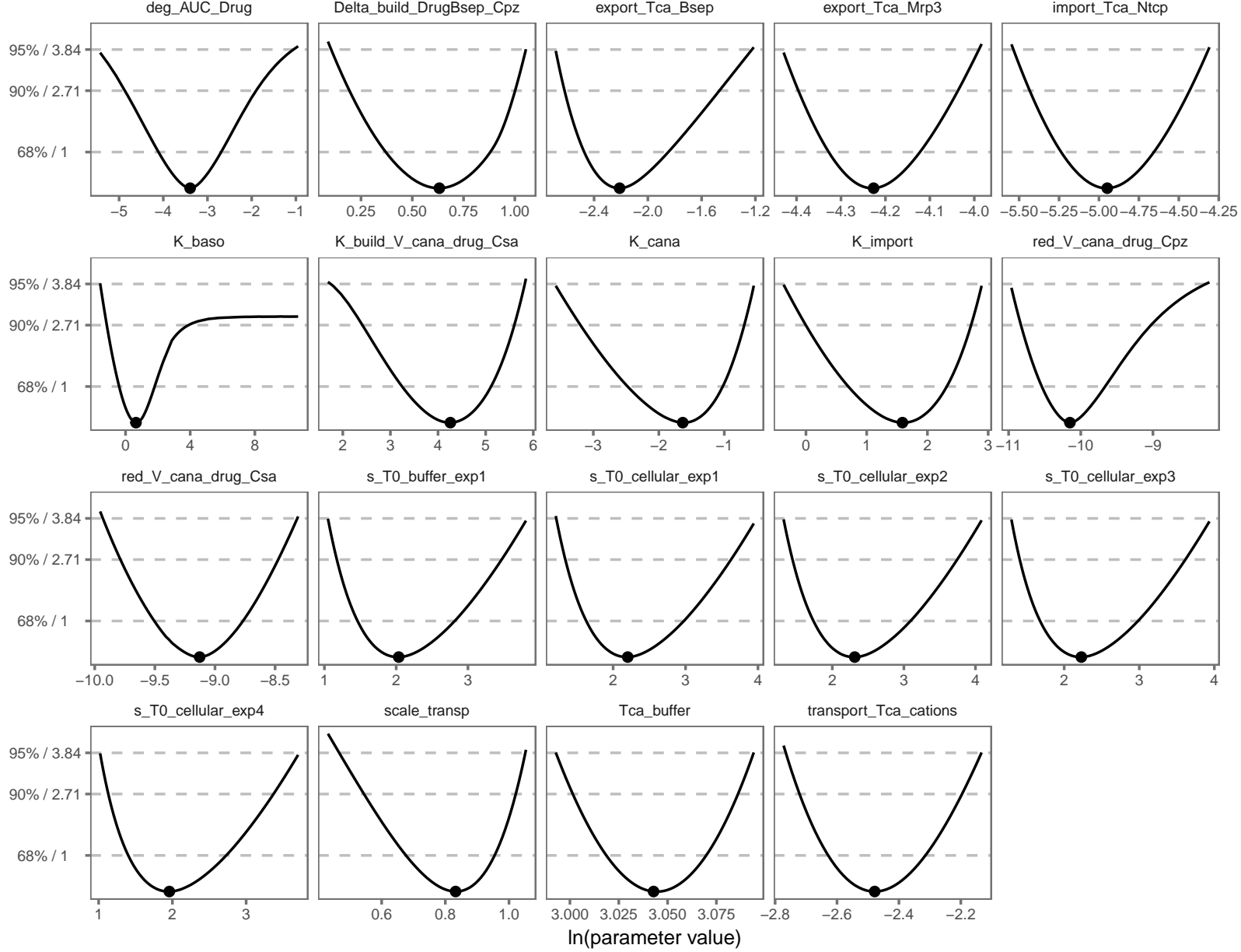

Figure S5: Profiles likelihood of the best optimum of the reduced model. The parameters of the best fit are indicated by dots. 


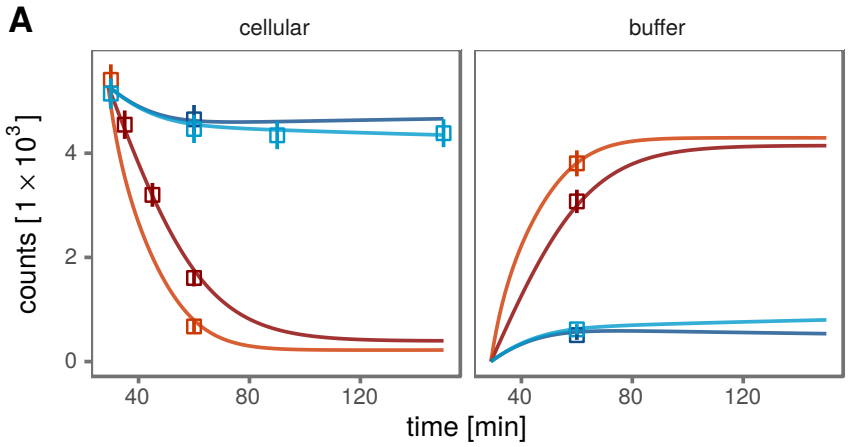

B

TCA buffer
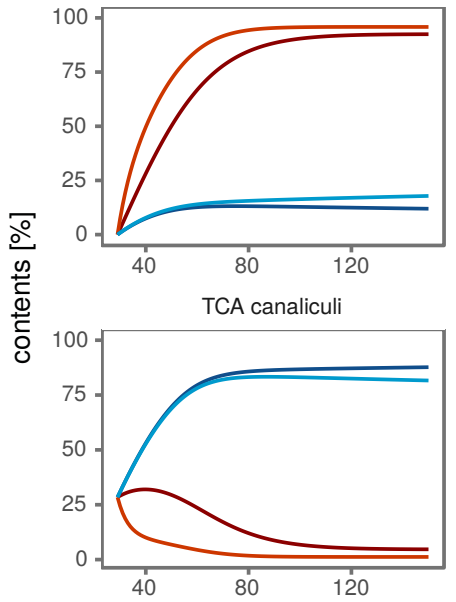

TCA cytoplasm

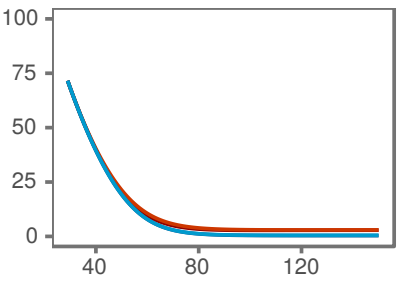

time [min]

$-37^{\circ} \mathrm{C}, \mathrm{Ca}^{2+}$

$-37^{\circ} \mathrm{C}$, no $\mathrm{Ca}^{2+}$

$-4^{\circ} \mathrm{C}, \mathrm{Ca}^{2+}$

$4^{\circ} \mathrm{C}$, no $\mathrm{Ca}^{2+}$ 
A cellular
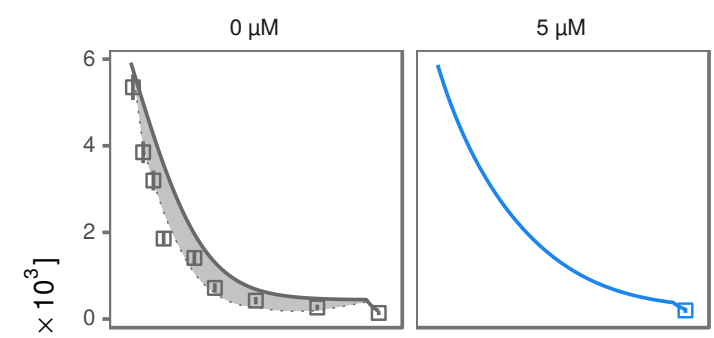

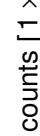

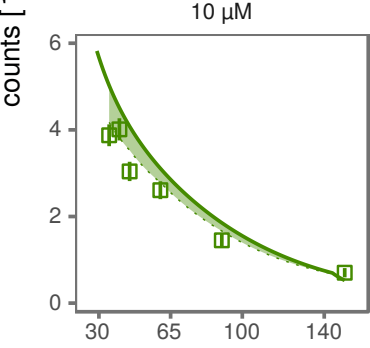

time [min]

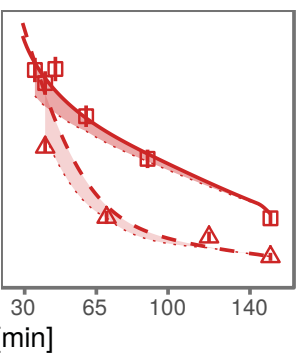

B

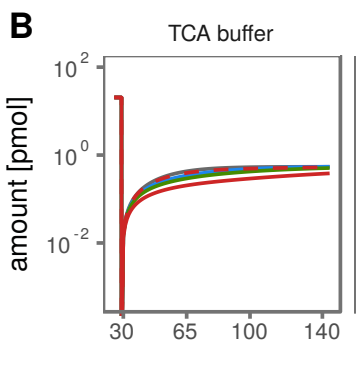

TCA cytoplasm
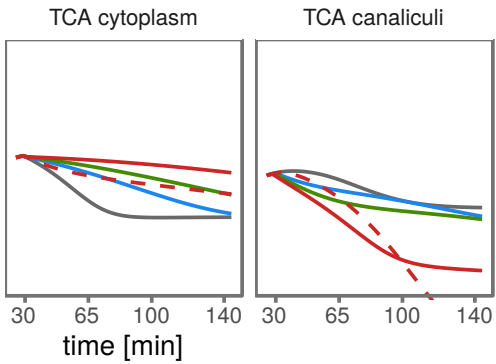

dose

$\rightarrow 0 \mu \mathrm{M}$

$-5 \mu \mathrm{M}$

- $10 \mu \mathrm{M}$

- $50 \mu \mathrm{M}$

compound

$\frac{\square}{-\triangle}$ CsA

C efflux (sinusoidal)

efflux (canalicular)

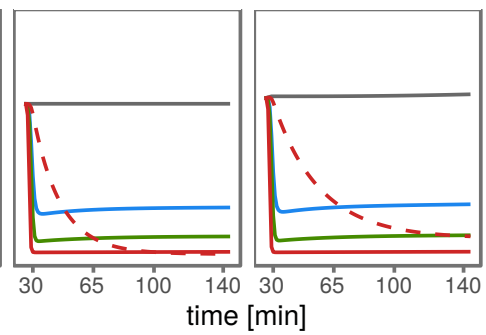

volume (canalicular)
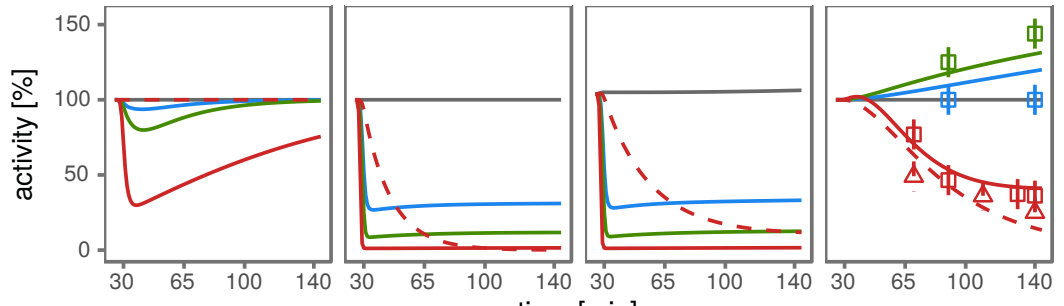
Figure 4

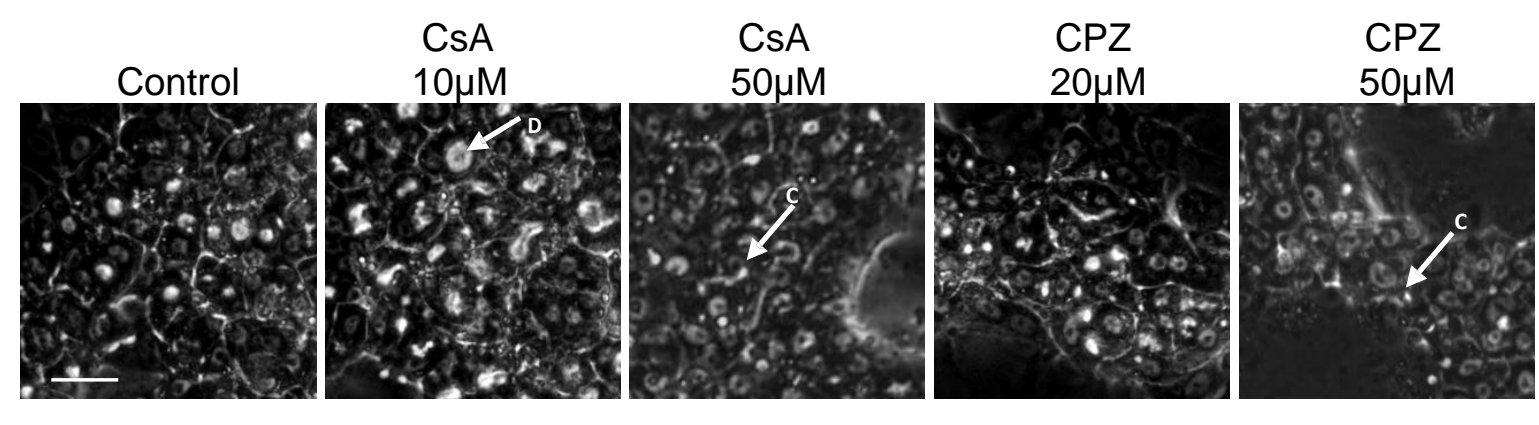


A cellular $\quad$ B $\quad$ CsA dose $-0 \mu \mathrm{M}-1 \mu \mathrm{M}-5 \mu \mathrm{M}-10 \mu \mathrm{M}-25 \mu \mathrm{M}-50 \mu \mathrm{M}$
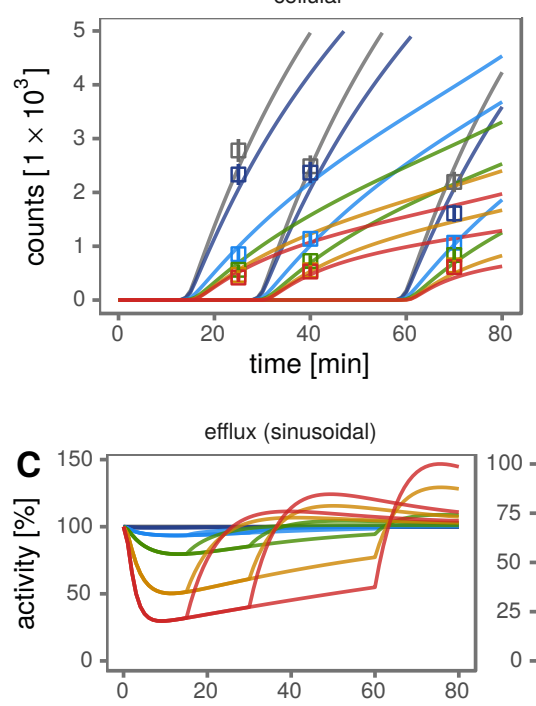

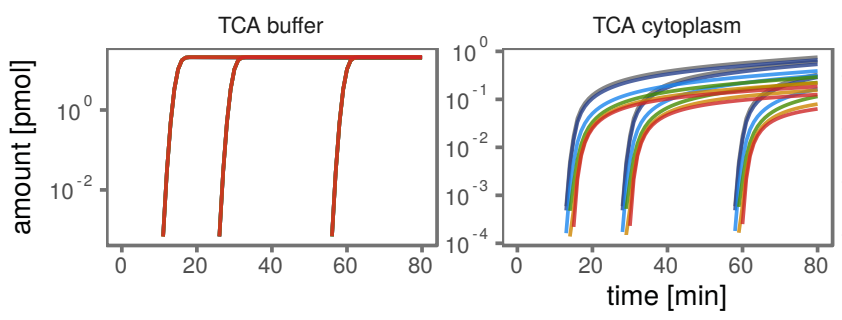

TCA canaliculi

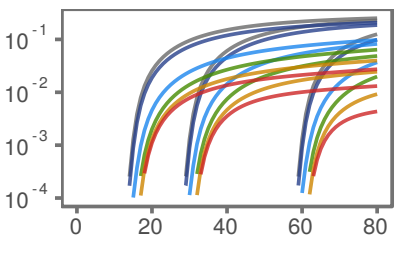

efflux (canalicular)

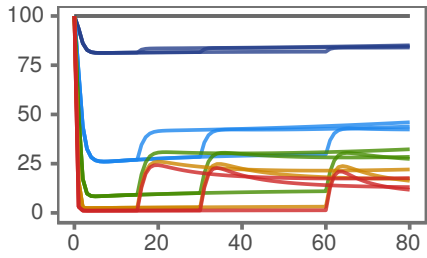

uptake

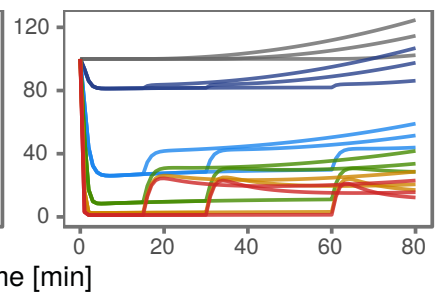

volume (canalicular)

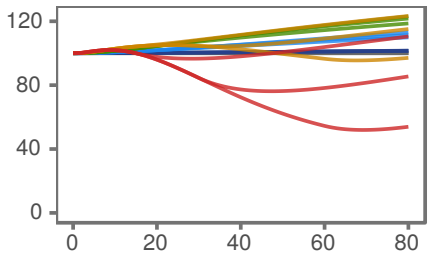




\section{$\begin{array}{lll}\text { A } & \text { cellular } & \text { B }\end{array}$}

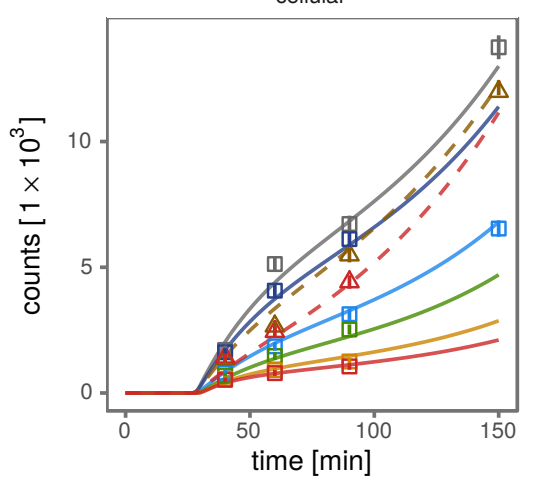

dose

$0 \mu \mathrm{M}$

$1 \mu \mathrm{M} \multimap 5 \mu \mathrm{M} \multimap-10 \mu \mathrm{M}$

$20 \mu \mathrm{M}-25 \mu \mathrm{M}$

compound $\square \mathrm{CsA} / \mathrm{no}-\triangleq{ }_{-} \mathrm{CPZ}$
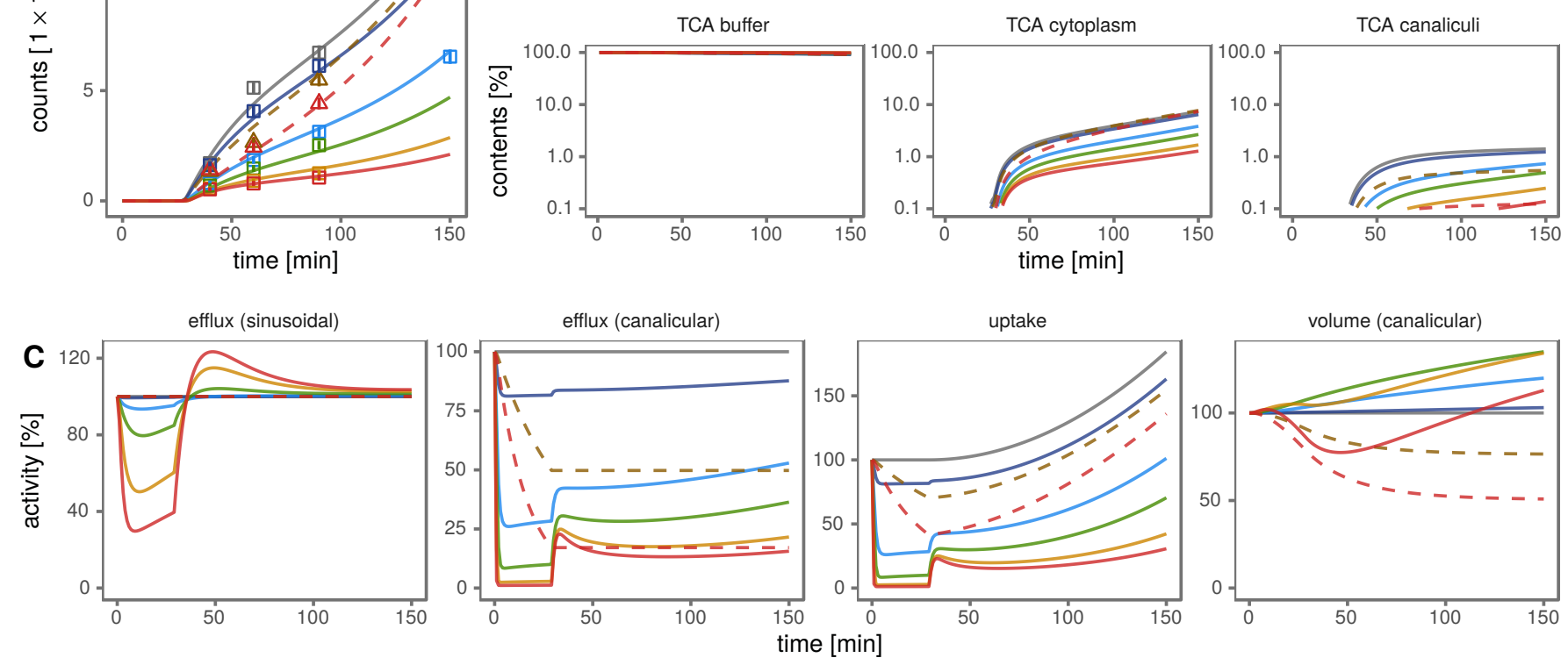

time [min] 


\section{Supplement: A dynamic mathematical model of bile acid clearance in HepaRG cells}

Daniel Kaschek, Ahmad Sharanek, André Guillouzo, Jens Timmer and Richard J. Weaver

\section{Contents}

1 Materials and Methods $\quad 1$

1.1 Reagents . . . . . . . . . . . . . . . . . . . . . . . . . . . . . 1

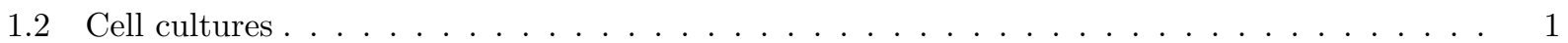

$1.3\left[{ }^{3} \mathrm{H}\right]$-TCA efflux in control (untreated) HepaRG cells and primary human hepatocytes $\ldots . .2$

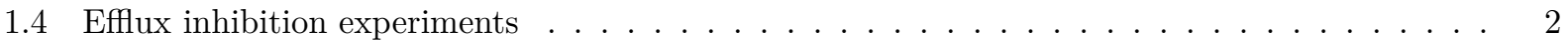

1.5 Uptake inhibition experiments . . . . . . . . . . . . . . . . . . . . 2

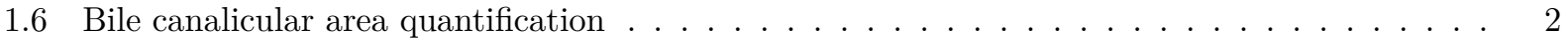

2 Data pre-processing $\quad 3$

3 Model specification $\quad 4$

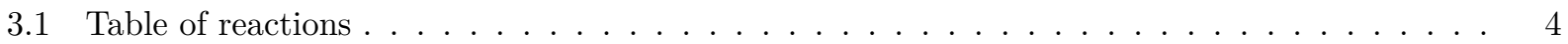

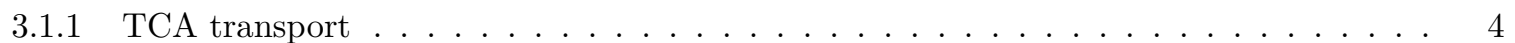

3.2 Specification of reaction rates $\ldots \ldots \ldots \ldots \ldots \ldots \ldots$

3.3 List of differential equations $\ldots \ldots \ldots \ldots \ldots \ldots \ldots \ldots \ldots$

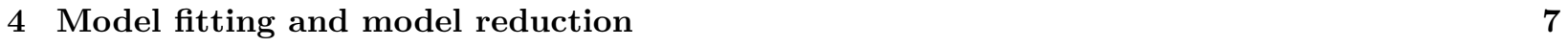

4.1 Table of parameters $\ldots \ldots \ldots \ldots \ldots \ldots \ldots$

\section{Materials and Methods}

\section{$1.1 \quad$ Reagents}

Cyclosporine A (CsA) and chlorpromazine (CPZ) were purchased from Sigma (St. Quentin Fallavier, France). $\left[{ }^{3} \mathrm{H}\right]$-Taurocholic acid $\left(\left[{ }^{3} \mathrm{H}\right]-\mathrm{TA}\right)$ was from Perkin Elmer (Boston, MA).

\section{$1.2 \quad$ Cell cultures}

HepaRG cells were seeded at a density of $2.6 \times 10^{4}$ cells $/ \mathrm{cm}^{2}$ in Williams' E medium supplemented with $2 \mathrm{mM}$ glutaMAX, $100 \mathrm{U} / \mathrm{mL}$ penicillin, $100 \mu \mathrm{g} / \mathrm{mL}$ streptomycin, $10 \%$ HyClone fetal calf serum, $5 \mu \mathrm{g} / \mathrm{mL}$ insulin, and $50 \mu \mathrm{M}$ hydrocortisone hemisuccinate. At confluence (after 2 weeks), HepaRG cells were further incubated in the same medium, but supplemented with $1.7 \%$ dimethyl sulfoxide for 2 additional weeks to obtain confluent 
differentiated cultures containing equal proportions of hepatocyte-like and progenitor/primitive biliary-like cells (16).

The differentiated hepatic cell cultures were used for the analytical assays. Human hepatocytes were obtained from Biopredic International (St Gregoire, France) in compliance with French bioethics legislation. Hepatocytes were isolated by collagenase perfusion of histologically normal liver fragments from 4 adult donors undergoing resection for primary and secondary tumors. Primary cultures were obtained by hepatocyte seeding at a density of $1.5 \times 10^{5}$ cells $/ \mathrm{cm}^{2}$ onto collagen-pre-coated plates in Williams' E medium supplemented as detailed above except for the addition of $10 \%$ fetal calf serum and $1 \mu \mathrm{g} / \mathrm{ml}$ bovine serum albumin. The medium was discarded $12 \mathrm{~h}$ after cell seeding, and the cultures were then maintained in the same medium as for the HepaRG cells and designated as conventional collagen cultured $\mathrm{HH}(\mathrm{CCHH})$, or maintained for 24 to $48 \mathrm{~h}$ and then washed with cold medium and overlaid with matrigel at a concentration of $0.25 \mathrm{mg} / \mathrm{mL}$ in ice-cold Williams' E medium for the preparation of sandwich cultured $\mathrm{HH}$ (SCHH). The medium of both the $\mathrm{CCHH}$ and $\mathrm{SCHH}$ preparations was renewed daily. $\mathrm{CCHH}$ and $\mathrm{SCHH}$ were prepared from the same donors and analyzed in parallel. SCHH cultures were used after at least a 3 day-matrigel overlay.

\section{$1.3\left[{ }^{3} \mathrm{H}\right]$-TCA efflux in control (untreated) HepaRG cells and primary human hepatocytes}

HepaRG cells and 4-5 days CCHHs and SCHHs were exposed to $\left[{ }^{3} \mathrm{H}\right]$-TCA for $30 \mathrm{~min}$. After washing, efflux of radiolabeled TCA was assessed for different time points $(0,5,15$ and $30 \mathrm{~min})$ in either standard with $\mathrm{Ca}^{2+}$ and $\mathrm{Mg}^{2+}$ or $\mathrm{Ca}^{2+}$ - and $\mathrm{Mg}^{2+}$-free buffer. Cells were then scraped in $0.1 \mathrm{~N} \mathrm{NaOH}$ and accumulation of radiolabeled substrate into cells + bile canaliculi (in the presence of $\mathrm{Ca}^{2+}$ - and $\mathrm{Mg}^{2+}{ }_{\text {-ions }}$ ) and into cells only (in the absence of $\mathrm{Ca}^{2+}$ - and $\mathrm{Mg}^{2+}$-ions) was measured through scintillation counting to evaluate TCA efflux. Absence of divalent cations promotes disruption of tight junctions and induces bile canaliculi opening (Swift, 2010).

\subsection{Efflux inhibition experiments}

HepaRG cells were first exposed to $43.3 \mathrm{nM}\left[{ }^{3} \mathrm{H}\right]$-TCA for $30 \mathrm{~min}$ to induce intracellular accumulation of $\left[{ }^{3} \mathrm{H}\right]$-TCA, then washed with standard buffer and incubated with CsA $(0,1,5,10,25$ and $50 \mu \mathrm{M})$ or CPZ $(0$, 20 and $50 \mu \mathrm{M})$ for different time points in a standard buffer with $\mathrm{Ca}^{2+}$ and $\mathrm{Mg}^{2+}$. After incubation, cells were washed and incubated for 5 min with $\mathrm{Ca}^{2+}$ - and $\mathrm{Mg}^{2+}$-free buffer in order to disrupt canalicular tight junctions. Cells were then scraped in $0.1 \mathrm{~N} \mathrm{NaOH}$ and the remaining radiolabeled substrate were measured through scintillation counting to determinate TCA efflux (Sharanek, 2014).

\subsection{Uptake inhibition experiments}

HepaRG cells were treated with different concentrations of CsA $(0,1,5,10,25$ and $50 \mu \mathrm{M})$ or CPZ $(0,20$ and $50 \mu \mathrm{M})$ for $30 \mathrm{~min}$. After washing, cells were loaded with $\left[{ }^{3} \mathrm{H}\right]$-TCA-containing buffer at different time points $(10,30,60$ and $150 \mathrm{~min})$. After the incubation period, $\left[{ }^{3} \mathrm{H}\right]-\mathrm{TCA}$-containing buffer was removed and cells were scraped in $0.1 \mathrm{~N} \mathrm{NaOH}$. The radiolabeled substrate was measured by scintillation counting to determinate TCA uptake. At the time they were used, HepaRG hepatocytes exhibited typical BC structures. As previously reported, HepaRG cells form bile acids (BA) and express BA metabolizing enzymes and BA transport activities and can be used to study drug-induced cholestatic effects. Primitive biliary cells do not express BA metabolizing enzymes or BA transporters (Sharanek, 2014).

\subsection{Bile canalicular area quantification}

Effects of CsA and CPZ on BC area were evaluated by time-lapse cell imaging and quantified by a software video analysis and a modelling tool (Tracker 4.87). Briefly, circular frames delimiting BC were manually 
identified using the free hand selection tool of Tracker 4.87 to track and record brightness variations. These records reflected the area of $\mathrm{BC}$.

\section{Data pre-processing}

All radioactive count data has been transformed by the transformation $n=2 \sqrt{N}$, where $N$ denotes the number of counts. Due to the Poissonian nature of count experiments, repeated measurements of the same sample would yield values for $n$ with unit variance. Repeated measurements for different samples, i.e. biological replicates, yield values for $n$ that necessarily have a higher variance. Therefore, the variance of $2 \sqrt{N}$ for these samples is a measure for the heterogeneity between biological replicates.

TCA has been measured in buffer or in cells for four experimental protocols, exp1, ., exp4. Data for each of these combinations have been pooled on a common scale and the variance has been estimated per celltype, i.e. HepaRG, HHclassic (human hepatocytes, classic culture) and HHsandwich (human hepatocytes, sandwich culture). The results are shown in Figure S1.

For the buffer measurements, human hepatocytes in sandwich culture (blue) show the highest variance, followed by the human hepatocytes in classic culture (red) and HepaRG cells (black). The shaded areas denote \pm 1 standard deviation and \pm 3 standard deviations of the pooled observations. The result is similar for cellular measurements where again human hepatocytes show a larger variance than HepaRG. Notably, the standard deviation of HepaRG does not exceed the value of 5.8 (cellular, exp1), for most experimental protocols it is even lower. 


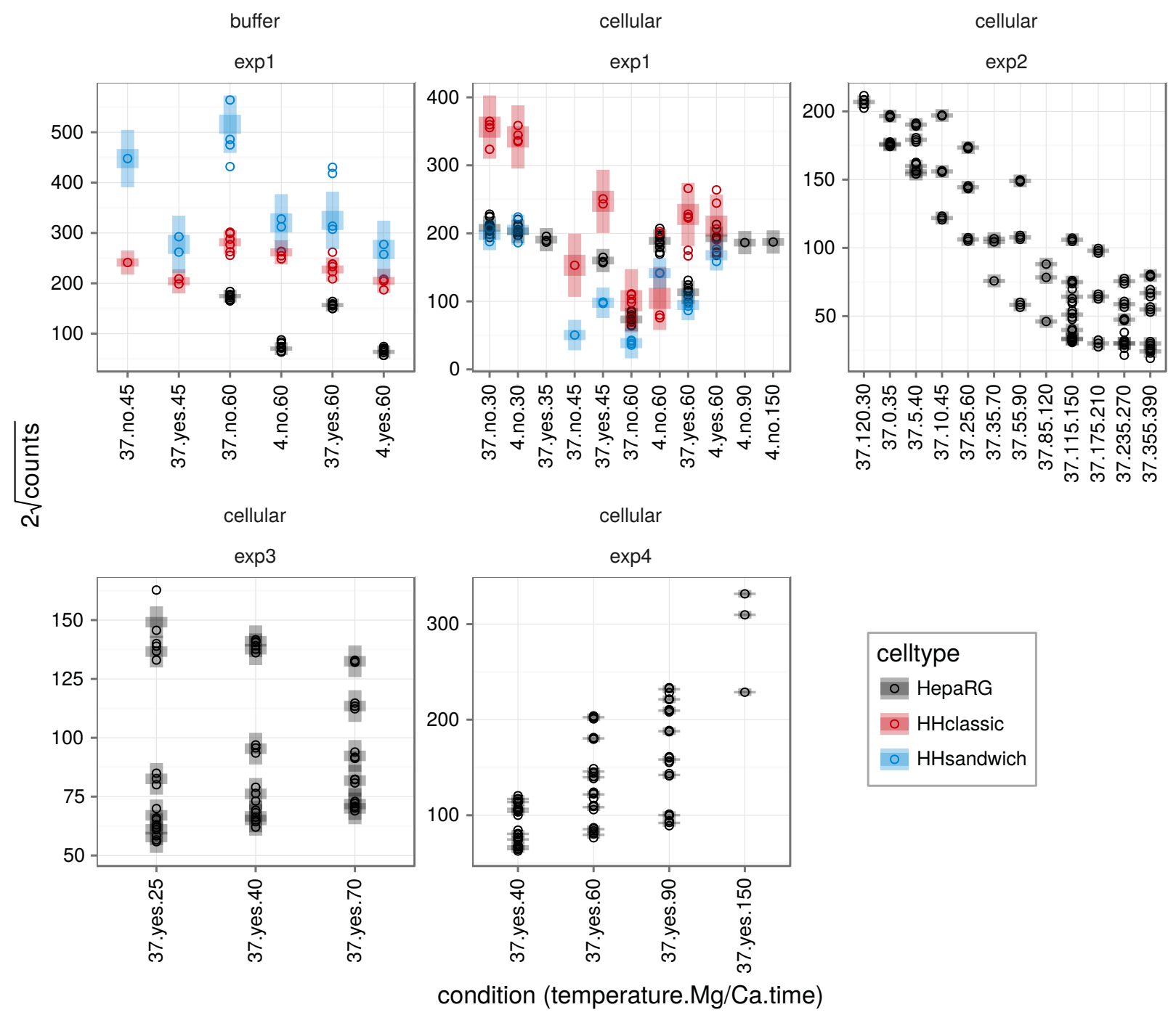

Figure S1: Data pre-processing. Twice the square root of the number of counts are plotted versus the different conditions. The data has been divided into buffer/cellular measurements and experimental protocols exp1, exp2, exp3 and exp4. Data from different celltypes are distinguished by color. Each dot represents one measurement. Confidence intervals with a $1 \sigma$ and $3 \sigma$ confidence level are visualized as shaded areas.

\section{Model specification}

The dynamic model of TCA transport in HepaRG cells is specified by a table of reactions and a list of expressions, specifying the rate constants and compartment volumes.

\subsection{Table of reactions}

The following table lists the elementary processes in the language of chemical reactions.

\subsubsection{TCA transport}




\begin{tabular}{lllll}
\hline Educt & $->$ & Product & Rate & Description \\
\hline Tca_buffer & $->$ & Tca_cyto & import_Tca * Tca_buffer & Basolateral uptake \\
Tca_cyto & $->$ & Tca_buffer & export_Tca_baso * Tca_cyto & Basolateral efflux \\
Tca_cyto & $->$ & Tca_canalicular & export_Tca_cana * Tca_cyto & Canalicular efflux \\
Tca_canalicular & $->$ & Tca_buffer & transport_Tca * Tca_canalicular & Transport bile \\
\hline
\end{tabular}

The table lists the four transport processes. The rates and how they are affected by temperature and calcium levels are listed below.

\begin{tabular}{|c|c|c|c|c|}
\hline Educt & $->$ & Product & Rate & Description \\
\hline & $->$ & Bsep & alpha_Bsep & Transporter levels \\
\hline \multirow[t]{2}{*}{ Bsep } & $->$ & & alpha_Bsep * Bsep & Transporter levels \\
\hline & $->$ & Ntcp & alpha_Ntcp & Transporter levels \\
\hline \multirow[t]{2}{*}{ Ntcp } & $->$ & & alpha_Ntcp $*$ Ntcp & Transporter levels \\
\hline & $->$ & Mrp3 & alpha_Mrp3 & Transporter levels \\
\hline \multirow[t]{3}{*}{ Mrp3 } & $->$ & & alpha_Mrp3 $*$ Mrp3 & Transporter levels \\
\hline & $->$ & AUC_Tca_buffer & Tca_buffer & Transporter levels \\
\hline & $->$ & Ntcp & build_Ntcp $*$ AUC_Tca_buffer & Transporter levels \\
\hline \multirow[t]{2}{*}{ rho_canalicular } & $->$ & & $\begin{array}{l}\text { beta_V_canalicular * } \\
\text { rho_canalicular }\end{array}$ & Volume level \\
\hline & $->$ & rho_canalicular & beta_V_canalicular & Volume level \\
\hline
\end{tabular}

The table shows the build-up and reduction of transporter levels. Both processes have equal rates to constrain the equilibrium to be 1. Large values for alpha parameters force the system to quickly go back into the equilibrium. To incorporate into the model that long exposure to TCA leads to increased uptake, the Tca_buffer concentrations are integrated over time, yielding AUC_Tca_buffer. Larger values of AUC_Tca_buffer cause higher import, attributed to the Ntca model state. Canalicular volumes are kept in an equilibrium, too. In analogy to transporter build-up and redution, the volume fraction $\rho_{\text {canalicular }}(t)=$ $\frac{V_{\text {canalicular }}(t)}{V_{\text {canalicular, equilibrium }}}$ is controlled by a rate beta_V_canalicular.

\begin{tabular}{|c|c|c|c|c|}
\hline Educt & $->$ & Product & Rate & Description \\
\hline Bsep + Drug & $->$ & DrugBsep & build_DrugBsep * Drug * Bsep & $\begin{array}{l}\text { DRUG } \\
\text { effect }\end{array}$ \\
\hline DrugBsep & $->$ & Bsep + Drug & decay_DrugBsep * DrugBsep & $\begin{array}{l}\text { DRUG } \\
\text { effect }\end{array}$ \\
\hline Ntcp + Drug & $->$ & DrugNtcp & build_DrugNtcp $*$ Drug $*$ Ntcp & $\begin{array}{l}\text { DRUG } \\
\text { effect }\end{array}$ \\
\hline DrugNtcp & $->$ & Ntcp + Drug & decay_DrugNtcp * DrugNtcp & $\begin{array}{l}\text { DRUG } \\
\text { effect }\end{array}$ \\
\hline $\begin{array}{l}\text { Mrp3 }+ \\
\text { Drug }\end{array}$ & $->$ & DrugMrp3 & build_DrugMrp3 ${ }^{*}$ Drug $*$ Mrp3 & $\begin{array}{l}\text { DRUG } \\
\text { effect }\end{array}$ \\
\hline \multirow[t]{2}{*}{ DrugMrp3 } & $->$ & $\begin{array}{l}\text { Mrp3 }+ \\
\text { Drug }\end{array}$ & decay_DrugMrp3 $*$ DrugMrp3 & $\begin{array}{l}\text { DRUG } \\
\text { effect }\end{array}$ \\
\hline & $->$ & AUC_Drug & Drug & $\begin{array}{l}\text { DRUG } \\
\text { effect }\end{array}$ \\
\hline AUC_Drug & $->$ & & deg_AUC_Drug $*$ AUC_Drug & $\begin{array}{l}\text { DRUG } \\
\text { effect }\end{array}$ \\
\hline rho_canalicula & & & red_V_cana_drug * rho_canalicular * AUC_Drug & $\begin{array}{l}\text { DRUG } \\
\text { effect }\end{array}$ \\
\hline
\end{tabular}




\begin{tabular}{lllll}
\hline Educt & $->$ & Product & Rate & Description \\
\hline & $->$ & rho_canalicularbuild_V_cana_drug * AUC_Drug / & DRUG \\
& & (K_build_V_cana_drug + AUC_Drug) & effect \\
\hline
\end{tabular}

Inhibition of transporters by the drug are modeled by drug binding and drug release. Only the "free" transporter is active. The different build and decay parameters determine equilibrium levels and time scales. The canalicular volume factor rho_canalicular is controlled by the integrated drug presence, AUC_Drug. Regeneration from the drug insult is captured in the rate deg_AUC_Drug. The integrated drug presence has both, stimulating and attenuating effects on the volume factor. The different functional dependency of the build and reduction rates on AUC_Drug leads to a separation of regimes where either of the processes dominates.

\begin{tabular}{lllll}
\hline Educt & $->$ & Product & Rate & Description \\
\hline & $->$ & Tca_buffer & injection_Tca & TCA input \\
& $->$ & Drug & injection_Drug & DRUG input \\
\hline
\end{tabular}

TCA injection and drug injection are modeled by bolus functions, see the rate specification below.

\subsection{Specification of reaction rates}

Some of the rates as well as the buffer volume are further specified by the following expressions:

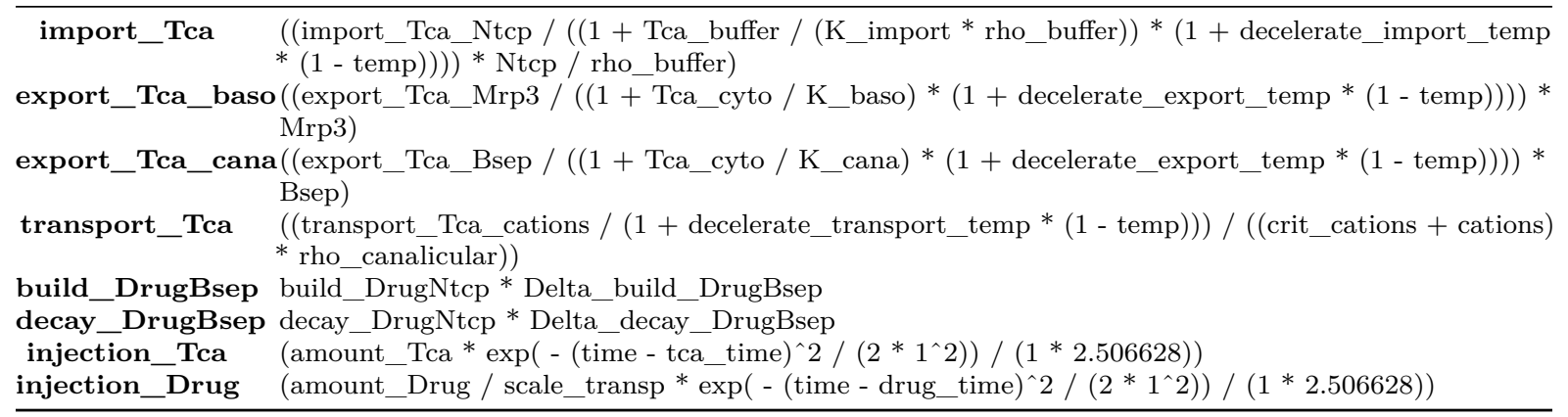

The rates import_TCA, export_Tca_baso, and export_Tca_cana associated to transporter activity are modeled by Michaelis-Menten kinetics. All transport processes, including the export from the canaliculi, are decelerated for the low-temperature measurement $\left(4{ }^{\circ} \mathrm{C}\right)$, i.e., temp $=0$. When temp $=1\left(37{ }^{\circ} \mathrm{C}\right)$, the deceleration parameter is switched off by the factor (1 - temp). Additionally, the transport rate is lowered by the presence of $\mathrm{Ca}^{2+}$ in the buffer, i.e., cations $=1$. Hence, the transport rate switches between transport_Tca_cations/crit_cations and transport_Tca_cations/(crit_cations +1 ) without and with calcium. Both, the compound and TCA get into the system by a bolus input function. The bolus function is the normalized Gauß peak

$$
G(t)=\frac{1}{\sqrt{2 \pi \Delta t^{2}}} \mathrm{e}^{-\frac{\left(t-t_{0}\right)^{2}}{2 \Delta t^{2}}},
$$

symmetric around $t_{0}$ with width $\Delta t$. In our case $\Delta t=1$ is fixed, hence, the factor $\sqrt{2 \pi \Delta t^{2}}$ becomes 2.506628 . 


\subsection{List of differential equations}

The reactions together with the rate specifications are translated in ordinary differential equations for each of the dynamic states. They read as follows:

\begin{tabular}{|c|c|}
\hline Tca_buffer & $\begin{array}{l}-1 *(((\text { import_Tca_Ntcp } /((1+\text { Tca_buffer } /(\mathrm{K} \text { _import } * \text { rho_buffer })) *(1+ \\
\left.\left.\text { decelerate_import_temp } *(1-\text { temp }))))^{*} \text { Ntcp } / \text { rho_buffer }\right) * \text { Tca_buffer }\right)+1 * \\
(((\text { export_Tca_Mrp3 / }((1+\text { Tca_cyto / K_baso }) *(1+\text { decelerate_export_temp } *(1-\text { temp })))) * \\
\text { Mrp3)* Tca_cyto })+1 *(((\text { transport_Tca_cations } /(1+\text { decelerate_transport_temp } *(1-\text { temp }))) \\
/((\text { crit_cations }+ \text { cations }) * \text { rho_canalicular })) * \text { Tca_canalicular })+1 *((\text { amount_Tca } * \text { exp }(-(\text { time } \\
\left.\left.\left.\text { - tca_time }) \wedge /\left(2 * 1{ }^{*} 2\right)\right) /(1 * 2.506628)\right)\right)\end{array}$ \\
\hline Tca_cyto & 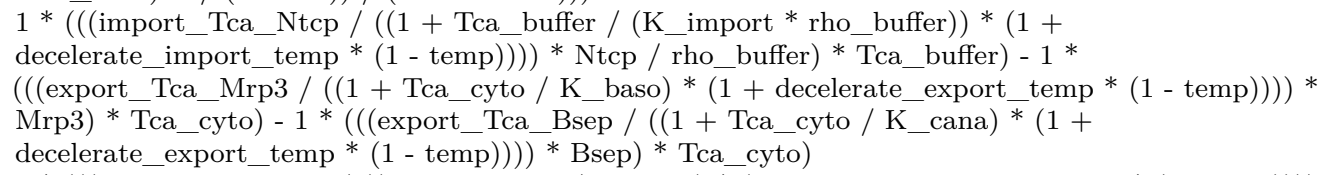 \\
\hline Tca_canalicular & $\begin{array}{l}1 *(((\text { export_Tca_Bsep } /((1+\text { Tca_cyto / K_cana }) *(1+\text { decelerate_export_temp } *(1-\text { temp })))) \\
* \text { Bsep }) * \text { Tca_cyto })-1 *(((\text { transport_Tca_cations } /(1+\text { decelerate_transport_temp } *(1-\text { temp }))) \\
/((\text { crit_cations }+ \text { cations }) * \text { rho_canalicular })) * \text { Tca_canalicular })\end{array}$ \\
\hline temp & $1 *(0)$ \\
\hline ca & $1 *(0)$ \\
\hline rho_buffer & $1 *(0)$ \\
\hline Bsep & $\begin{array}{l}1 * \text { (alpha_Bsep) }-1 *(\text { alpha_Bsep } * \text { Bsep })-1 * \text { (build_DrugNtcp } * \text { Delta_build_DrugBsep } * \text { Drug } \\
* \text { Bsep })+1 *(\text { decay_DrugNtcp } * \text { Delta_decay_DrugBsep } * \text { DrugBsep })\end{array}$ \\
\hline Ntcp & $\begin{array}{l}1 * \text { (alpha_Ntcp) }-1 *(\text { alpha_Ntcp } * \text { Ntcp })+1 *(\text { build_Ntcp } * \text { AUC_Tca_buffer })-1 * \\
\text { (build_DrugNtcp } * \text { Drug } * \text { Ntcp })+1 *(\text { decay_DrugNtcp } * \text { DrugNtcp })\end{array}$ \\
\hline Mrp3 & $\begin{array}{l}1 *(\text { alpha_Mrp3) }-1 *(\text { alpha_Mrp3 } * \text { Mrp3) }-1 *(\text { build_DrugMrp3 } * \text { Drug } * \text { Mrp3) }+1 * \\
\text { (decay_DrugMrp3 } * \text { DrugMrp3) }\end{array}$ \\
\hline AUC_Tca_buffer & $1 *($ Tca_buffer $)$ \\
\hline Drug & $\begin{array}{l}-1 * \text { (build_DrugNtcp } * \text { Delta_build_DrugBsep } * \text { Drug } * \text { Bsep })+1 *(\text { decay_DrugNtcp } * \\
\text { Delta_decay_DrugBsep } * \text { DrugBsep) }-1 *(\text { build_DrugNtcp } * \text { Drug } * \text { Ntcp })+1 *(\text { decay_DrugNtcp } \\
* \text { DrugNtcp })-1 *(\text { build_DrugMrp3 } * \text { Drug } * \text { Mrp3 })+1 *(\text { decay_DrugMrp3 } * \text { DrugMrp3 })+1 * \\
((\text { amount_Drug } / \text { scale_transp } * \exp (-(\text { time }- \text { drug_time }) \wedge /(2 * 1 \wedge 2)) /(1 * 2.506628)))\end{array}$ \\
\hline DrugBsep & $\begin{array}{l}1 * \text { (build_DrugNtcp } * \text { Delta_build_DrugBsep * Drug * Bsep) }-1 *(\text { decay_DrugNtcp } * \\
\text { Delta_decay_DrugBsep } * \text { DrugBsep) }\end{array}$ \\
\hline DrugNtcp & $1 *($ build_DrugNtcp $*$ Drug $*$ Ntcp $)-1 *($ decay_DrugNtcp $*$ DrugNtcp $)$ \\
\hline DrugMrp3 & $1 *($ build_DrugMrp3 $*$ Drug $*$ Mrp3) $-1 *($ decay_DrugMrp3 $*$ DrugMrp3) \\
\hline AUC_Drug & $1 *($ Drug $)-1 *($ deg_AUC_Drug * AUC_Drug $)$ \\
\hline rho_canalicular & $\begin{array}{l}-1 * \text { (beta_V_canalicular } * \text { rho_canalicular })+1 * \text { (beta_V_canalicular) }-1 * \text { (red_V_cana_drug } * \\
\text { rho_canalicular } * \text { AUC_Drug })+1 * \text { (build_V_cana_drug } * \text { AUC_Drug } /(\text { K_build_V_cana_drug } \\
+ \text { AUC_Drug) })\end{array}$ \\
\hline
\end{tabular}

\section{Model fitting and model reduction}

As described in the main text, the parameter space is explored by starting deterministic, derivative-based optimization runs from random points in parameter space. This way, the model has the chance to converge to different local optima. Figure S2 shows the 100 best fits out of 1000. Several local optima are found out of which the six best have been selected for further analysis (red squares).

Besides the contribution from the data points, the objective function contains a general quadratic prior on all parameters. For the analysis, the six selected fits have repeatedly been refitted while lowering the general prior. This yields six final fits, labled by 1 to 6 .

For the best fit, the profile likelihood has been computed, see Figure S3.

The profile likelihood indicates that some parameters which are open to the left, i.e., the profiles towards negative log-parameter values are flat and, consequently, parameter values are compatible with 0 . This is the case for decelerate_import_temp, decelerate_export_temp, beta_V_canalicular, s_T0_buffer_exp2, alpha_Bsep_Csa, alpha_Bsep_Cpz, alpha_Mrp3_Cpz, alpha_Ntcp_Csa, decay_DrugNtcp_Cpz, and the scal-

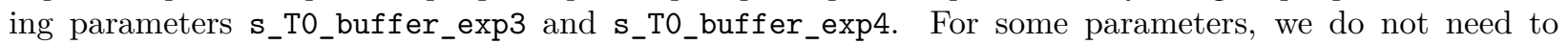




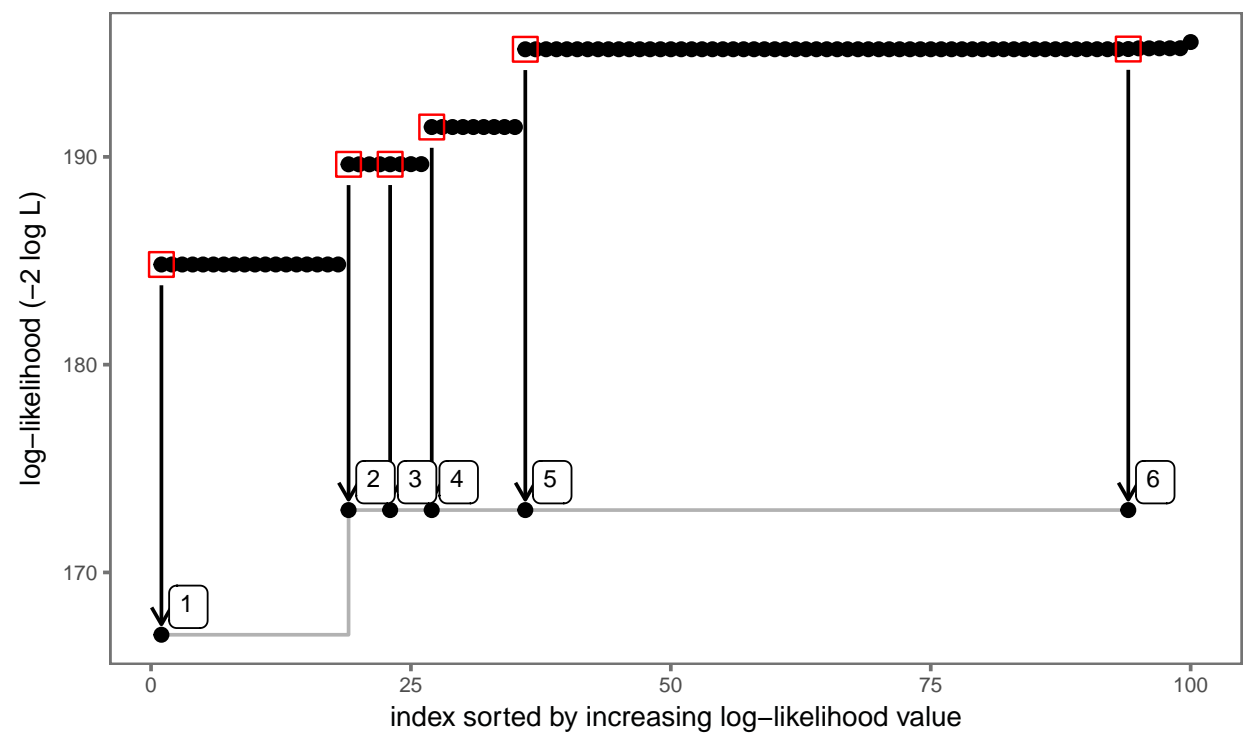

Figure S2: Fit objective values sorted by value. Each point corresponds to one fit and gives the final objective value for the corresponding optimization run. Six fits, marked by red squares, were selected for prior relaxation, resulting in fits labeled by 1 to 6 .

distinguish between the two drugs, e.g., deg_AUC_Drug_Csa = deg_AUC_Drug_Cpz. Also, some of the distinctions having made between the drug effect on Bsep compared to Ntcp turn out to be unnecessary, e.g., Delta_decay_DrugBsep_Cpz, Delta_decay_DrugBsep_Csa and Delta_build_DrugBsep_Csa which are compatible with 0 .

With these parameter reductions, the model has been fitted again 1000 times from different positions in parameter space. Again, we find local optima, however much less as being confirmed by the best 200 fit results, Figure S4.

Again, the profile likelihood has been computed, for the best optimum. See Figure S5.

\subsection{Table of parameters}

The following table shows the estimated parameter values. Since all parameters have been estimated on the log-scale, their values have been transformed back to normal scale. Confidence intervales are computed for a 95\% confidence level from the profile likelihood.

\begin{tabular}{lllll}
\hline parameter & value & lower [95\% CL] & upper [95\% CL] & unit \\
\hline alpha_Mrp3_Csa & 0.09987 & 0.02846 & 0.298 & $1 / \mathrm{min}$ \\
alpha_Ntcp_Cpz & 0.003349 & 0.001836 & 0.01188 & $1 / \mathrm{min}$ \\
alpha_Ntcp_Csa & $7.923 \mathrm{e}-05$ & 0.0002076 & 0.003253 & $1 / \mathrm{min}$ \\
build_DrugMrp3_Csa & 0.02014 & 0.01014 & 0.0431 & $1 / \mathrm{min}$ \\
build_DrugNtcp_Cpz & 0.001595 & 0.0009416 & 0.002696 & $1 / \mathrm{min}$ \\
build_DrugNtcp_Csa & 0.6275 & 0.2118 & $\infty$ & $1 / \mathrm{min}$ \\
build_Ntcp & $5.686 \mathrm{e}-06$ & $3.755 \mathrm{e}-06$ & $7.684 \mathrm{e}-06$ & $1 /\left(\mathrm{pmol} \cdot \mathrm{min}^{2}\right)$ \\
build_V_cana_drug_Csa & 0.02236 & 0.006742 & 0.09908 & $1 / \mathrm{min}$ \\
crit_cations & 0.3393 & 0.2072 & 0.5702 & 1 \\
decay_DrugMrp3_Csa & 0.0351 & 0.01297 & 0.1025 & $1 / \mathrm{min}$ \\
decay_DrugNtcp_Csa & 0.1348 & 0.06727 & $\infty$ & $1 / \mathrm{min}$ \\
decelerate_transport_temp & 237 & 79.26 & $\infty$ & 1 \\
deg_AUC_Drug & 0.03362 & 0.004143 & 0.349 & $1 / \mathrm{min}$
\end{tabular}




\begin{tabular}{lllll}
\hline parameter & value & lower [95\% CL] & upper [95\% CL] & unit \\
\hline Delta_build_DrugBsep_Cpz & 1.881 & 1.11 & 2.869 & 1 \\
export_Tca_Bsep & 0.1097 & 0.06808 & 0.2938 & $1 / \mathrm{min}$ \\
export_Tca_Mrp3 & 0.0146 & 0.01189 & 0.01851 & $1 / \mathrm{min}$ \\
import_Tca_Ntcp & 0.007098 & 0.003942 & 0.01338 & $1 / \mathrm{min}$ \\
K_baso & 1.905 & 0.2084 & $\infty$ & pmol \\
K_build_V_cana_drug_Csa & 70.74 & 5.724 & 337.6 & $\mathrm{~min}$ \\
K_cana & 0.1951 & 0.02757 & 0.5802 & $\mathrm{pmol}$ \\
K_import & 4.898 & 0.6874 & 18.17 & $\mathrm{pmol}$ \\
red_V_cana_drug_Cpz & $3.906 \mathrm{e}-05$ & $1.714 \mathrm{e}-05$ & 0.0002574 & $1 / \mathrm{min}^{2}$ \\
red_V_cana_drug_Csa & 0.0001086 & $4.858 \mathrm{e}-05$ & 0.0002448 & $1 / \mathrm{min}^{2}$ \\
s_T0_buffer_exp1 & 7.657 & 2.853 & 45.91 & $1 / \mathrm{pmol}$ \\
s_T0_cellular_exp1 & 9.042 & 3.369 & 53.65 & $1 / \mathrm{pmol}$ \\
s_T0_cellular_exp2 & 10.11 & 3.733 & 60.42 & $1 / \mathrm{pmol}$ \\
s_T0_cellular_exp3 & 9.284 & 3.648 & 52.35 & $1 / \mathrm{pmol}$ \\
s_T0_cellular_exp4 & 7.091 & 2.77 & 41.32 & $1 / \mathrm{pmol}$ \\
scale_transp & 2.299 & 1.595 & 2.862 & $\mathrm{mmol} / \mathrm{l}$ \\
Tca_buffer & 20.96 & 19.94 & 22.07 & $\mathrm{pmol}$ \\
transport_Tca_cations & 0.0839 & 0.06295 & 0.1185 & $1 / \mathrm{min}$ \\
\hline
\end{tabular}



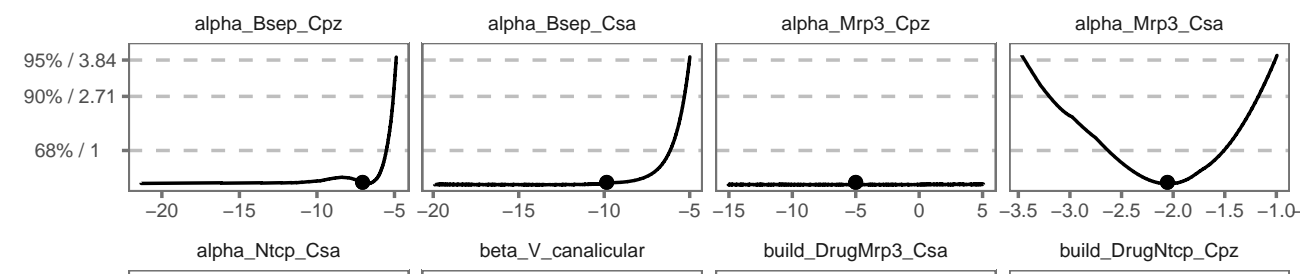

alpha_Ntcp_Cpz
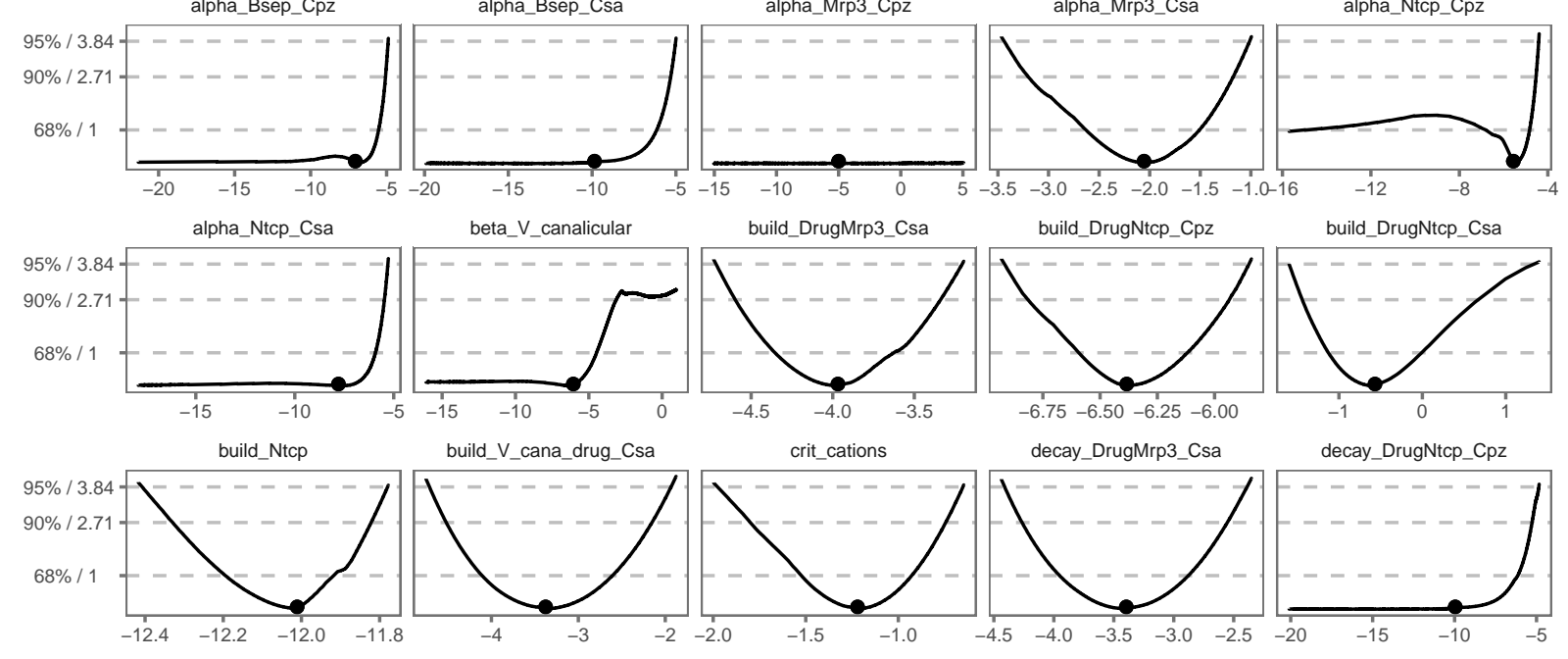

build_V_cana_drug_Csa

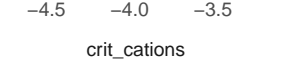

$-6.75-6.50-6.25-6.00$
decay_DrugMrp3_Csa
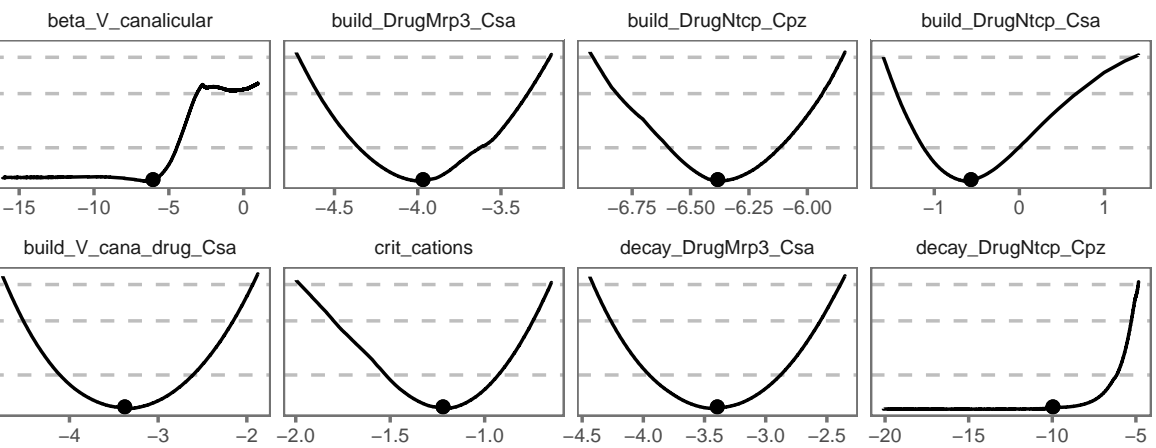

decay_DrugNtcp_Cpz
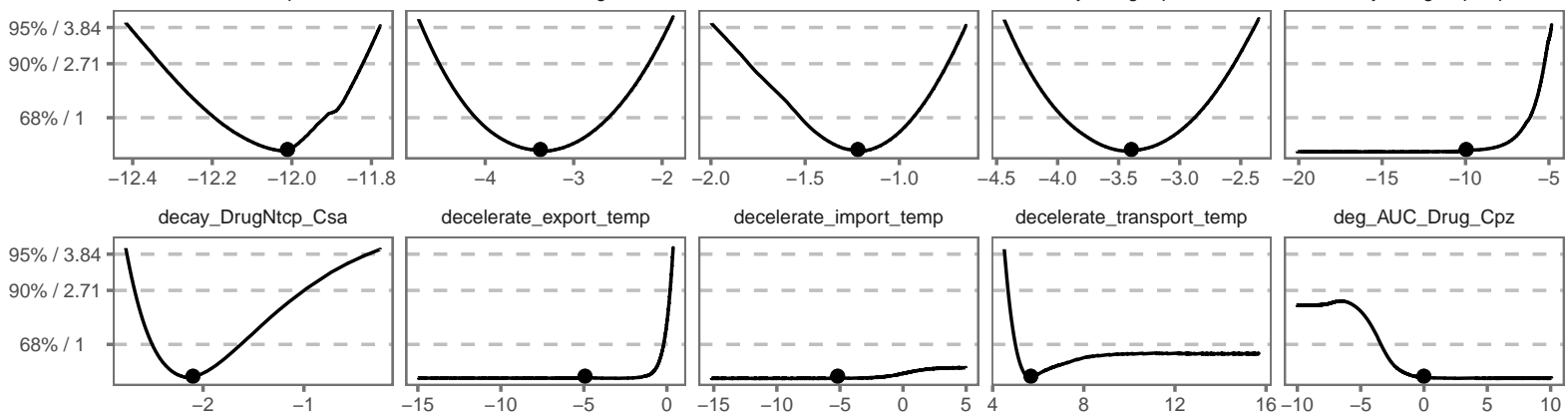

Delta_build_DrugBsep_Cpz

Delta build DrugBsep Csa
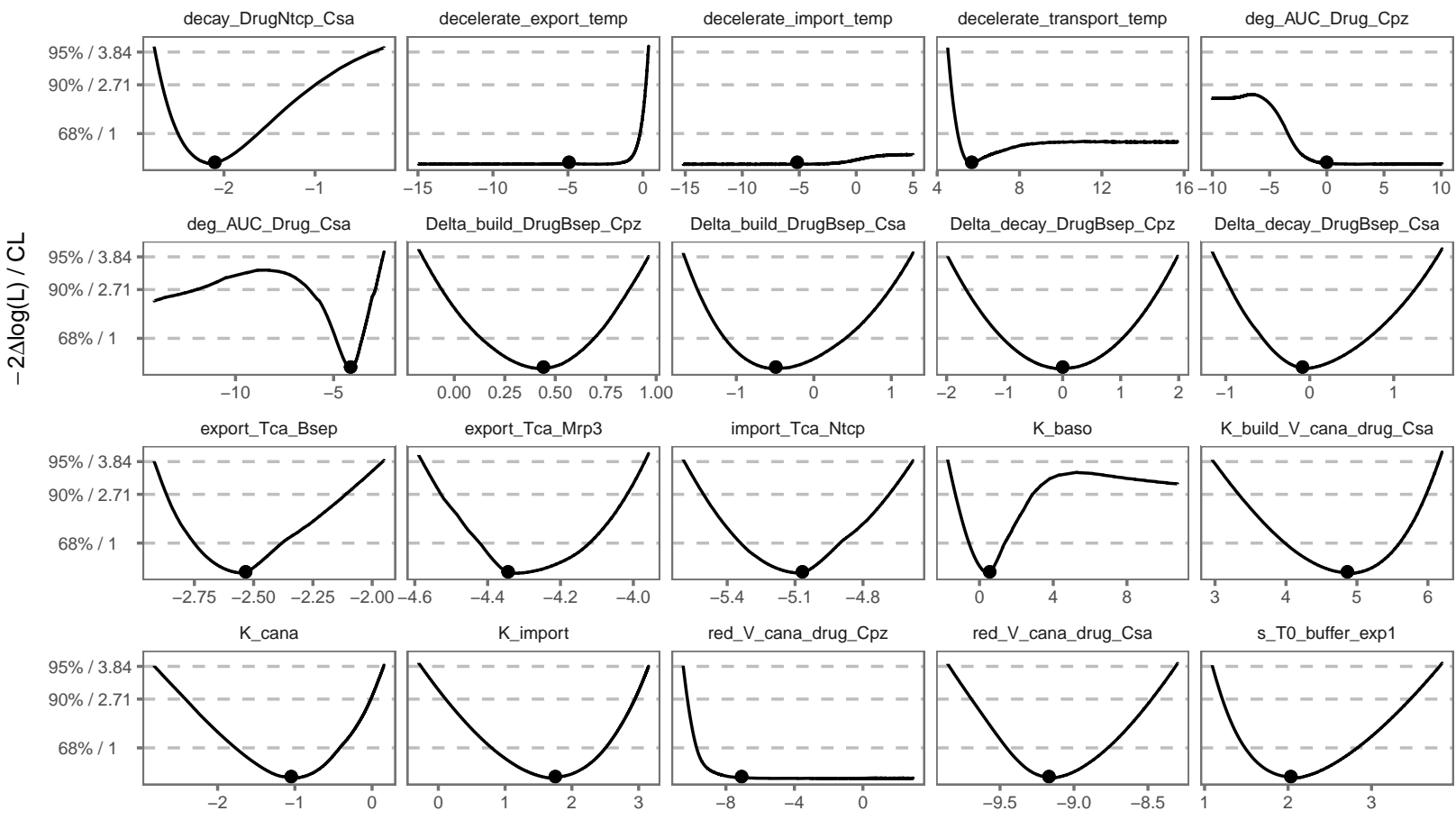

red_V_cana_drug_Cpz
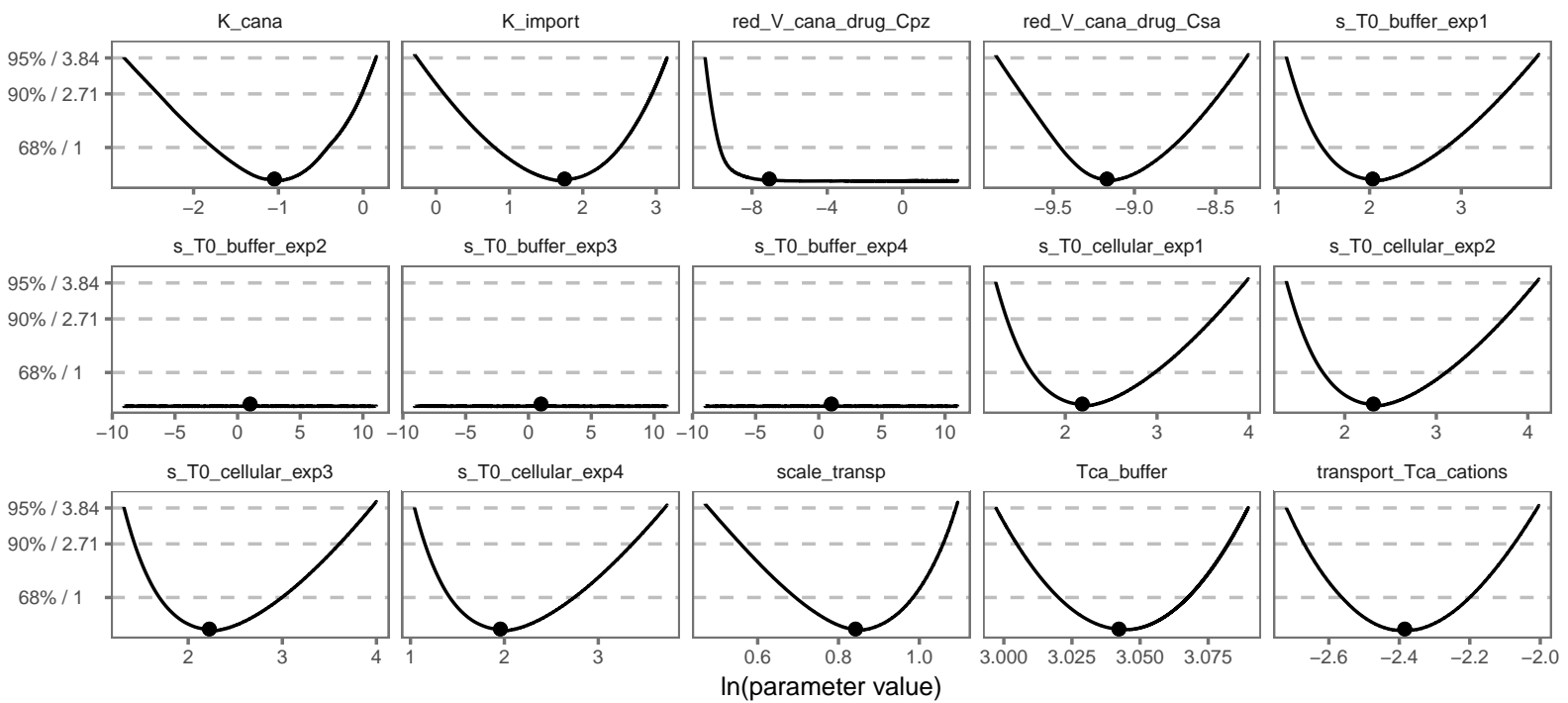

Figure S3: Profiles likelihood of the best optimum. The parameters of the best fit are indicated by dots. 


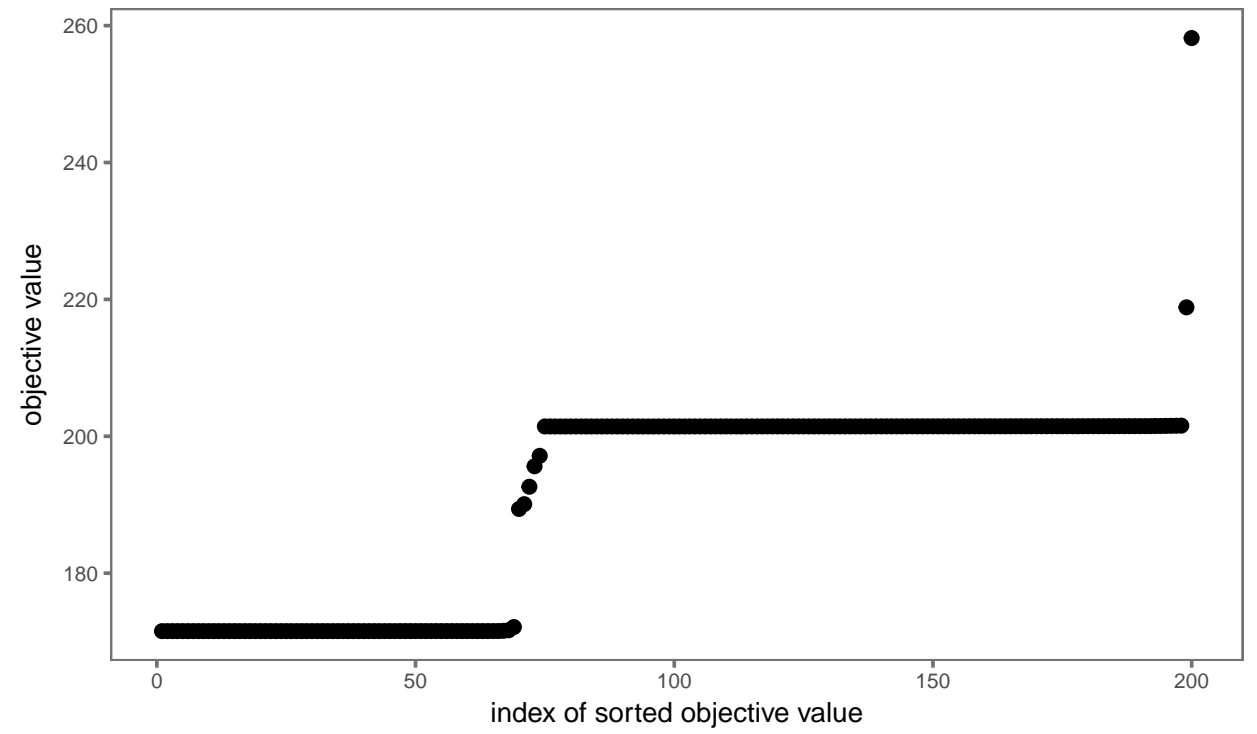

Figure S4: Fit objective values for the reduced model, sorted by value. Each point corresponds to one fit and gives the final objective value for the corresponding optimization run. 

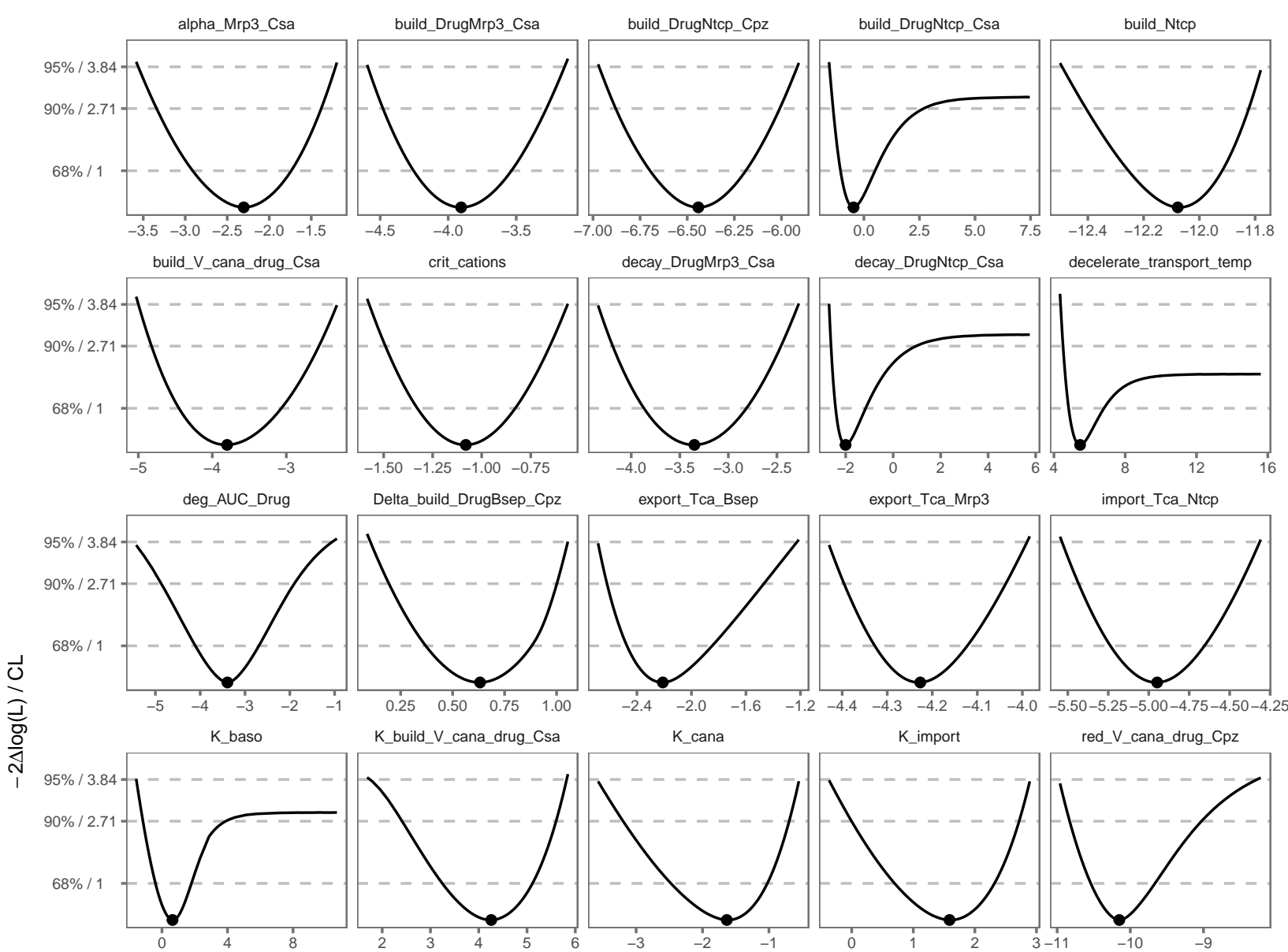

import_Tca_Ntcp
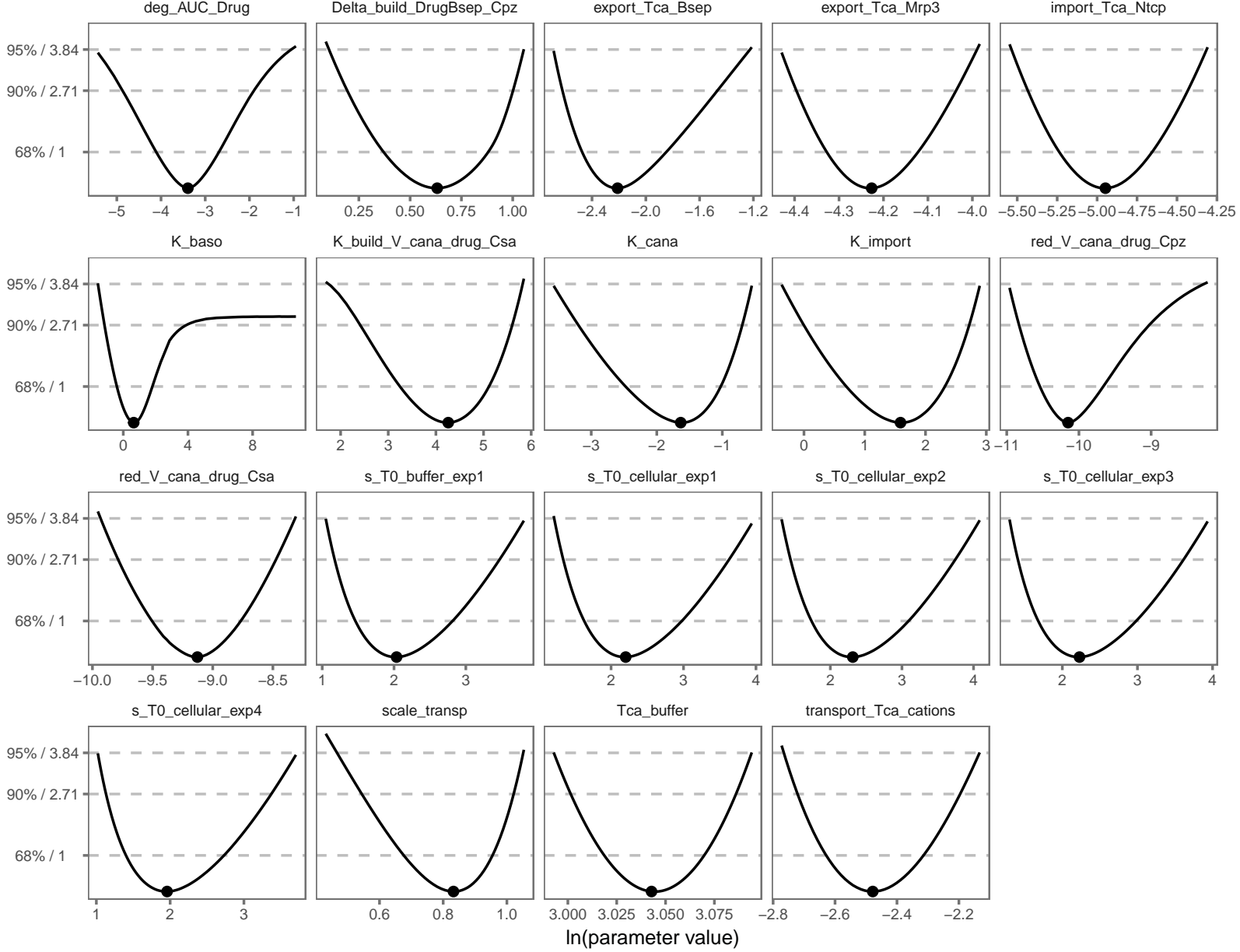

Figure S5: Profiles likelihood of the best optimum of the reduced model. The parameters of the best fit are indicated by dots. 